\title{
CHALLENGING THE LACK OF REPRESENTATION IN MAINSTREAM MEDIA THROUGH THE ESTABLISHMENT OF INCLUSIVE DIGITAL SPACES
}

\author{
By \\ Emilia Zibaei \\ Honours Bachelor of Arts, Global Studies, Wilfrid Laurier University, 2017 \\ An MRP \\ presented to Ryerson University \\ in partial fulfillment of the \\ requirements for the degree of \\ Master of Digital Media \\ in the program of \\ Digital Media \\ Toronto, Ontario, Canada, 2018 \\ (C) Emilia Zibaei, 2018
}




\section{AUTHOR'S DECLARATION FOR ELECTRONIC SUBMISSION OF A MRP}

I hereby declare that I am the sole author of this MRP. This is a true copy of the MRP, including any required final revisions.

I authorize Ryerson University to lend this MRP to other institutions or individuals for the purpose of scholarly research.

I further authorize Ryerson University to reproduce this MRP by photocopying or by other means, in total or in part, at the request of other institutions or individuals for the purpose of scholarly research.

I understand that my MRP may be made electronically available to the public. 


\title{
CHALLENGING THE LACK OF REPRESENTATION IN MAINSTREAM MEDIA THROUGH THE ESTABLISHMENT OF INCLUSIVE DIGITAL SPACES
}

\author{
Emilia Zibaei, 2018 Master of Digital Media \\ Yeates School of Graduate Studies, Ryerson University
}

\begin{abstract}
Media representations of marginalized people are a growing concern given the state of the current social climate. The origin of intolerance stems from a lack of exposure and knowledge and as a result, marginalized groups struggle to maintain adequate space and representation in mainstream media. This reflects a lack of inclusivity, diversity and safe spaces. Establishing inclusive digital environments that promote the equality of peoples rather than perpetuating stereotypes is a vital way to achieving visibility and growth among marginalized and underrepresented people. INFLUENCE Magazine is a digital publication that is committed to equality, representation and opportunity. By providing a safe space for marginalized and underrepresented sectors of society to express every aspect of their identity, art and lived experiences, INFLUENCE Magazine fosters a positive environment for artists and individuals to freely express themselves.
\end{abstract}




\section{$\underline{\text { Acknowledgements }}$}

I would like to show sincere gratitude to my supervisor, Dr. Matthew Wells, for the support and guidance he has provided during this process. I am grateful to have been mentored by someone who cares deeply about my success and the impact that this project has generated. Matt - your passion for technology and its impact is clearly evident in your demeanor and it was an honour being taught by you.

I would like to thank my second reader, Harry Dearden, for guiding me through the final stages of this project and for his priceless advice and support. Your guidance was valuable and contributed to the success of this MRP.

To my fellow classmates - I do not have the words to convey the absolute gratitude I have for experiencing this past year with you. We have gone through incredible challenges, and have become a family in the process. As I reflect on the work we have accomplished and the memories we have made, I am filled with pride and sincere joy. I look forward to our futures and the opportunity to stay connected.

Finally, my best friend, Mawadda. We have been attached at the hip for almost ten years and as the years go by, I often wonder how two people can have such a strong bond. Thank you for the endless support you have shown me, especially throughout this past year. My life would not be the same without your friendship. 


\section{$\underline{\text { Dedication }}$}

This project is dedicated to my parents, May and Feraydoon, and siblings, Gloria, Maxwell and Alexander. The way my parents have raised me and championed my goals have been instrumental to my success. To my parents, anything is possible with hard work, passion and determination. My siblings are an extension of the support my parents have provided. Thank you for believing in the work I do and the impact I strive to generate. I love you all very much.

Second, I dedicate this project to my uncle, Ramin Zibaei, and the Baha'is of Iran who are barred from attaining a higher education on the basis of their religious beliefs. For decades, Baha'is have been systematically persecuted as a matter of government policy. The constant threat of raids, arrests and imprisonment is a daily reality for them and my uncle, having served a sentence, experienced this discrimination in its purest form. I'm proud to come from a long line of people who stand up for what is right and fair, who are passionate about their beliefs and are unwavering in their dedication to a cause. This project is for them.

Lastly, this is dedicated to every person who strives for visibility and equality. It is for the people who live in fear of being misrepresented, misgendered and misunderstood. It is for all $\mathrm{PoC}$ who have fought so bravely to have their cultures and identity accepted. I hope that with this project, people feel encouraged to express themselves and the value they can bring to society. 


\section{TABLE OF CONTENTS}

ABSTRACT

LIST OF ABBREVIATIONS

1. INTRODUCTION

2. INTENTION

3. EXISTING GAPS

4. VALUE

5. RECEPTION

12

6. CONCLUSION

13

REFERENCES

14 


\section{Introduction}

The origins of intolerance stem from avoidance and a lack of exposure (Council of Europe, 2017). Over time, marginalized groups have struggled to maintain adequate space in mainstream media and have often been misrepresented and cast aside; an occurrence that can be described as "chronic" (Wilson \& Chock, 2012). By understanding the current state of the social climate that exists in Western culture, I answered the following question: How can marginalized and underrepresented people feel validated and included in mainstream culture through digital media? The definition of mainstream is the "principle, dominant course, tendency, or trend" (cite dictionary). Concepts and topics covered in mainstream media are widely accepted as the norm and seldomly include people or cultures that do not follow the dominant discourse. The underrepresentation of genders and ethnic minorities, "can lead to the perpetuation of racist or sexist stereotypes and myths about marginalized groups...due to bias or lack of experience with that group" (Erigha, 2015). There is a need to increase representation for the sake of social cohesion; I argue that this can be pushed to a greater audience through digital media. This project is my approach to solving this question in order to bridge the growing gap between underrepresented groups and mainstream media.

To truly provide equity within digital media for underrepresented groups, the answer is both to create separate media outlets specifically for them and to create incentives for existing media to include them. The establishment of INFLUENCE Magazine met the goal of the former, while still encouraging the latter by forming a community of like-minded individuals.

INFLUENCE Magazine is a digital publication that is committed to equality, representation and opportunity by providing a safe space for marginalized and underrepresented sectors of society to express every aspect of their identity, art and lived experiences. A safe space 
is an environment in which an individual can exist freely without fear of discrimination, harassment or any other physical or emotional harm (Amenabar, 2016). Within the context of this digital publication, a safe space is one that encourages the diversity of marginalized people and experiences as well as one that has no tolerance for disrespect and harassment committed against said populations.

In the magazine, eighty percent of content is based on submissions; with only one issue released to date, submissions were from people across Ontario and New York (established via content sharing and reposts on Instagram). The other twenty percent are interviews that the INFLUENCE team has conducted with unique organizations and people in Toronto who we feel strive to make a difference in their community, with a special focus on marginalized groups. This includes SPICYWTR, an NGO dedicated to South Asian art and community building, [domain], a Toronto clothing brand committed to inclusivity and Noomi Shop, a fashion label that strives to represent Middle Eastern culture in the Canadian marketplace. All of these establishments were started by Canadian individuals who chose to turn their passion into small businesses that positively impact an aspect of a marginalized community.

Representation of minorities in media has changed throughout the years, however the most stereotypical portrayal is commonly negative (Tisdell, 2007). For example, young African American men positioned as gangsters and thieves or Middle Easterners viewed as terrorists. INFLUENCE Magazine allows these individuals to re-brand themselves to society, going against the grain of the stereotypes portrayed about them. The exclusion of certain groups from the media is a way to silence them; to not accept and validate their identities and their existence in society, which has detrimental effects. These effects are referred to Elfriede Fursich as "symbolic annihilation" (2010). 
This paper will discuss the progression of INFLUENCE Magazine, existing gaps and solutions, and the impact and value of this project in relation to the greater theme of representation in mainstream media and lastly, the feedback it has gotten from the community. 


\section{Intention}

The intention behind establishing INFLUENCE is to foster a space of representation and validity for marginalized and underrepresented people. Mainstream media and conventional cultural channels promote a formulaic idea of what could be considered as the norm with respect to gender, identity and experiences. Establishing a digital space through a magazine and its related social media outlets promotes the awareness that safe spaces for these individuals are required in order to foster inclusivity. Equally important, a magazine is a channel to tell stories through the digital arts in order to promote diversity and equality. Every submission, whether written or visual, provides a canvas for disenfranchised artists to safely share their lived experience. Utilizing digital media and digital art to express this is a major theme of this project as well.

It is important for the overall feel of the INFLUENCE brand to implement values that both contributors and viewers can understand upon associating with the publication. Inclusivity is the primary value. Being mindful to the diversity of our readership and audience is incredibly important to INFLUENCE'S brand consciousness. We encourage members of marginalized and underrepresented communities to become actively involved in the publication, and all of our methods of engagement. This includes, regardless of socioeconomic class or status, those who identify within the LGBTQ+ spectrum, Person of Colour (PoC), and individuals living with disabilities. All video content will be appropriately transcribed and/or subtitled for those that are deaf or hard of hearing by the INFLUENCE team. For those with visual impairments or colour blindness, INFLUENCE will soon have a method of increasing text size and colour representations on the home site (Thomson, 2016). All community events will be wheelchair and service/assistance accessible (Thomson, 2016). Before corresponding with any individual whether through social media, email, phone, or in-person, it is essential that members of the INFLUENCE 
team ask what gender pronouns they prefer us to use. In any case where pronouns cannot or are preferred not to be shared to a member of the team, INFLUENCE staff will use gender neutral pronouns (they/them). This policy ensures a safe space for all and creates an atmosphere of unwavering inclusivity and tolerance. This is only one example of the measures that will be taken to foster a positive and safe digital space.

The second value is togetherness and community encouragement. Supporting the community and understanding that there is no competition, but rather community building through positive encouragement is vital to the culture we aim to cultivate within INFLUENCE as well as the idea that we are all working toward a common goal of respect and equality within society. INFLUENCE hosts content covering community events that highlight any and all marginalized experiences directly from the lens of individual within their own cultures. This can include anything from culturally specific gatherings, religious holidays and celebrations, to times of remembrance and reflection — and anything in between. Further, INFLUENCE prides itself on having culturally sensitive teams of creatives directly covering and reporting local events for future issues.

Accreditation is the third pillar of the magazine's values. Absolutely all published written, visual, and auditory content must be the artist(s) own intellectual property, credited using full names, social media handles and applicable websites. All individuals (i.e., models, photographers, stylists, editors, etc.) must be credited at the time of submission. As artists ourselves, it is incredibly important that any and all work is respected and treated with utmost integrity upon submission to INFLUENCE. Failing to provide recognition is both a disservice to our creatives and to the quality of our publication. Further, no improperly or uncredited content (purposeful or otherwise) will be published. 
Lastly, mindful engagement. INFLUENCE recognizes that as the world changes, the way we interact with our world and those of it must be actively committed to adaptivity and inclusivity. Essential to this is the understanding that all of us are human and may make mistakes or errors in judgement when it comes to the sensitivity of content, regardless of format or location (i.e., web content, social media, email contact and issue content). In any case of this, INFLUENCE will aptly issue any contextually necessary apologies, and will remove the content and potentially the creatives responsible, dependent on each case's severity and intention. We also openly and warmly welcome suggestions and feedback from the communities we hope to be a platform for at any time. Any of our represented artists or featured creatives may also have any personal details or their full identity kept completely anonymous at their request. Those who submit their work to INFLUENCE will fully be protected by our team in any case of potential identity-based violence or harm. An example of this could include a contributor who writes an experience on being transsexual or not a traditional gender norm but is not out to friends or family; or someone who belongs to a targeted religious group who wishes to have personal details altered or removed in the event of backlash.

I came to find these values based on my personal lived experiences and those of my peers. Through informal conversation and knowledge sharing, I came to understand the social challenges of my peers, while recognizing my own as a woman of colour. This formed the basis of the aforementioned values and inspired me to establish them for this publication in order to cultivate a progressive and positive space for everyone involved. 


\section{Existing Gaps}

A "zine" is most commonly defined as an online or offline magazine publication that is produced on a small scale through individual publishing efforts, sometimes consisting of reproduced (but credited) work as well as original work (Issuu, 2017). Zines are commonly created to "add often unheard voices into the mix" rather than making a large profit (AGO, 2008). A zine is a trend in popular culture that has seen relevance not just with photographers and creators on a local level but also among famous musicians who aim to market their work to a larger fanbase by producing a publication with more content than an album artwork or cover would convey. For example, when Frank Ocean released his sophomore album Blonde in 2015, he released a limited print publication named Boys Don't Cry; in this publication, he included photos and interviews that supported his album. The magazines were never reproduced and he distributed them on a "gone when gone" policy - fans lined up for hours in front of a SoHo pop-up shop on the day of release in order to try to get a free copy. Another example is the queer-focused zine "Fear Brown Queers" that consists of art from QTIPOC (an acronym used to describe queer, transgender and intersex PoC). These are experiences and content that is not widely publicized in mainstream publications like Vogue or Rolling Stone; this zine allows queer culture to be visible and accessible in the market.

Over the past 5 years, by understanding the contemporary Instagram-driven photography and art-sharing culture, INFLUENCE Magazine has been able to understand that zines have become extremely popular both in terms of demand and supply. Whether it acts as a passion project or its intention lies in being a ground-breaking new form of dialogue with a community, zines have created the potential for an accessible space where any artist can have the platform to produce and share their experiences. They are an important source for communities with respect to independent publishing. Big publishing houses publish based on mainstream appeal. However, not everyone 
operates under a mainstream mindset. A trans individual is not mainstream due to the way that media portrays cis women and men and the "normalcy" that follows with that ("cis" derived from "cisgender" meaning that a person's gender and identity corresponds with the sex they were born with) (Blank, 2014). Individual publishing allows the otherwise unheard - women, minorities, LGBTQ+ - to voice their political and/or artistic views as well as their lived experiences.

In terms of how the production of zines has become so accessible, domain names and hosting sites have free and low-cost options that encourage the legitimacy of these publications. Additionally, as millennials gain more knowledge of technology in this digital age, people are becoming both professionally and self-taught with the software needed to support the production process. The appeal of zines is a great force in how we look at the publication of art. The Pew Research Centre is a think-tank based in Washington DC that conducts various surveys including the impact of technology on the arts. The survey showed that fifty percent of people strongly agreed that the internet has "increased engagement in the arts by providing a public platform through which more people can share their work" (Thomson, Purcell \& Rainie, 2013). Since the distribution of art is so heavily influenced by technology, it comes as no surprise that creators tend to favour a digital distribution; digital media supports accessibility and culture sharing. Although zines are largely digital due to cost however, I would argue that the appeal for holding a physical copy of something you have either created or that you support is far more precious to a consumer than to only be able to access a digital copy; tangible goods provide aesthetic pleasure (Weinswig, 2017).

Regardless of the preference of how a zine is distributed, INFLUENCE Magazine holds a significant place within this space. Over the last few years, Western culture has seen a shift in the way the topics of gender, sexual orientation and race are discussed and internalized. Although this 
shift is dependent on perspective, the existence of such topics in the social dialogue has increased. This is a topic that has many questions and answers and oftentimes, people who do not identify in this community are left confused and unable to accept a different reality. Creating resources that support and educate marginalized communities as well as make them feel valued and safe encourages a dialogue of acceptance and understanding. Whether advocating for non-mainstream music, youth, women, PoC or LGBTQ+ communities, zines do an efficient job in touching on subjects that are not talked about in mainstream magazines such as Time, Vogue, Cosmo or Rolling Stone. Media - no matter the format or channel - "affects people's beliefs and ideas about groups both similar to and very different from themselves based on race, class, gender, religion, marital status and sexual orientation." (Tisdell, 2007). These channels of digital media can work to reinforce stereotypes or change them; INFLUENCE aims to affect this change.

A significant example of a lack of representation in mainstream media is in regards to Vogue Magazine. The September Issue of Vogue is regarded as the most iconic issue, as it represents the change from Spring/Summer to Fall/Winter while establishing the trends for the rest of the year. For the September 2018 issue featuring Beyonce Knowles-Carter on the cover, Vogue Editor-in-Chief, Anna Wintour, gave Beyonce full artistic control. For the first time in the publications' 126-year history, they hired an African American photographer, as per Beyonce's creative control (Salter, 2018). It took Vogue 126 years to give an African American artist the opportunity to shoot a cover, which seems surprising given the increase in diversity Vogue and other Conde Nast publications have shown in its casting system over recent years. This is an example of how representation is not only important in what we directly see, but also plays an important role behind the curtain with respect to creating cultural cross-pollination. 
$\underline{\text { Value }}$

As much as mainstream media commonly asserts a narrow idea of gender and identity, different forms of media also challenge these ideals and stereotypes by portraying experiences that are not from the dominant cultural group (Tisdell, 2007). The existence of these forms of media, no matter how widespread, are highly sufficient in challenging the status quo; INFLUENCE Magazine has done an efficient job at creating a platform to challenge what is typically seen in traditional magazine outlets with minimal resources. The target audience is highly receptive to this dialogue, as "millennials, regardless of race, are more likely than members of previous generations to watch and even seek out media by or about people from racial/ethnic groups different than their own" (Erigha, 2015).

This type of publication also gives people visibility because it can show them that their reality is not the only version that exists and the issues and challenges they face are shared; tackling the idea of representation in mainstream media by establishing an inclusive digital space also does well in establishing a community among these people. Mainstream media also asserts a gendered compulsory role meaning that they portray an ideal life that a certain gender should carry out (for example, woman who gets married, has kids and stays home to care for the children). Inserting a different dialogue of gender roles through this publication asserts a new idea of how people live and expands the understanding that marginalized groups can lead drastically different but equally valuable lives.

A publication is a valuable source of education about the cultural differences present in society. In schools, students are taught critical media literacy while being encouraged to consider what they see and hear in the media. This avenue of learning has proven to teach students about how to critically analyze racist, sexist or homophobic texts, asserting that "media texts, more than parents, or even schools, increasingly teach about race and racism" (Gainer, 2010). In the 
same way that schools try to encourage critical media literacy and diversity of thought through that, INFLUENCE explores the politics of representation and agency over marginalized bodies while working toward building a productive dialogue.

In terms of where digital media and technology fits into addressing this issue, there is evidence to suggest that the internet and technology can "undermine traditional repressive systems of representation by adding new outlets for representation" (Fursich, 2010). This is exactly the route I have taken with INFLUENCE Magazine, as I have understood the value of using digital media and technology to curate a space of inclusivity and acceptance for marginalized and underrepresented individuals. 


\section{$\underline{\text { Reception }}$}

The feedback on this project thus far has been incredible, and more importantly, a sobering testament to the need for such an inclusive publication. With over seventeen hundred online views since the July 4 release, INFLUENCE has had a memorable start within the community. The launch party that was held on July 7, 2018 was packed and artists who had submitted their work, and they spoke about their intention behind the pieces submitted. It was a fantastic opportunity for the INFLUENCE community to form and support local artists.

In terms of print, over $\$ 350$ has been raised from pre-orders toward the print issues that will be distributed by the end of the summer. The feedback from the community and other initiatives was so positive that INFLUENCE is in the process of hosting a women's empowerment event in September, in partnership with a number of other Toronto and Mississauga-based organizations, artists and publications. The second issue release date is set for October 5 and the submission inbox is already full; it is evident that the theme of this project resonated with the community and they are excited to continue their support in future issues. 


\section{Conclusion}

Adequate representation in mainstream media is an ongoing issue that contributes to intolerance toward marginalized and underrepresented groups. By using digital media and technology, I created an inclusive digital space in the form of a magazine that is accepting of a diverse set of art and experiences. INFLUENCE Magazine recognizes the existing gap that is present in mainstream media and strives to change the social landscape by allowing underrepresented and marginalized individuals to share their art, experiences and identity to a greater audience without fear of misrepresentation or physical and/or emotional violence. INFLUENCE Magazine is categorized as a zine - an independent published work that falls within the category of offering niche and unconventional topics that are not covered in mainstream media. This zine consists of a majority of submissions and a number of featured interviews, all of which are sourced from members of the community who belong to religious, cultural, ethnic or gender minorities. The measurable impact of the project thus far has showcased the need for the cultural dialogue being created by the magazine. More broadly, the enthusiasm with which a community of artists, thinkers and activists has formed is a significant step forward towards the much-needed inclusivity and equity in digital media. 


\section{$\underline{\text { References }}$}

AGO. (2009, March 14). What is a Zine? Retrieved from http://artmatters.ca/wp/2008/08/whatis-a-zine/

Amenabar, T. (2016, May 19). What college students mean when they ask for "safe spaces".

Retrieved from https:/www.washingtonpost.com/sf/style/2016/05/19/what-collegestudents-mean-when-they-ask-for-safe-spaces-and-triggerwarnings/?noredirect $=$ on\&utm term $=.083414073 \mathrm{~b} 5 \mathrm{e}$

Blank, P. (2014, October 04). Will the Word "Cisgender" Ever Go Mainstream? Retrieved from https://www.theatlantic.com/entertainment/archive/2014/09/cisgenders-linguistic-uphillbattle/380342/

Discrimination and Intolerance. (2017). Retrieved from https://www.coe.int/en/web/compass/discrimination-and-intolerance

Erigha, M. (2015). Race, Gender, Hollywood: Representation in Cultural Production and Digital Medias Potential for Change. Sociology Compass, 9(1), 78-89. doi:10.1111/soc4.12237

Fürsich, E. (2010). Media and the representation of Others. International Social Science Journal, 61(199), 113-130. doi:10.1111/j.1468-2451.2010.01751.

Gainer, J. S. (2010). Critical Media Literacy in Middle School: Exploring the Politics of Representation. Journal of Adolescent \& Adult Literacy, 53(5), 364-373. doi:10.1598/jaal.53.5.2 
Salter, S. (2018, July 31). Beyoncé hires the first black photographer to shoot a us vogue cover in 126 years. Retrieved from https://i-d.vice.com/en uk/article/9kmdyz/beyonce-hires-thefirst-black-photographer-to-shoot-a-us-vogue-cover-in-126-years

Thomson, G. (2018, June 25). Accommodating Visually Impaired Workers. Retrieved from https://www.aoda.ca/accommodating-visually-impaired-workers/

Thomson, G. (2018, July 24). Ontario Public Transit: Accessible for Everyone. Retrieved from https://www.aoda.ca/ontario-public-transit/

Thomson, K., Purcell, K., \& Rainie, L. (2013, January 04). Section 6: Overall Impact of Technology on the Arts. Retrieved from http://www.pewinternet.org/2013/01/04/section-6overall-impact-of-technology-on-the-arts/

Tisdell, E. J., \& Thompson, P. M. (2007). 'Seeing from a different angle': The role of pop culture in teaching for diversity and critical media literacy in adult education. International Journal of Lifelong Education, 26(6), 651-673. doi:10.1080/02601370701711349

Weinswig, D. (2017, January 23). From Digital to Physical: The Growing Demand for Tangible Media Products. Retrieved from https://www.fungglobalretailtech.com/research/digitalphysical-growing-demand-tangible-media-products/

Wilson, E. J., Costanza-Chock, S., \& Forelle, M. C. (2016). A Provocation on Behalf of the Excluded. The Communication Crisis in America, And How to Fix It, 249-266. doi:10.1057/978-1-349-94925-0_16 


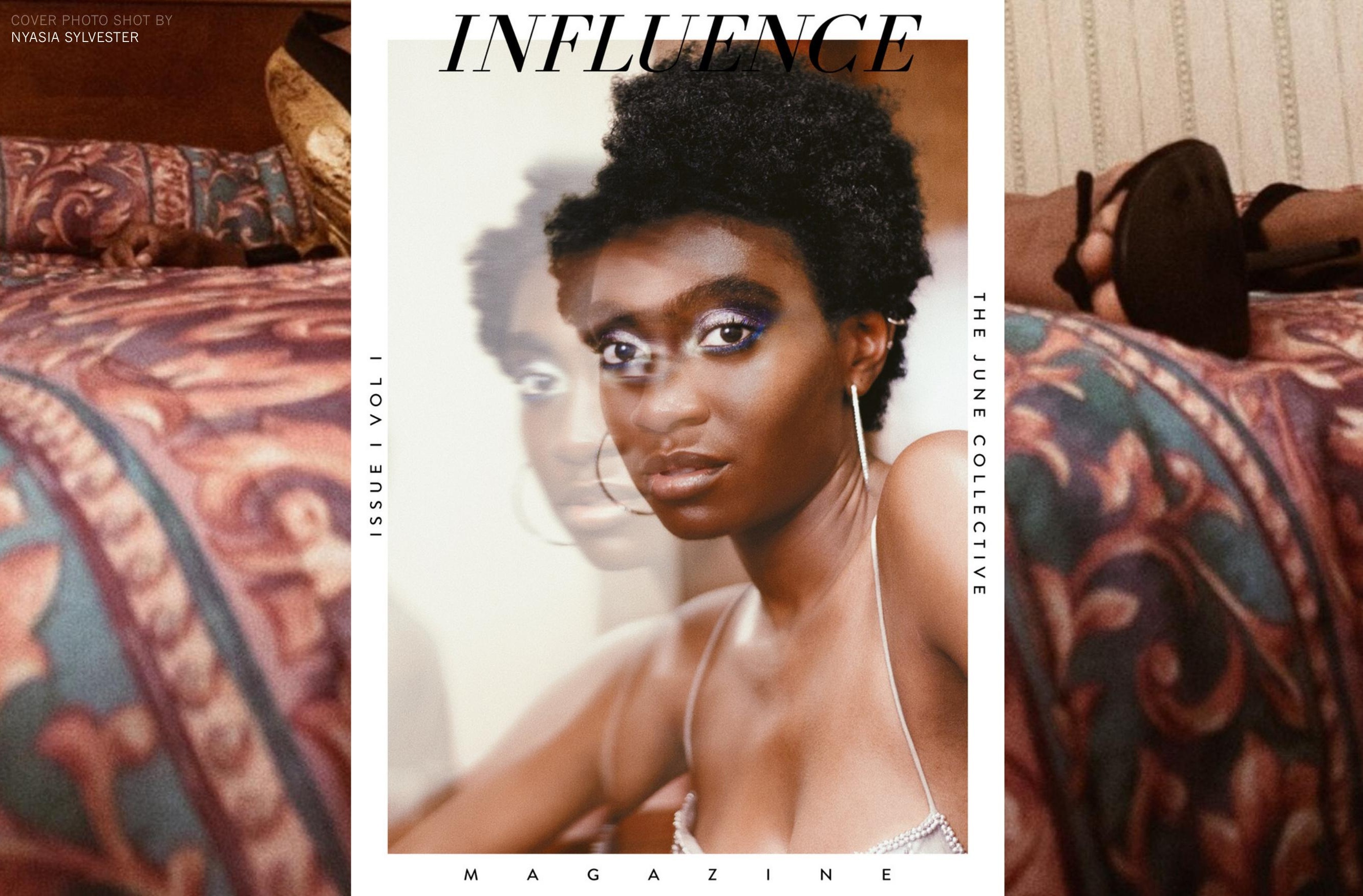




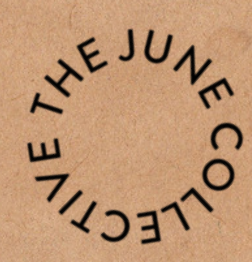

for the best viewing experience...

PLEASE VIEW IN LANDSCAPE MODE

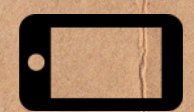


TABLE OF

\section{contents}

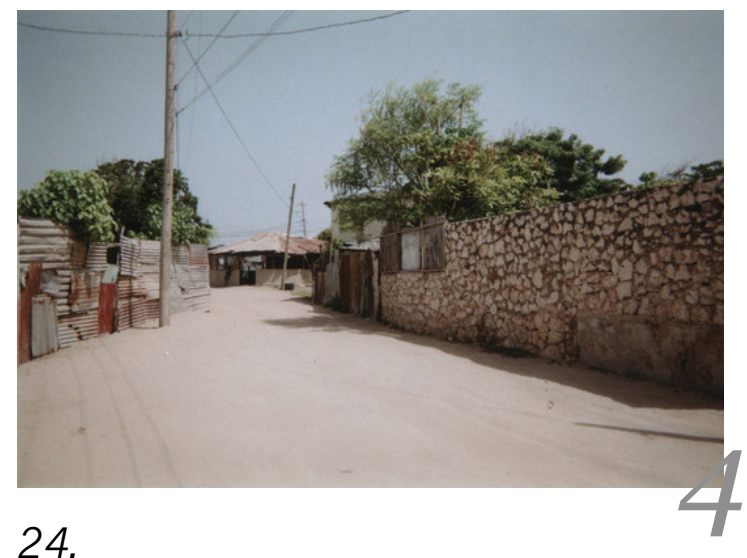

24.

BLU MOON MOTEL

36.

INTÉRVIEW: SPICYWTR

40.

AT HOME FOREIGNER:

46.

POOL HOPPERS

56.

SPRING SUMMER ' 17

62.

INTERVIEW: NOOMI SHOP

64.

REUNION

68.

CO-DEPENDENCY

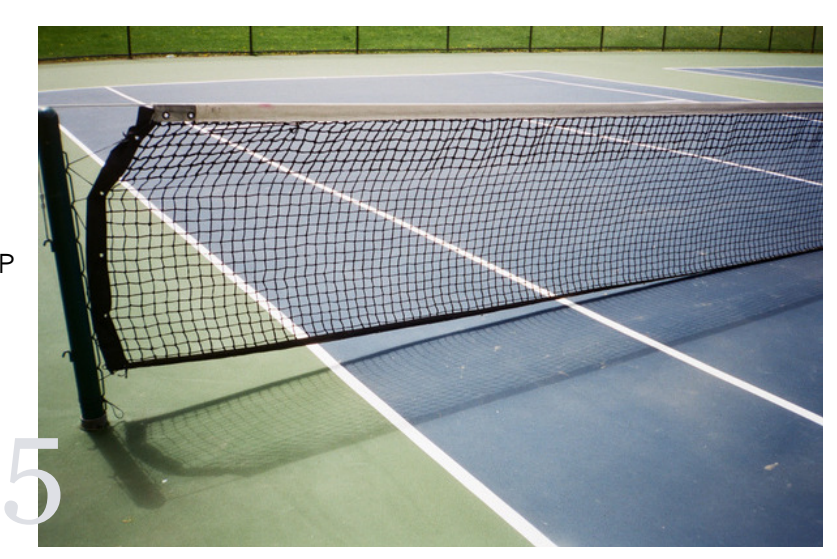

8

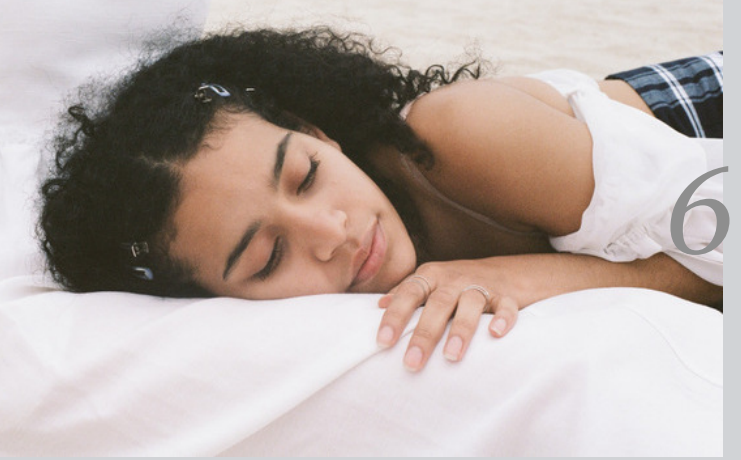

LETTER FROM THE EDITORS

08.

SHORT FILM: UNDRESSED

ARTIST FEATURE: LAURA 18.

A LETTER ON CUPS, CRAYONS, \& THE STRUGGLE FOR A NATIONS RACIAL AWAKENING

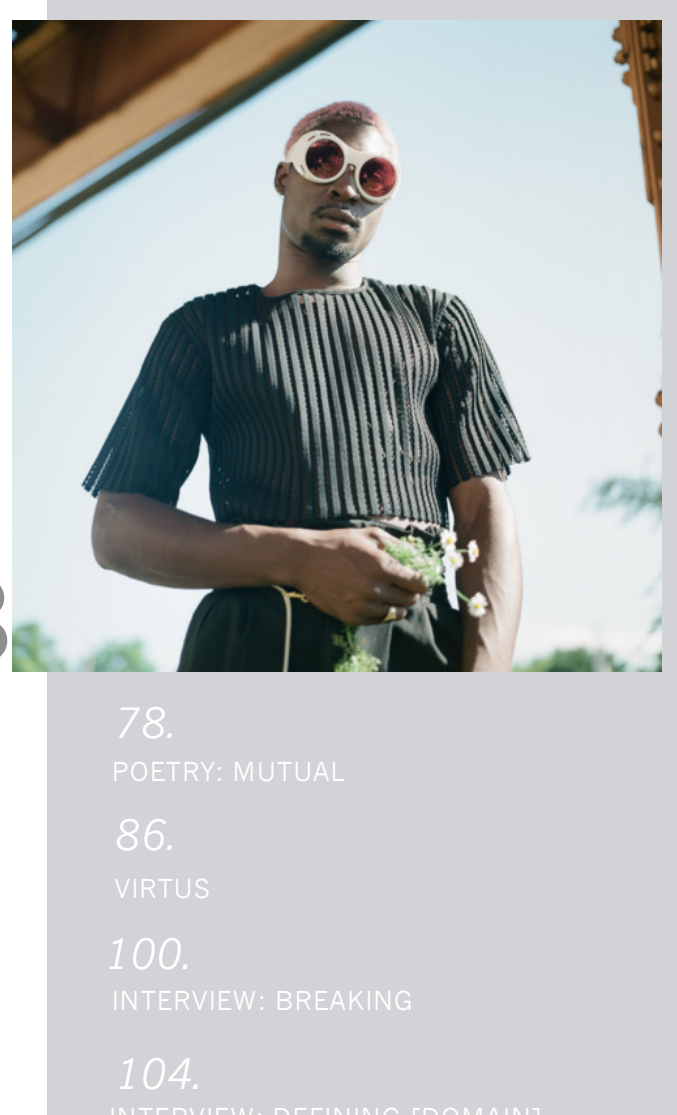

104.

INTERVIEW: DEFINING [DOMAIN]
112.

SERIES 00

120.

INTERVIEW

130.

ARTIST FEATURE: MIRANDA CRABTREE

132.

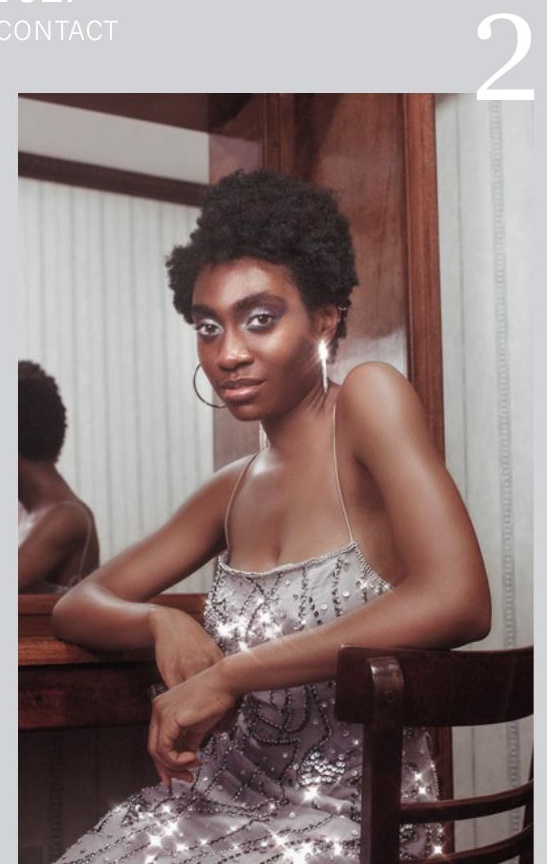




\section{truer vouver p̂n}

Welcome to The June Collective! First and foremost, we want to thank you for putting your faith into us, and into this publication as a whole. It really means more than you will ever know.

We believe one of the best ways to connect with one another is through music, so we've decided to give you folks a curation of the songs that have been on heavy rotation for both of us over the time that we spent crafting and perfecting this issue.

All of these songs can soundtrack just about anything you desire - but personally, we recommend pressing play and flipping through the contents of this issue. We hope that these songs draw out of you the same inspiration and excitement for this project that they did for us.

If you're an upcoming artist and would like to see your music in one of our issue playlists, we'd love to hear from you! You can get in touch via any of our social channels, or feel free to just send us an email directly. We can't wait to expand this creative community to represent every single one of you.

Love always,

The Influence Team

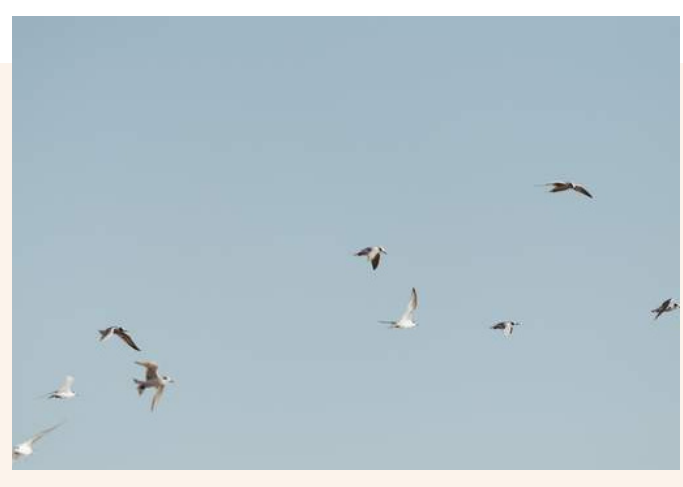

on the low - tove styrke

no exit - tennis

down 4 whatever - kingdom, sza

summer friends - chance the rapper

pine \& ginger - amindi k. frost

something foreign - sir, schoolboy q

the weekend [funk wav remix] - sza, calvin harris

you're the one - kaytranada

wishing it was you - k. flay

feel it still [lido remix] - portugal, the man

sweet - brockhampton

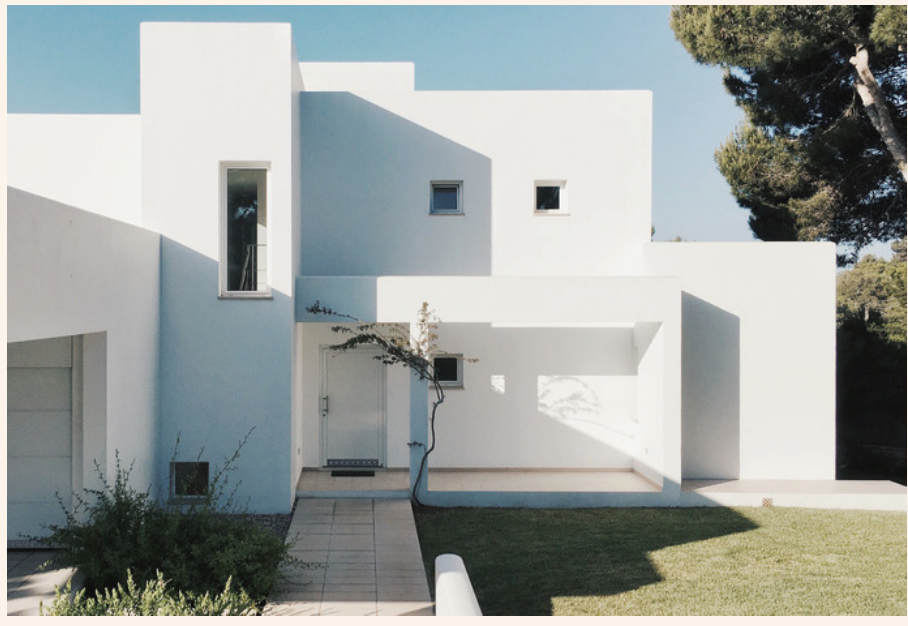




\section{LETTERS FROM THE EDITORS}

\section{Hi friends!}

I'm totally unsure how to start this letter. This is due to a few things, but, in part, is in fear of misrepresentation of the complete and utter gratitude and humility I feel at the chance I've gotten to create this publication. I am in awe at the fact that the artists within the pages of this issue have put enough faith and trust into Emi and I as creatives to gift us their work and their invaluable time to make something this incredible. Without them, this magazine wouldn't be anything. But I'm getting ahe myself. Let's start with the basic

My name is Norelle, and Influence Magazine. Even just typing out that title makes it so much more real then I ever thought possible. Influence started as a backburner 作 people that I met in school that shared my core beliefs and fundamentally inspired me as a person; in fact, the day that I met her I told myself that this was someone I needed to keep in my life for a long time. This publication stemmed first out of a friendship and a genuine partnership between two likeminded individuals with a passion for equity and equality. I think with that driving this, the sky is truly the limit.

And so, with all of that being said, I would like to welcome you to the first ever issue, The June Collective. Almost a year in the making. In the months spent crafting this issue, I have learned so much about art, life, myself, and the incredible artists that
What's poppin!

My name is Emi and I'm the co-founder and art director of Influence Magazine, a publication dedicated to the inclusivity of ideas, identities, art and experiences. Norelle and I have worked tirelessly during these past few months to finalize this project and we are excited and proud to present our first issue - The June Collective - to you. As we go along, l'm sure the way we do things will adapt to our growing knowledge of this industry but we are thankful to have created a platform to express our passions and those of the incredible individuals who are in these pages.

From the beginning, we wanted to create a safe space where people could express themselves without watering down any aspect of their identity or culture. We find it important to provide marginalized and underrepresented people an

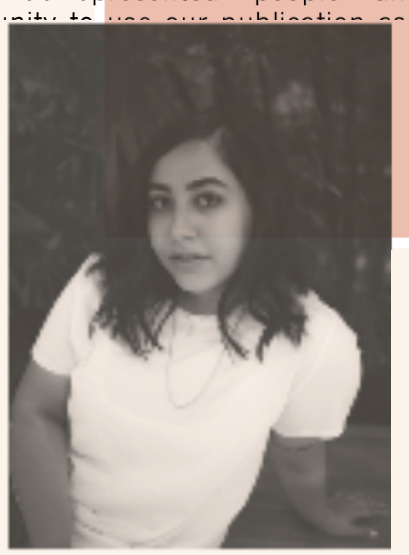

Overall, this publication is about expression. It's about experiences and differences; impact and allyship. It's about finding parts of yourself in these pages and relating to something in its purest form. We all hail from different places, like different things and act in different ways. Sometimes we can't explain the way we are other than to say "that's just who I am"; being cognizant of the fact that our differences don't need an explanation differences don't need an explanation is important in how we embrace them. We are who we are, without apology. We can't control how the media paints us and how the world will then see us - but we can try - and tois publication is hopefully a start.

For many reasons, this means the world to me. It has given me hope and it would not be possible without you; thank you for Delieving in us and the change we strive to generate in our community, I encourage you to take the time to read the words and look at the people in these pages. Hopefully you will, like me, be inspired and influenced in some way by what you

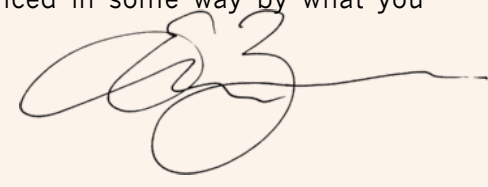




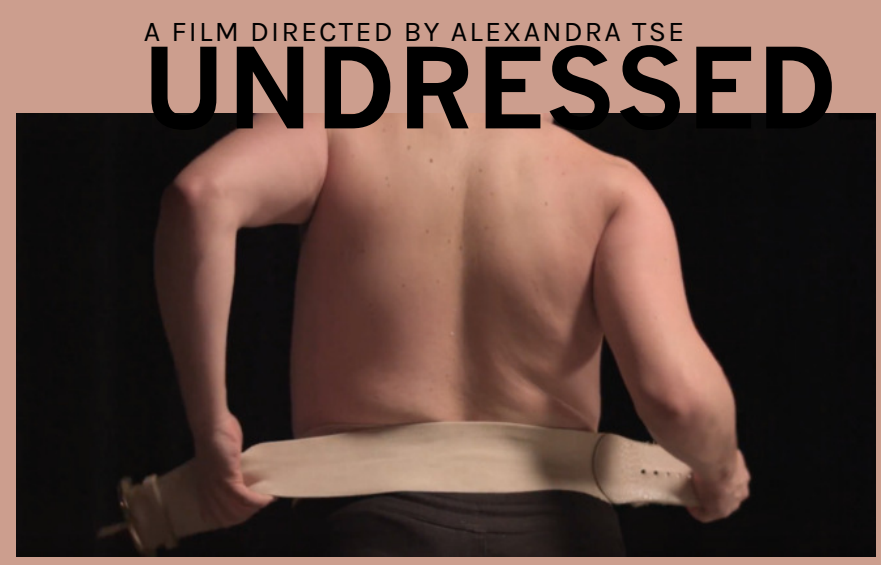

A DOCUMENTARY EXPLORING CONSENT ISSUES IN THE WORLD OF DRAG FROM THE PERSPECTIVE OF THREE TORONTO-BASED DRAG QUEENS.
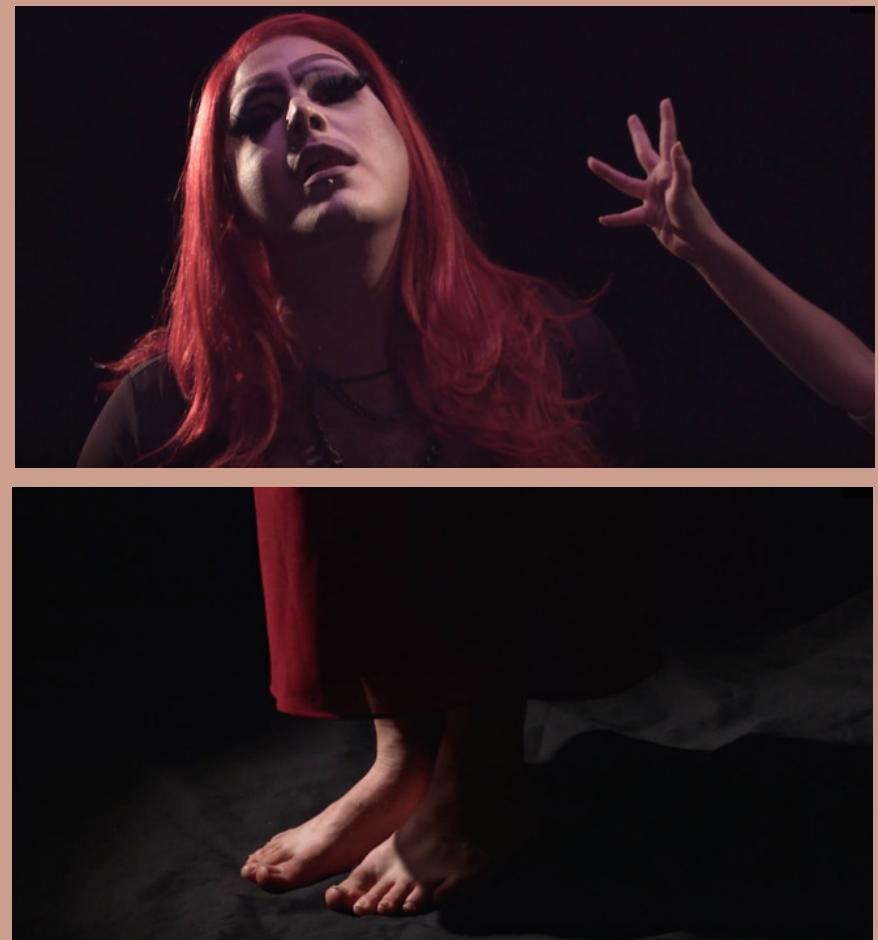

U

PUNK DRAG PERFORMER IN TORONTO

MANGHOE LASSI

CU TORONTO'S FAVOURITE DESI DRAG

POPPEA VICTORIA

AN INDO-CARIBBEAN QUEEN CURRENTLY

COMPLETING HER PH.D ON QUEER

DIASPORIC SOCA/CARNIVAL SPACES

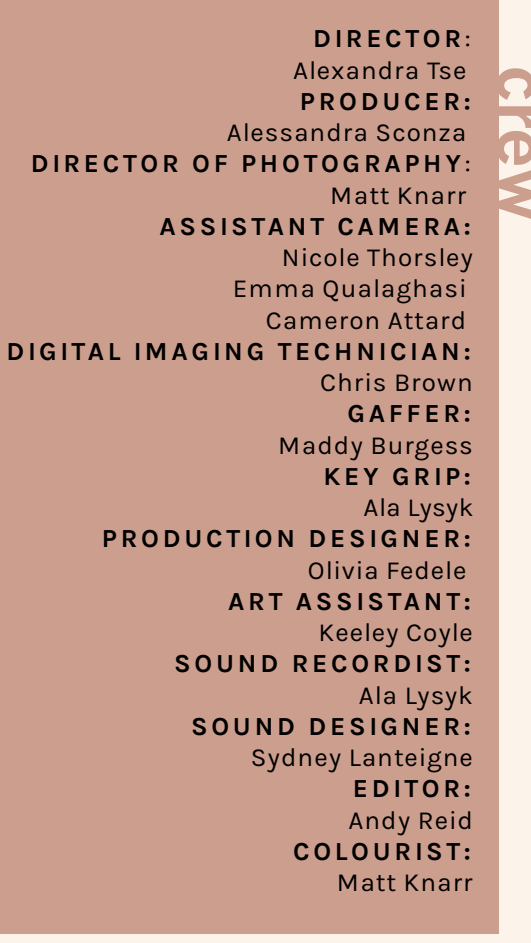

0

(D) (D) () 


\section{W A T C H N O W :




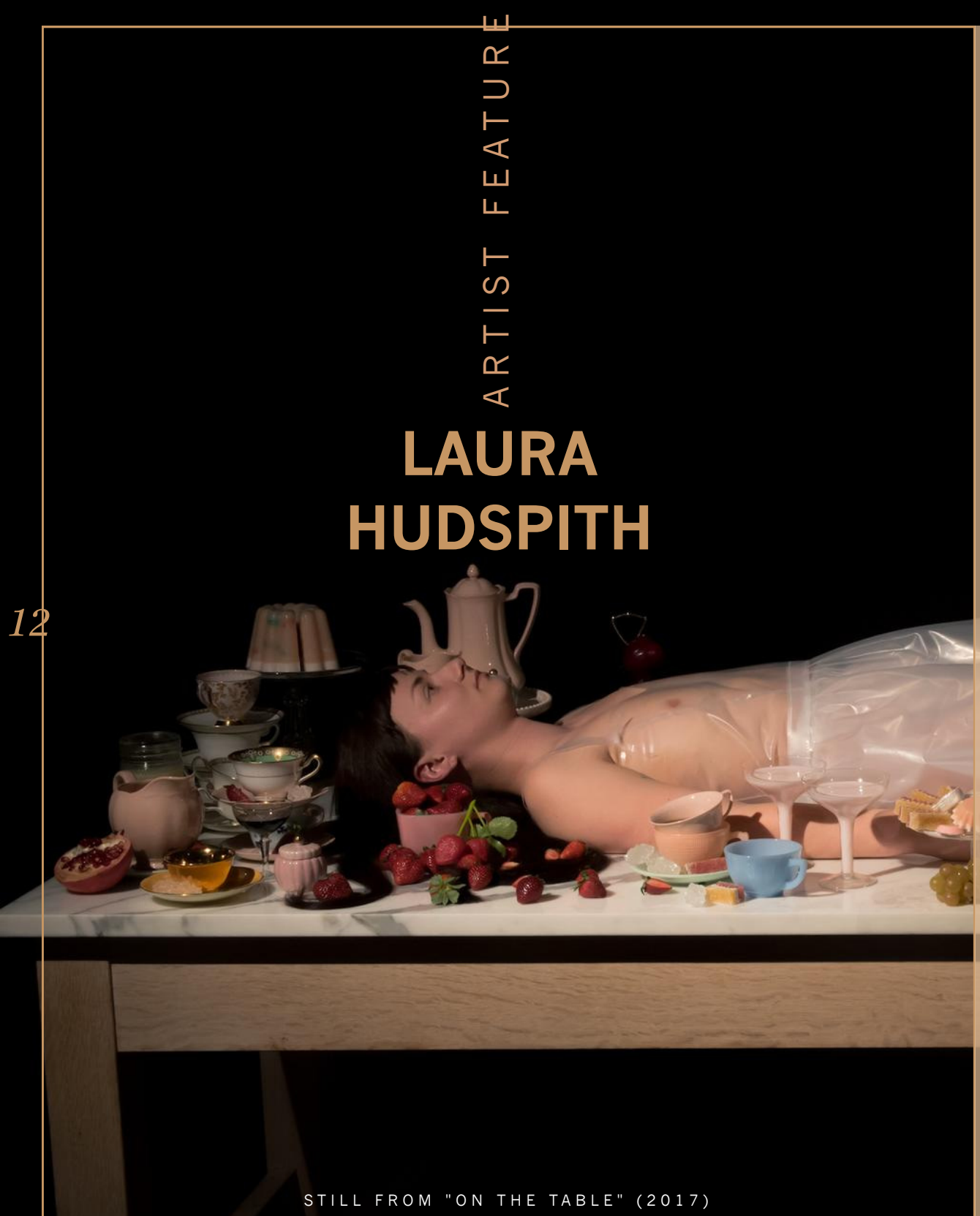

The uncanny valley hypothesis describes the moment when our perception shifts from kitsch to grotesque as the distinction between simulation and reality dissipates. The theory simultaneously indicates our fascination with simulation and simulacra as well as our necessity for categorization.

By simulating reality or positing possible near futures, my work operates within the territory of the uncanny valley, creating the space to negotiate authenticity and artifice. Factory-made replicas and cast objects convey a set of connotations which build to create new/additive meaning in series. In this way, benign objects take on a seriousness unfamiliar to kitsch and work to articulate political ideas.

Whether used performatively or cast in peculiar materials, my work plays upon associations inherent in commonplace objects and explores authenticity and the allure of simulation through the ersatz mirror. With an interest in merging civic conviction with artistic intent, curious arrangements and seductive visuals give way to inquiry of an equally personal and political nature, both provocative and antidotal.

Working predominantly in sculpture, installation and video performance, my work highlights the space where human nature and culture contradict. Of particular interest to me is the effect of culture on perceived [im]mobility within the structures that order our day-to-day experience. Either through the vulgarity of satire or by sobering sincerity, my work engages with these constructs by highlighting their effect on agency. 

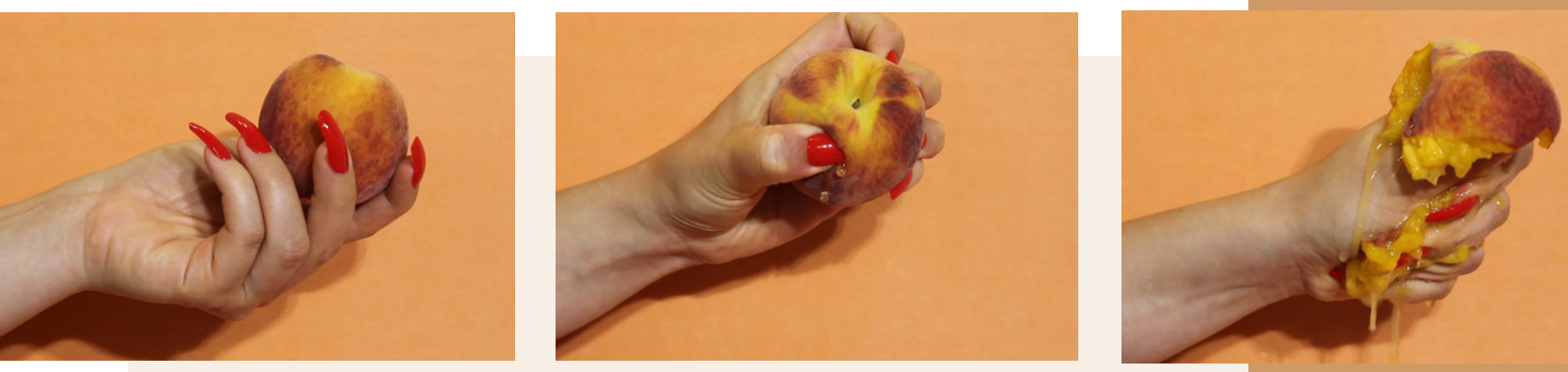

\section{PEACH'S}

Titled from its namesake

sculptural piece, Peach's

Peaches, examines the

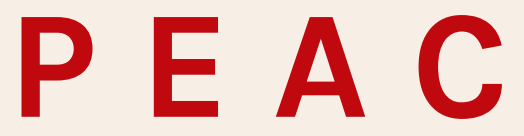

idiom that work to detach woman from agency. No sooner than leftist ideals created the sexually liberated woman, the very notion had been co-opted and reshaped by capitalist industry into marketable sex appeal. The work depicts this precarious position between exterior expectation and interior modes of expression, or, the nebulousness of obtaining authentic autonomy. 'She's a real Georgia peach!' Playing on the decades old phrase that posits woman as juicy object ripe for the picking, as well as its iconic contemporary use as a digital symbol connoting the same, hands adorned with red

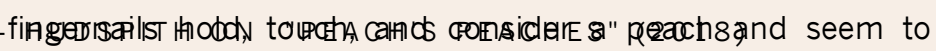

WATCH

C RE DIT S :

Lighting \& videography by Tamara Léger website / instagram
A silent video made to be screened in a busy space, [Peach's Peaches'] running time is 00:09:59.

This piece was created for and first screened at Katzman Contemporary for their event, DRIVE-IN, summer 2017.

\section{LOREM I P S U M}

This particular cornucopia installation recalls the structure of shrine and combines the tone, subject(s) and mechanisms of past works, with a collection of popular tropes seen in 2017/18 contemporary art: astroturf, vinyl surfacing, neon, mirror, chains, mundane objects, precarious leanings, hardware, industrial materials, gradients, ombres, potted plants, I $\mathrm{I}$ tropical foliage, lush fruits, nautical objects, casino $\square$ symbols, Greco-Roman statuary, etc.

This extensive index of objects, often removed so far from context as to appear haphazardly placed or perhaps plucked from the Instagram garden are here $\mathbf{z}$ arranged to show an aptitude for its language, the = installation forms a venn diagram where contemporary ${ }_{0}^{-}$ art and pop/party culture closely overlap. 0 Contemporary art object, artist, dealer and tastemaker 3 are each greeted with an abundance of their pleasure, $\bar{\tau}$ and equally met with its own absurdity. Gallery white of wine teeters on the edge of a cinder block, spilling $\underset{\complement}{\lessgtr}$ "Guilty Men" frivolity onto the scene. Similarly, an outstretched arm emerges from the wall to white- N wine-water a plastic plant. Backed by a pixelated $\underset{\infty}{\stackrel{\infty}{\infty}}$

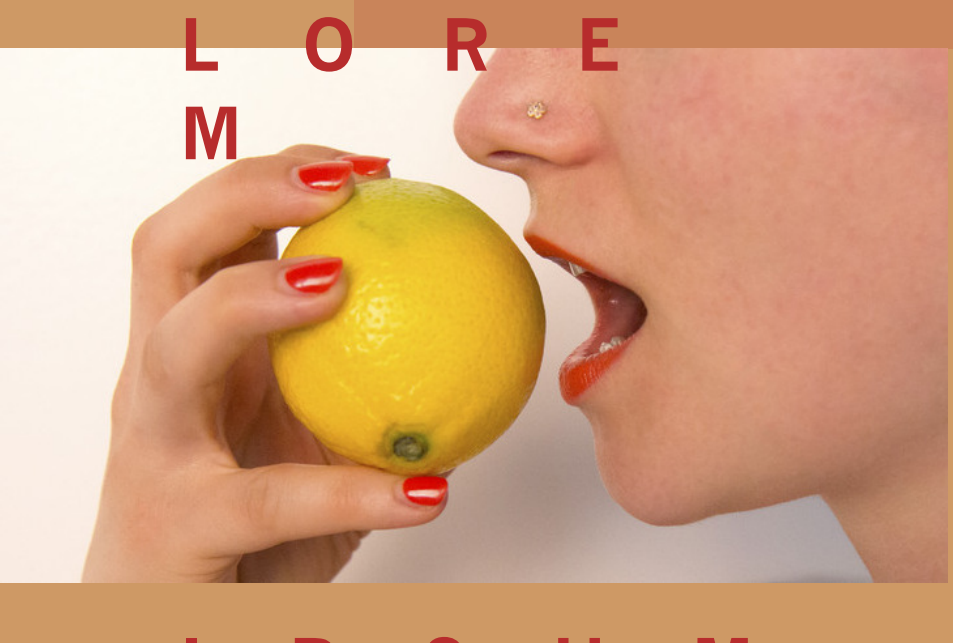


don't want to start these ideas off with some cushion of Canadian sentiment where the sensitive can rest their delusions. I won't pander to the moderate majorities in their belief that my being part of this nation somehow necessitates a fervent appreciation of its supposed values and freedoms. It's time to spill the tea on Canadian inaction in the face of a growing divide. While the struggles of all the oppressed within these borders disturb me and embolden my resolve to speak, I can only write about what I have experienced and understand.

Canadian political discourse is changing. Our active legitimizing of previously veiled and coded forms of racism, sexism, and generalized phobia in recent months signals a shift in the political climate. Essentially, we've regressed to the point of fighting for the right to be terrible to each other. Canadians on the left seem surprised that these thoughts could even exist in the minds of their fellow comrades and yet, I know this is not some new phenomenon spurred by a Trumpist political shift. This shift has emerged from within. Beyond our supposed compact theories and origin stories, the truth remains; Canada is founded on a set of

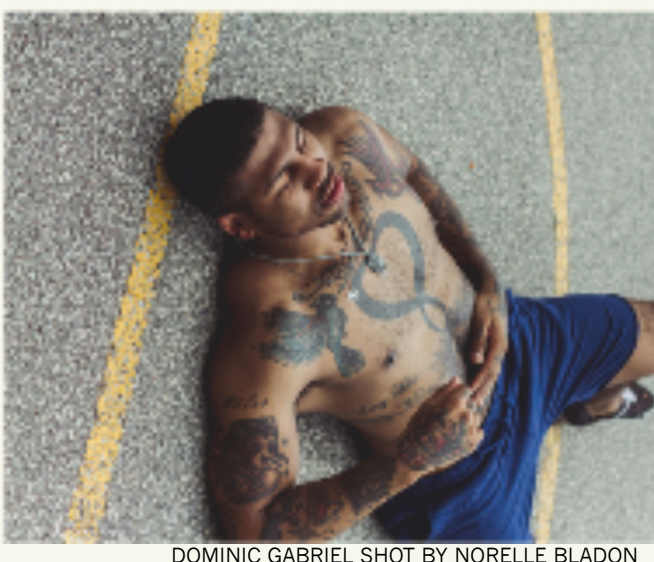

It's clear that from an uncomfortably young age, children are exposed to the alleged principles of the nation. Equality, diversity, and multiculturalism are woven into conversations surrounding the state and ingrained is the principle that nowhere else in the world can these values be found and delivered upon. Alongside those ideas, children grow and are left to perceive the world through what lens they were given.

Engineered discussions on identity occur later, framed in the context of an imagined societal mosaic and national norms. Our near extermination of Indigenous peoples; our documented history of enslaving Africans; our tax on the lives of Asians; and various other crimes are presented as tame relative to our neighbors down south. This approach to our history has allowed us to coast on by, unscathed for our mistreatment of those who struggled and continue to struggle to maintain their rights.

Regardless, the general populace seems to buy in and truly believe that Canada is beyond reproach. It bolsters its sense of purity by citing national narratives. Our endless repetition of this vein of history cites a genuine lack of understanding and 
This reality takes time to craft and adopt. However, once entrenched, it is a force against the very rea circumstances facing those left out of the narrative. Why else has this nation not undergone the reckoning it deserves for its past and present crimes? Brilliantly, the state appears to crimes? Brill have muted the people into believing it has no crimes to atone for.

Afua Cooper said it best: "black history in Canada has less to do with black history and more with white pride." Why else would Canada highlight the underground railroad as highlight the underground railroad as
opposed to the nations' own foray into opposed to the
slave holdings?

I remember drinking up the broth of Canadian idealism as a child. I clearly recall our first encounter; stewed in displays of multiculturalism, it felt old and contrived. And beneath the warming effects of the drink were notes that for years have gone willfully unnoticed: erasure extirnation an The damage of such a lie can be seen in the lives of so many on the fringes. remember in kindergarten, my classmates and I, innocent, set out to draw self-portraits in crayon. Being fair in complexion as a child I reached for a colour similar to that of my white classmates. As I began drawing, a little girl seemed confused by my choice and called out my apparent mistake: "that's not yours, that's mine. Here, this is your colour." And she placed a black crayon in front of me as she took the peach out of my grasp.

That was the day I realized | was different. It signaled the beginning of my grappling with identity. Comical as it is to recall, the moment has never left me. A recognition of what is theirs left me. A recognition of what is theirs a single word: exhaustion.
I think a general feeling for people of colour in this country can be summarized in a single word: exhaustion. It's exhausting to juggle your identity along with how others perceive you and how you want to be perceived. Some of us are stronger than others and being perfectly honest, I was not strong. I embraced the alleged mosaic crafted in my adolescence and believed in its power and I became a token. It allowed me to weave through blanched echelons of influence. I let go of my questions and anger. When encountered with comments of how "white" I acted, I wore it as a badge of honour. I drank deep from the cup and pacified my feelings and awareness. Sadly, I can say that for many years this strategy worked. In rejecting myself and fowards race, I earned the respect of a white. I was a part of that I knew I was meant to bed Ap undersement $^{2}$, gaye way to rage rage to shame, and shame to
understanding of who was. dream that I could be equal if I could just get as close to being white as possible.

I'm generally surprised when I meet white Canadians that are aware of the circumstances facing people of colour and actively trying to change them. The education system wasn't built to encourage this. In fact, it actively seeks to subvert it. My years in academia definitely proved that.

Twenty years in various classrooms and only one person of colour as a teacher can highlight that fact. And that's why I'm not surprised to see so many young men flock to figures like Jordan
After I finished my schooling, I remember realizing the confined cages I had engineered for myself and the external pressures I had become sadly, accustomed to. I packed my things and knew I needed to escape. I bought a ticket to Ethiopia and hid for a year, bouncing around and seeing my parents' homeland. For the first time in my life, I blended in. I wasn't the "other." Ethiopia is not without its problems but it will always be a place that I look back fondly on as a refuge.

Coming back to Canada was rough, tough, and dirty. I recall standing in line at a store and dropping my wallet. A man behind me motioned to the ground. As I bent down to pick up my debit card and money, a white woman two lines over loudly asked "Are you sure those cards are all yours?" I paused, and thought to myself "this again." I hadn't experienced racism in a year and in my initial reencounter, it hit me like a ton of bricks. Standing up for yourself takes practice and she made me realize that I hadn't been doing my due diligence. I never wanted to feel like that again. I recognized my running away to Ethiopia was simply another form of hiding from race and $m y$ ever-constant encounters with the subject.

choose to sit in my blackness and embrace it for all it imparts. I want to love myself in a way I was never taught. 

sit in my blackness
It's an ongoing discussion in my head. I can't shake it. But watching my fellow Canadians react to the blatant entrance of right white wing politics in political discourse with shock or surprise is becoming old. People of colour have been dealing with this and will continue to deal with this until the disentanglement of whiteness and the Canadian state occurs. Frankly, it doesn't matter what colour sits in Ottawa be it blue, red, orange or green. For people of colour, this country has a habit of actively subverting their perspectives on the sole basis that it just doesn't feel "Canadian”. I used to drink deep from the cup and I believed it worked. I mean, if you want to live like how this country lives, coasting and unaware, by all means, I won't stop you mid-chug. But if you recognize the ever-increasing gap between what we

' ' AUTHORED BY

TORONTO, ON
LOCATION

PRONOUNS

$\mathrm{HE} / \mathrm{HIM}$

@bemnetdebebe 


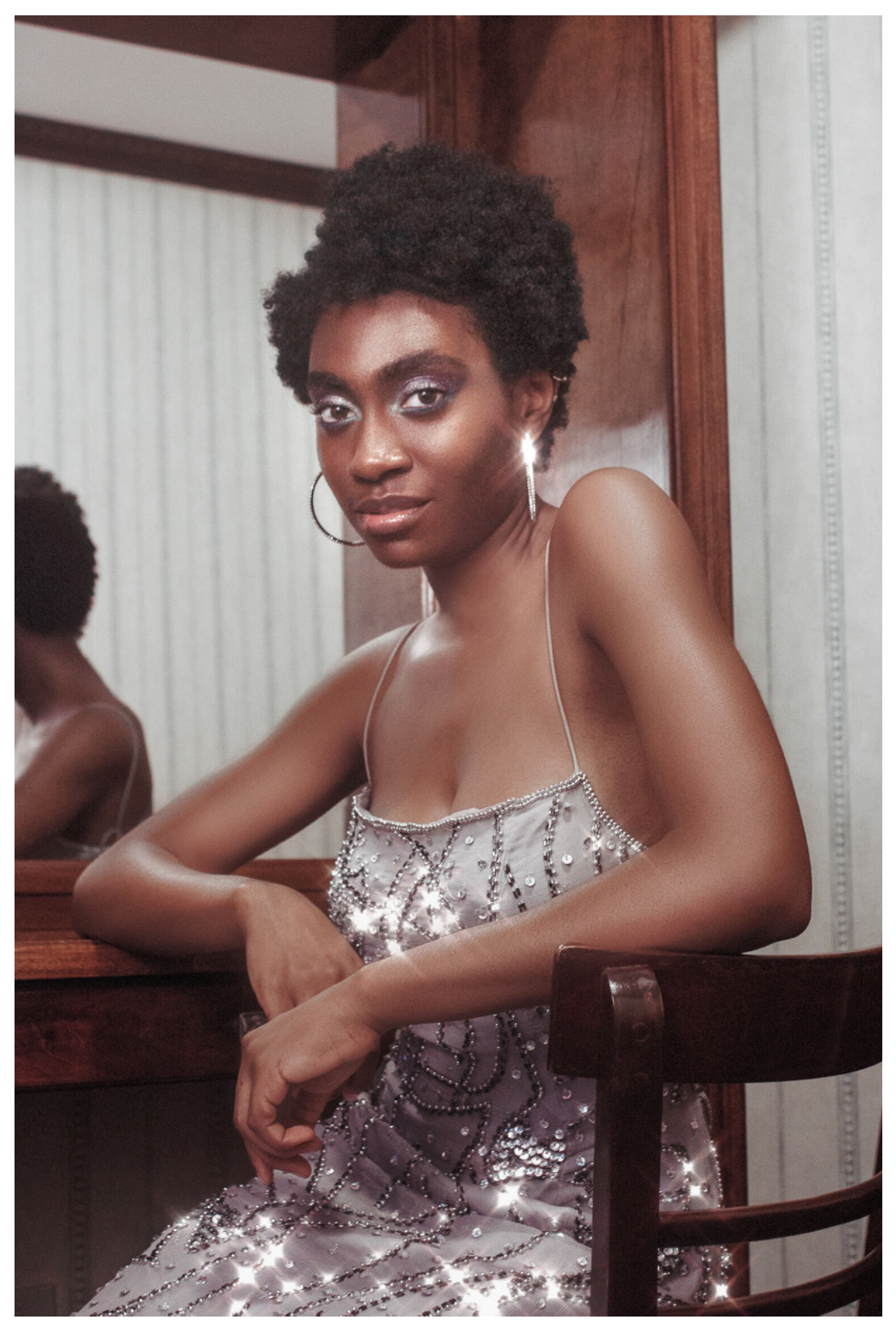

33 


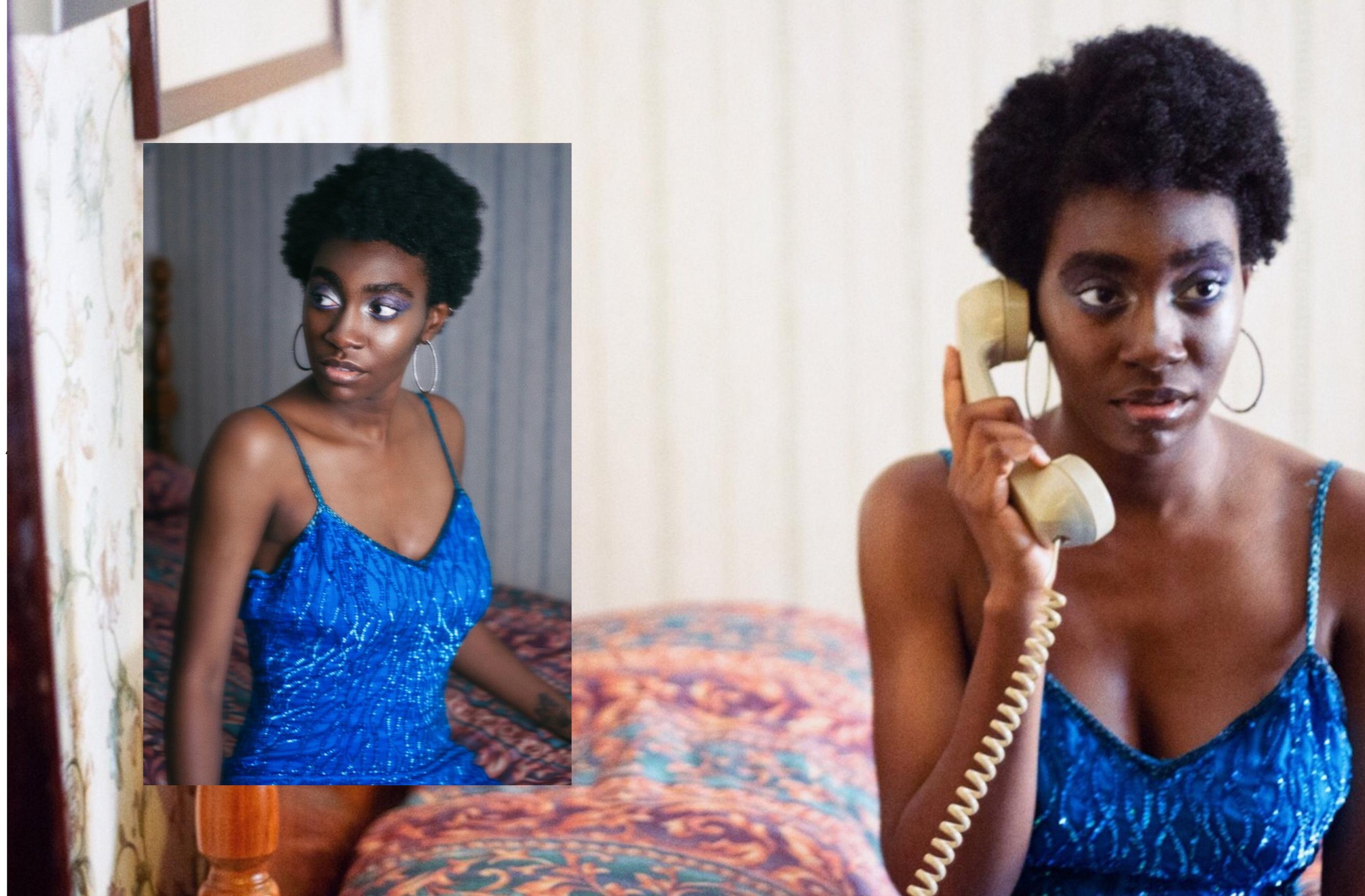




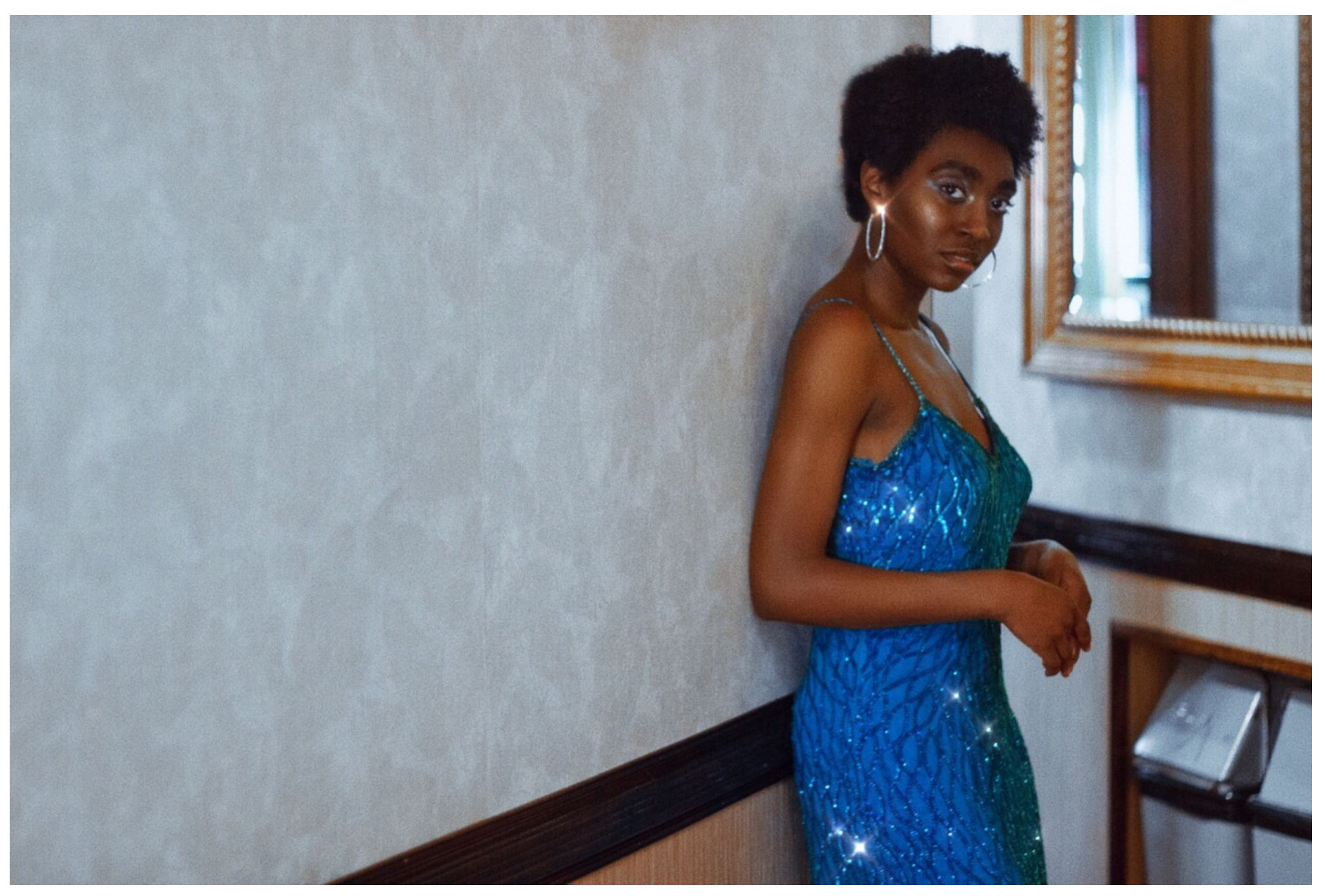




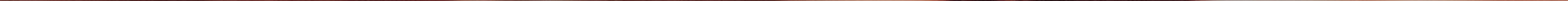


SOUTH ASIAN ART, REPRESENTATION + RESILIENCE

\section{st}

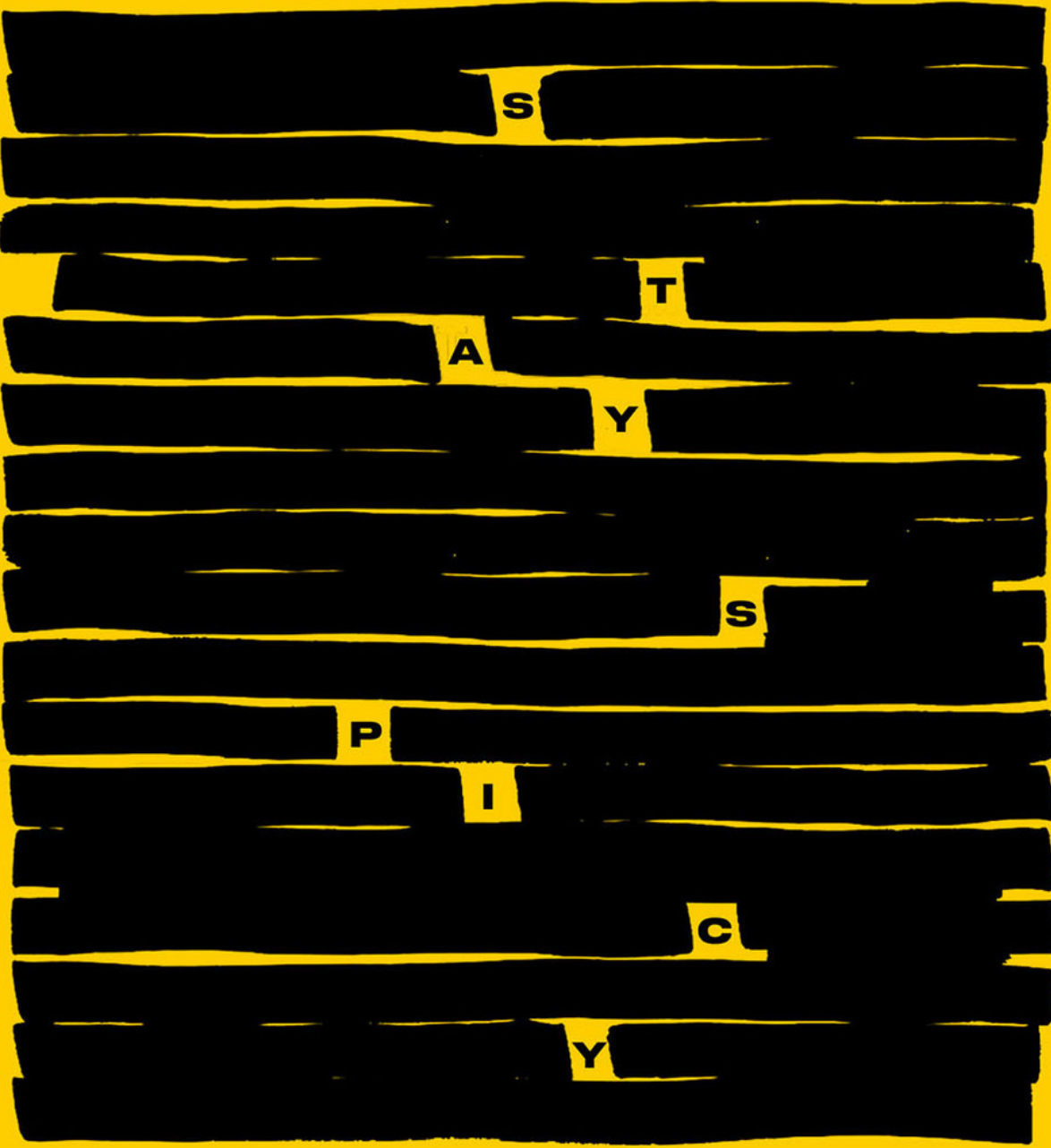

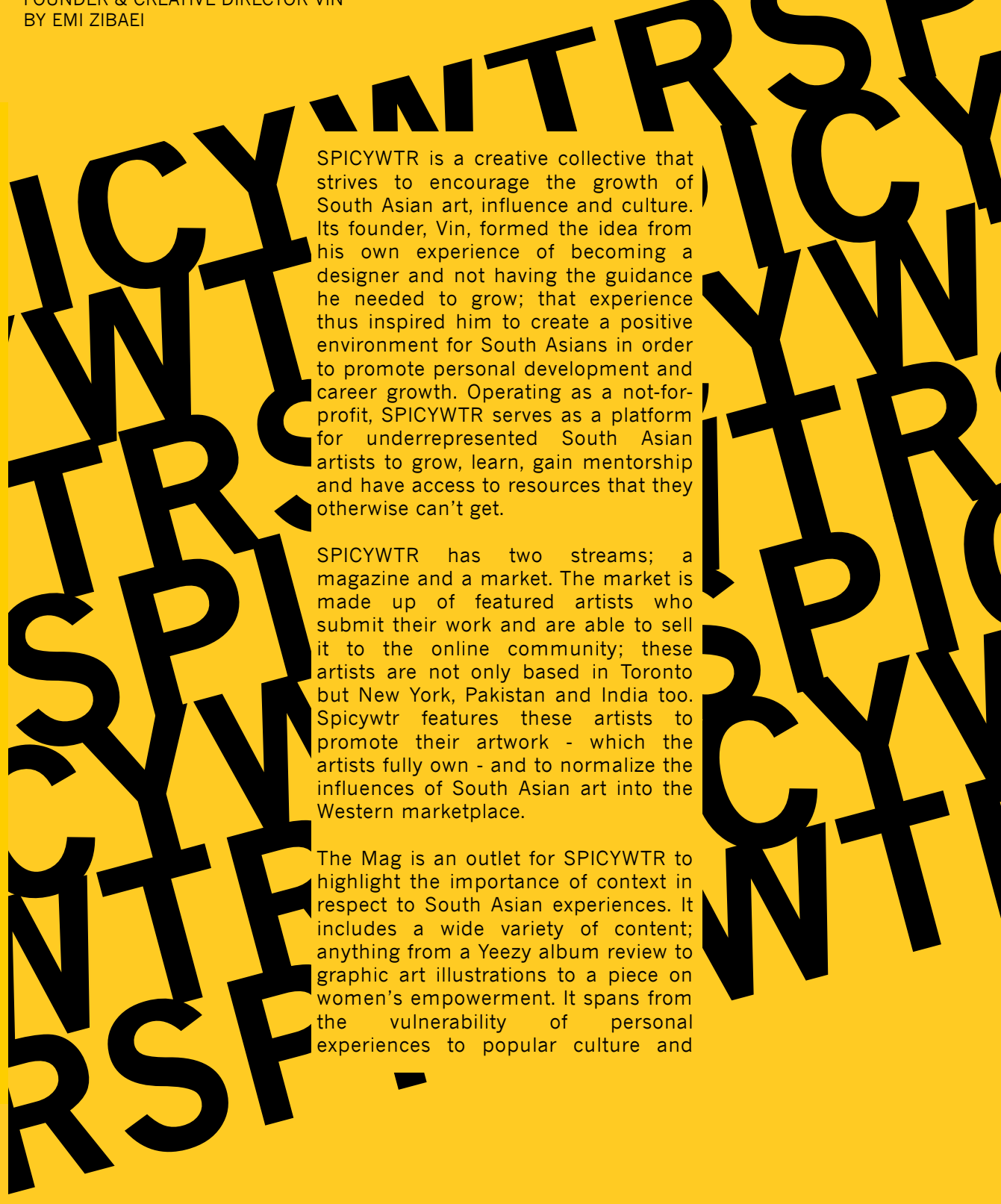



-appreciation, exposure, support, and the lack of resources, with resources being the main issue. From what l've seen, some artists don't have the knowledge or tools on how to get their work out there to an audience or know how to get grants or putting their work in ga!leries, for pvample.

We're currently working on it. Our future goal is to provide a space that contains the resources for creatives to prosper; this not only includes providing educational support and tutorials such as workshops, but also tools, such as equipment, which many tools, such as equipment, which many have access to or be able to afford. We also want to share experiences through galleries, installations, screenings, etc., that display work from artists at all stages of their careers (from ... amateurs to

46

RESILIENCE IS TAUGHT

FROM THE PERSONAL

STRUGGLES OF WHAT

OUR PARENTS HAVE

BEEN THROUGH, AND

FROM GROWING UP

AS A PERSON OF

COLOUR. SOCIAL, ECONOMIC, AND POLITICAL NORM, AND THINK IT'S EASY TO PERCIEVE THEM AS A SETBACK TEGARDILSS, THE WAY SOUTH ASIAN PEOPIE RROMOTE THEIR ART AND EXPERIENCES IS SO PRSTIVE AIVD PRODUCTIVE TO THE GREATE DELOGUE. ALWAYS THINK BACK TO THE FIRST TIME I READ RUPI KAUR'S MILK\& HONEY, AND HOW A FEV PELNSS TALKED ABOUT NEGATIVE SEXUAL PRFERENCES THAT CAN LEAVE PEOPLE BROKEN AND VAS GRACEFUL. WHAT ARE YOUR THOUGHTS ON TH'S

think that resilience is taught from the personal struggles of what our parents have been through and from growing up as a person of colour. Tamil people from Sri Lanka, for example, who have had to deal with the war back home, carry a big weight that still follows them today. Even we like mental health and sexual assault - it's not really discussed in the South Asiar commuinity arid fo: pe:o jle to write about it is big.

For the mag, we have open submissions. People can submit any work and it doesn't need to be South-Asian-centric content as long as you identify as South Asian. You can write about whatever you want but we just want to see more representation. There aren't a lot of publications or opportunities where people can just submit work so we're mindful of that. We've slsos struggled with the wolume of submissigns beralu'se we've found people maycr note want to openly share their experiences for a number of reasons and that's why we've added an anonymous feature.

For SPICYWTR - to be THE space to represent South Asian art of all mediums. Just seeing one artist flourish and prosper and make it is a fulfilling reward. The arts 



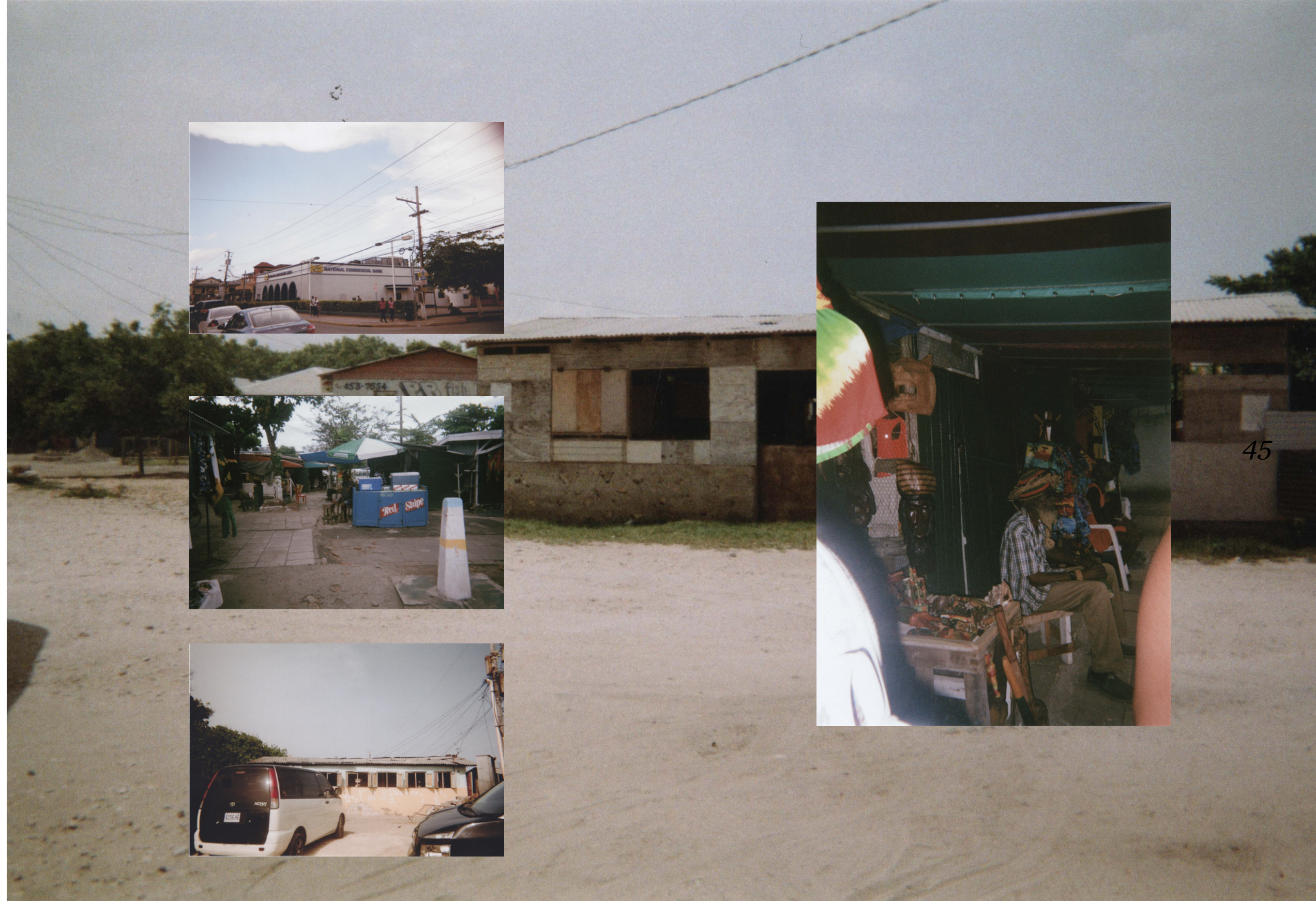




\section{POOL}

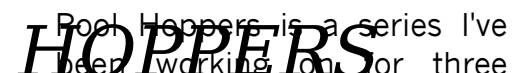
months in Toronto, young people can be found breaking into one of the many public, outdoor, swimming pools late in the night. I go over the fence first as a participant, shedding my clothes and jumping into the pool as fast as I can. After I've climatized, I pull out my camera and start photographing the individuals with their permission. Sometimes we're in the pools for hours, sometimes only for ten minutes before the police show up and kick everyone out. I find it interesting that nver the lact derade $\mathrm{nnol}$

\section{MIKE} Mike MritiRR Toronto. photographing fringe narratives/people within the city. His practice is entirely done on film using his medium format Rolleiflex INSTAGRAM / W'BEBSITE

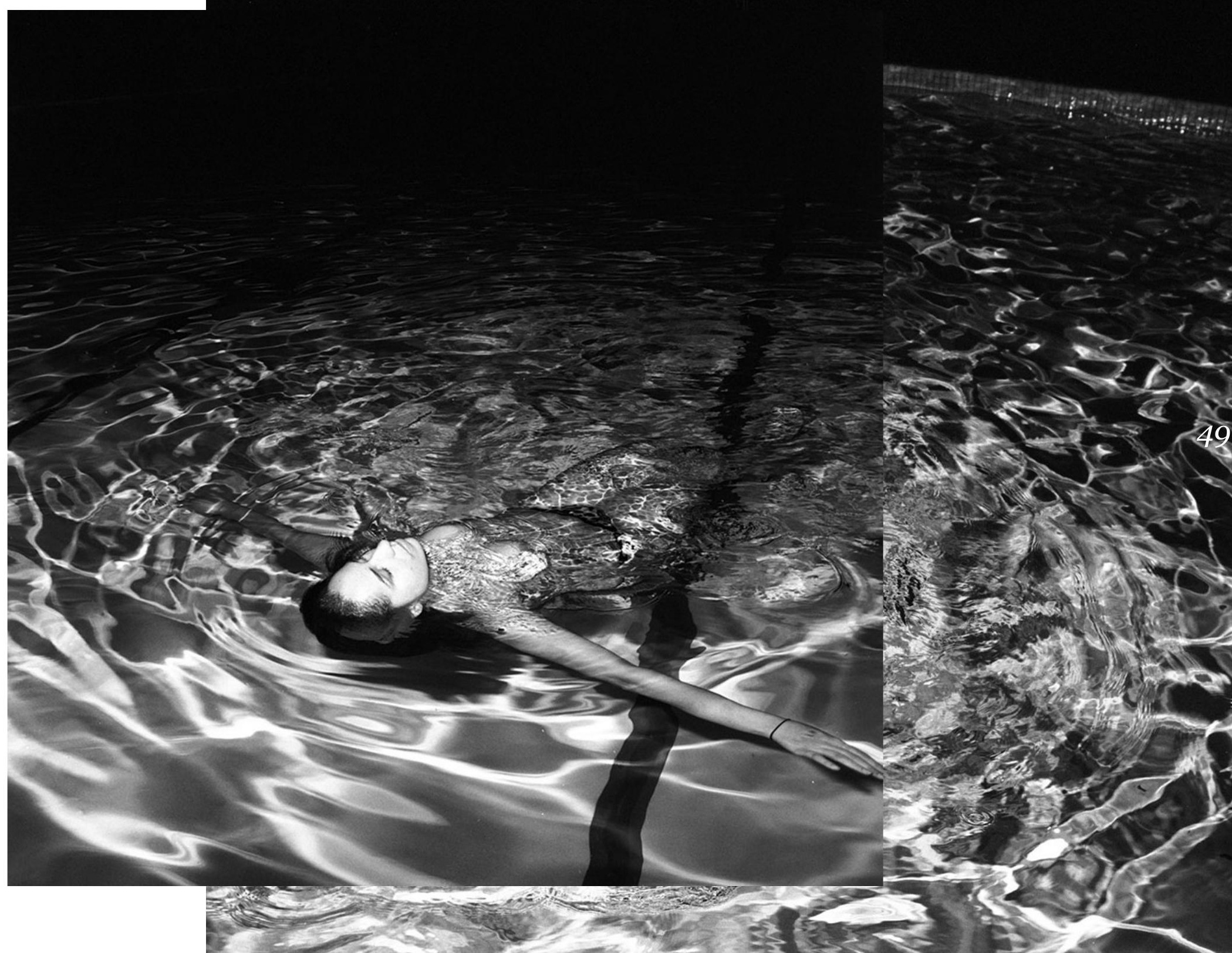



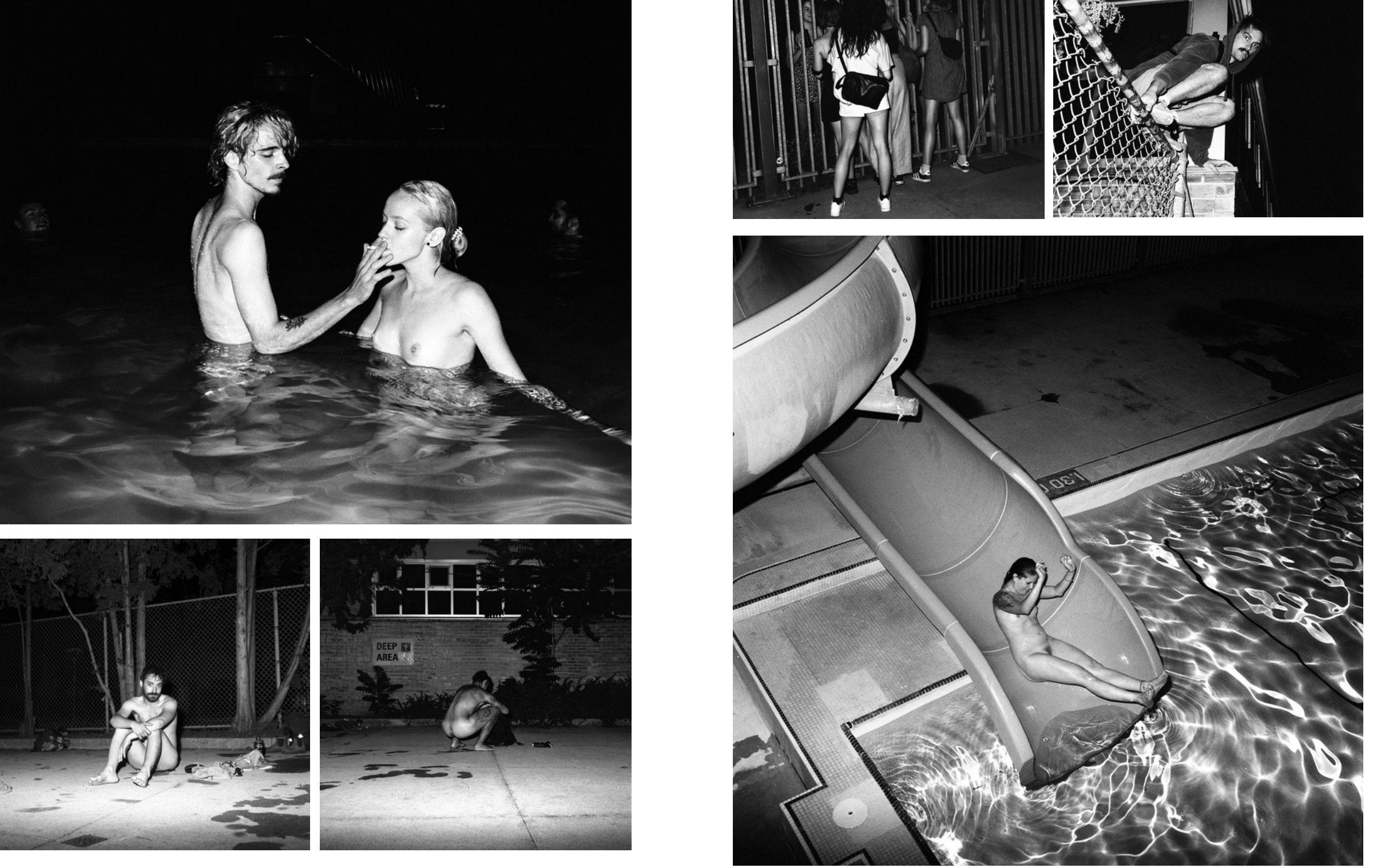

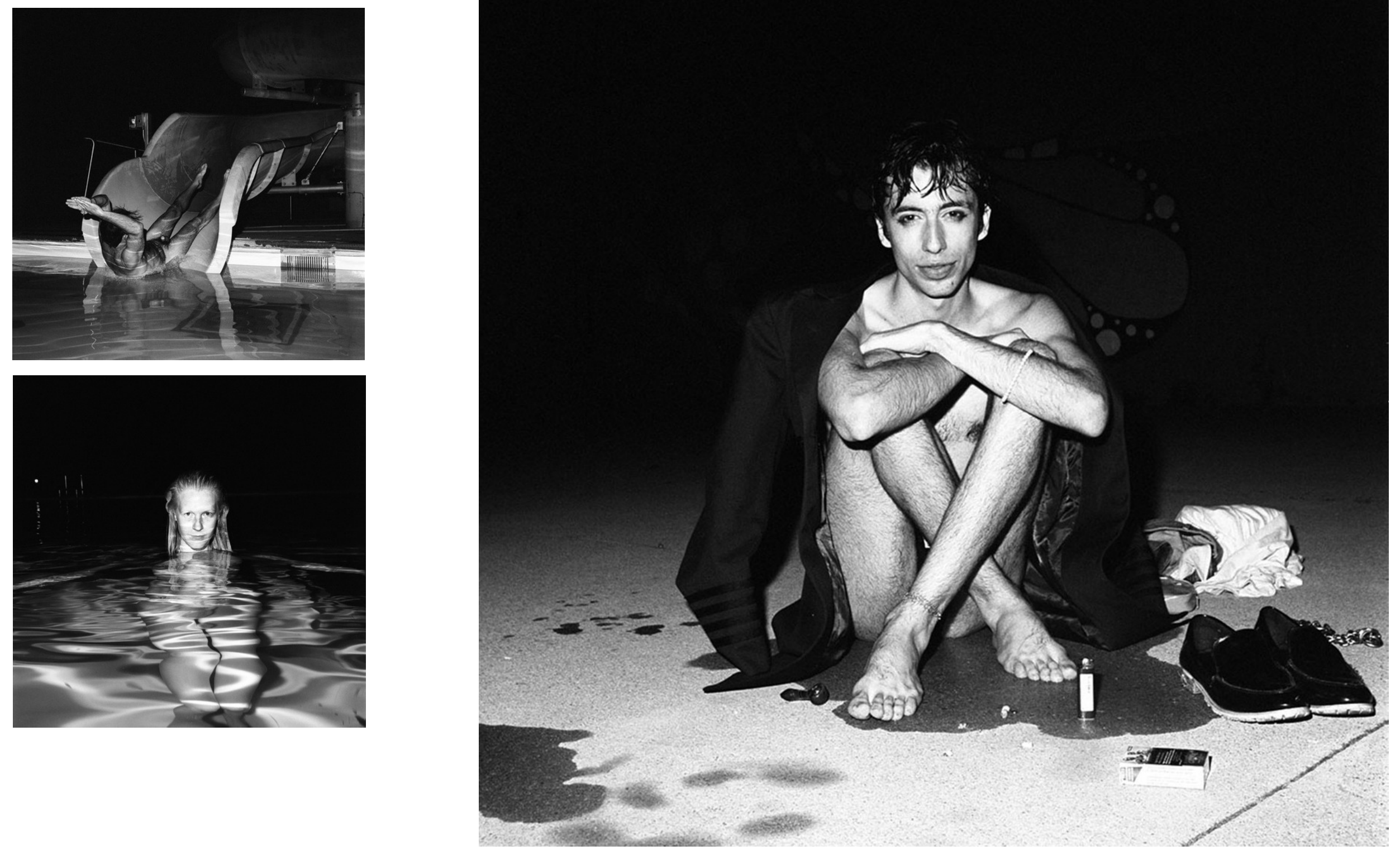


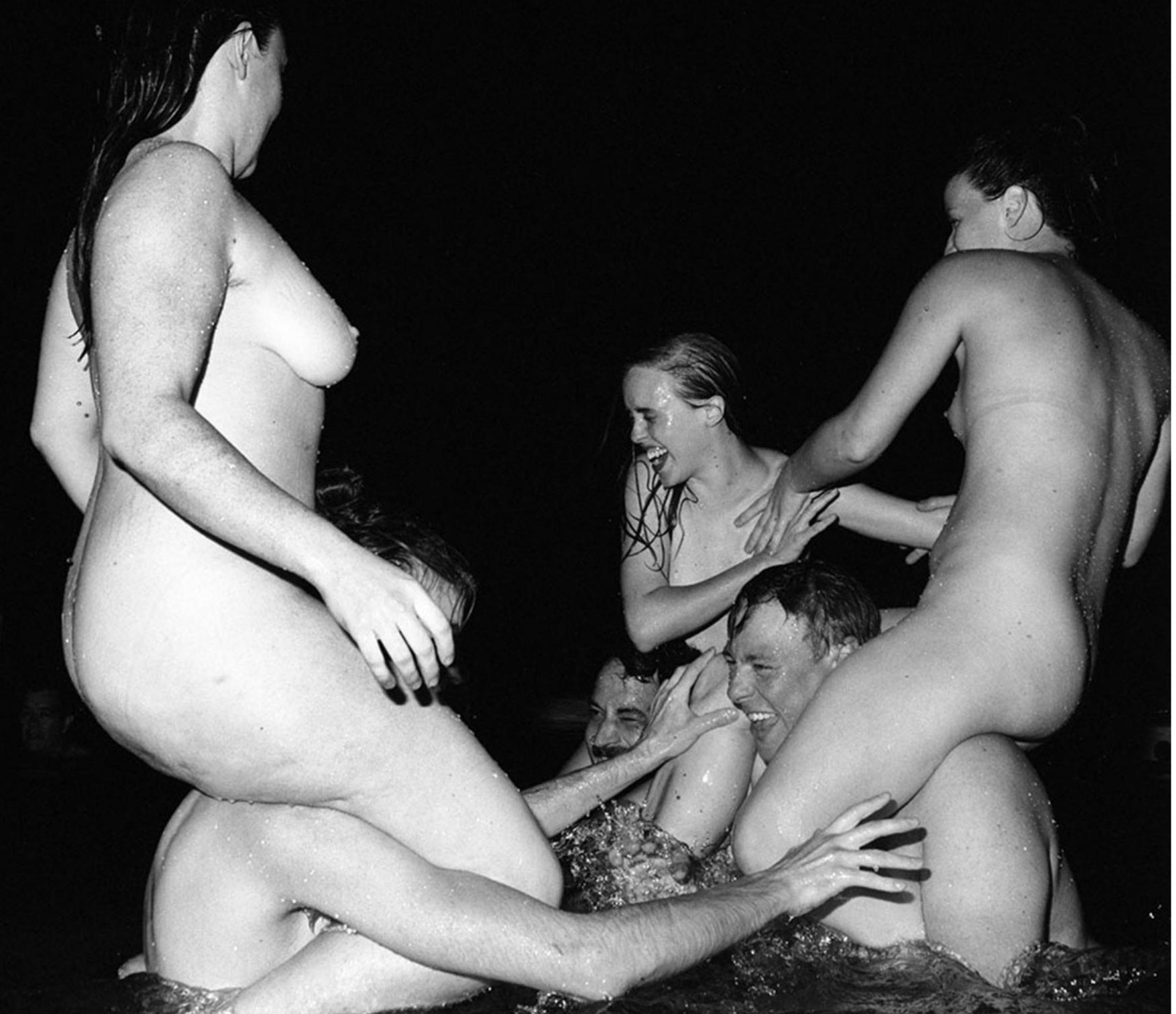




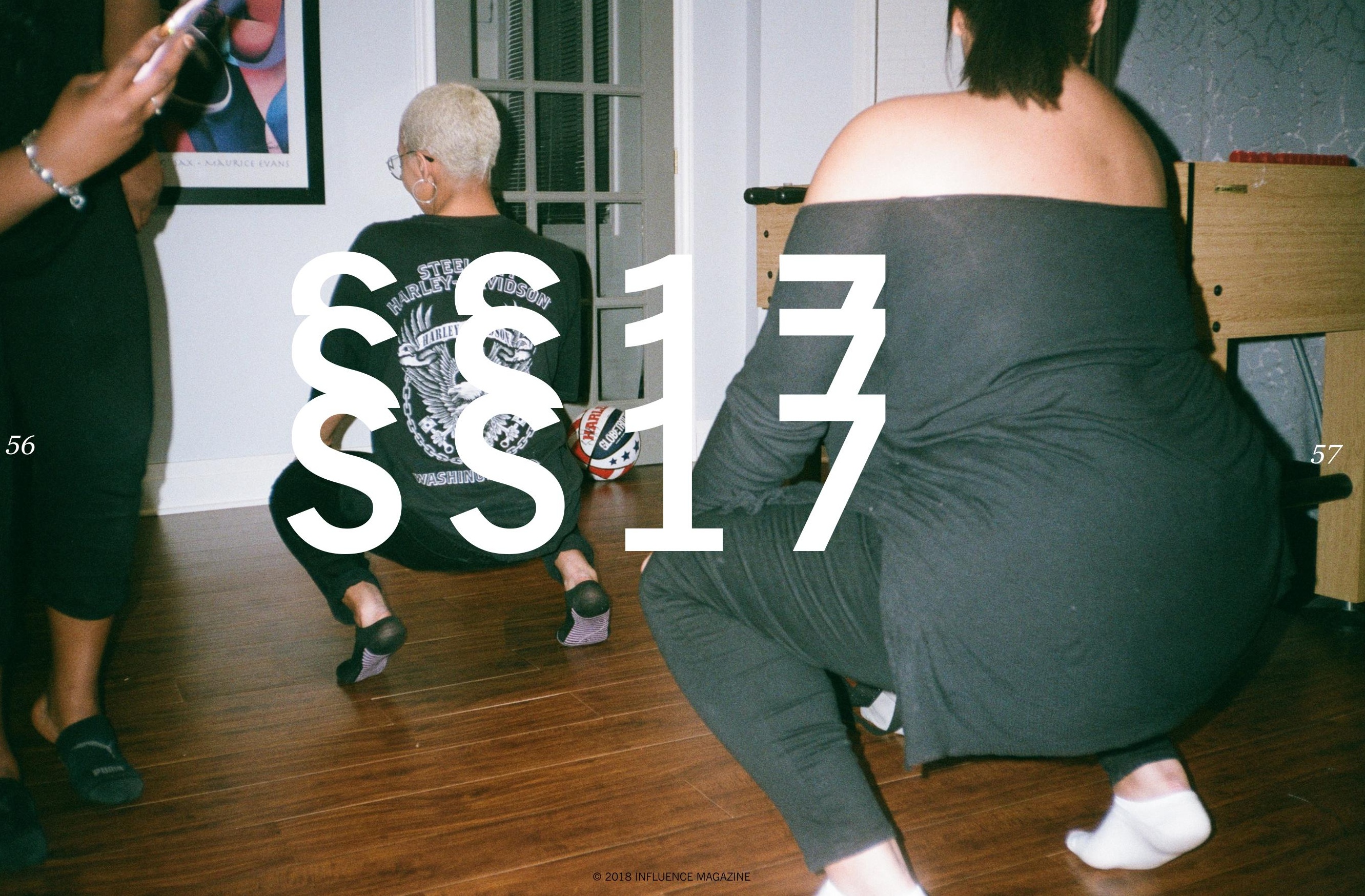


$\$ 17$

SHOT BY CATHERINE EBORA @CATEBORA

@OFFMYCELLULARPHONE
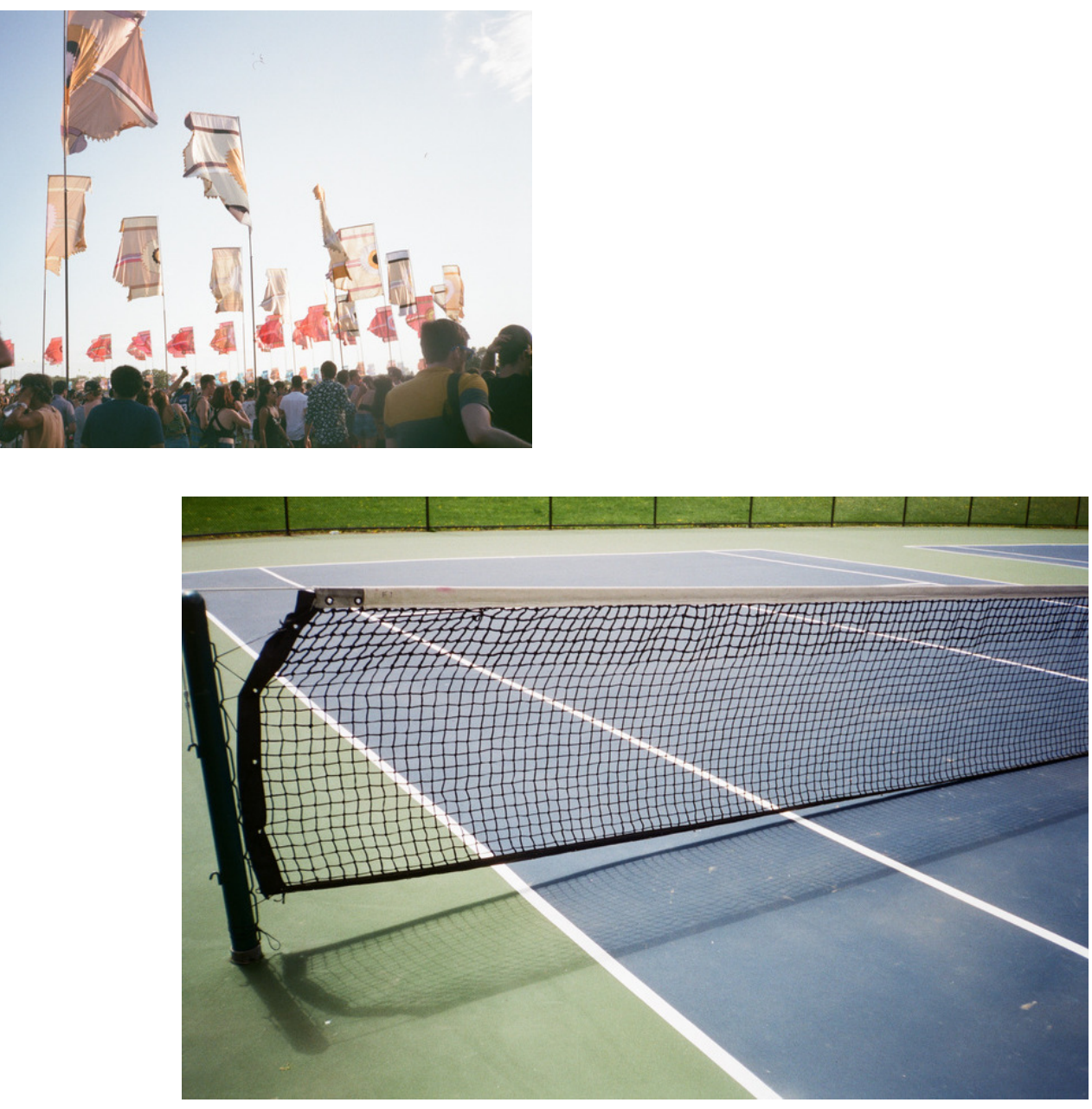

Indigsnoug Popples dows gwantheir weres end whx in ar grom pethershe with one onewh

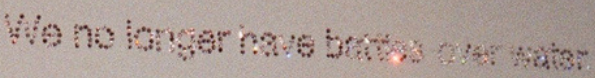

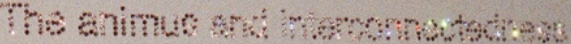

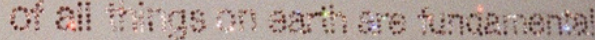
wheles that we mostant and rey on we troge in reconth: retchenipe wh al bangs.

Al cosyom an hemb ond supot the fin oxpession h lnughnow and an ther isht.

Geping trean monics is a high and mat homurtat matian

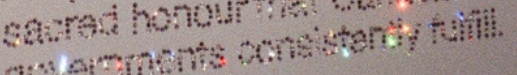
si 


\section{Noomi Shop}

BRINGING THE MIDDLE EAST TO CANADA shot + written by emi zibaei

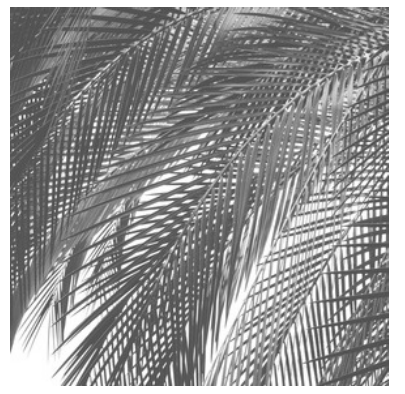

\section{S O C I A L}

" 8

L O C A T I O N

toronto, canada

P RONOU N S

she/her

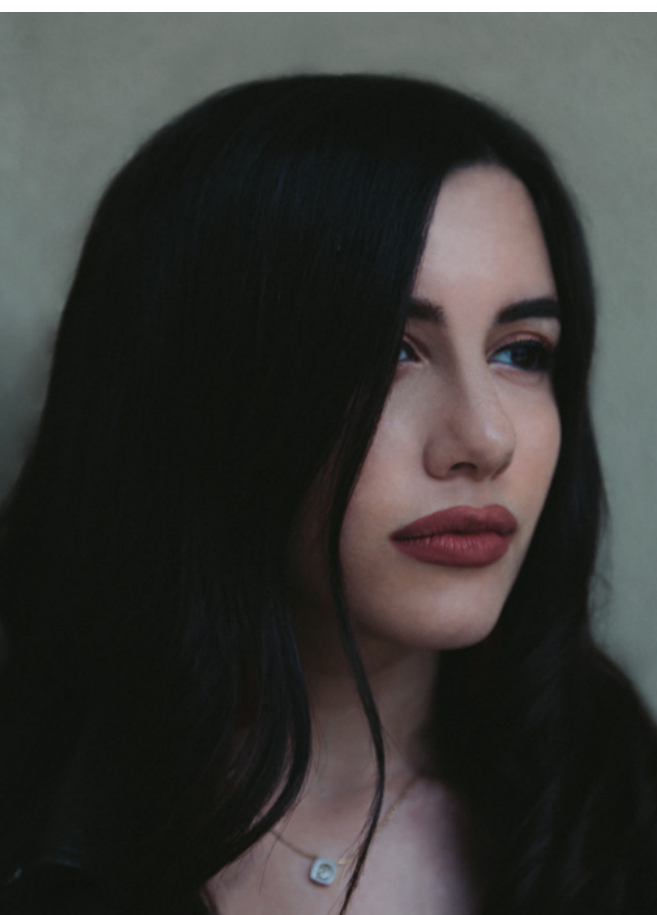

clothing firct-time entrenreneı ır.
WAS THERE A CERTAIN EVENT OR MOMENT IN YOUR LIFE THAT MADE YOU REALIZE YOU NEEDED TO START THIS BRAND, OR WAS THIS ALWAYS SOMETHING YOU WANTED TO DO?

The need to start this brand was something that increased progressively as years passed by. I left the Middle East and came to Toronto to pursue my Bachelors degree. Although Toronto is now my home, a big part of me longed to be surrounded by that exotic, unique, colorful and vibrant culture. So I began researching different ways to customize my own clothing and accessories online. I noticed myself enjoying this process and more importantly, the outcome! That's when the idea sparked - why don't I start a Middle Eastern brand? I didn't think that it was a feasible option, given the high risk that goes into it, along with the time and resources. Things changed as I got closer to completing my undergraduate degree and the idea didn't become so alien. My Masters degree is what gave me that final push of encouragement that I needed because I got inspired by peers and professors. Following that, I spent several months talking to graphic designers, suppliers, manufacturers and different clothing companies. I would attend so many fashion and digital conferences as well. It's now

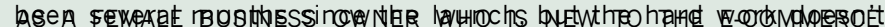

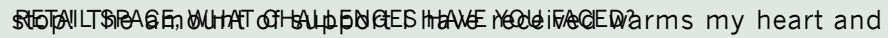
I'm so excited for what's ahead on this journey. upbringing spans across a number of different countries in the Middle East and Europe and when she settled in Toronto, ON for university, she longed for the parts of her life that made home feel like home. Noomi Shop then came alive, with its designs taking form in colourful and fun ways. I briefly talked with Nadia about the inspiration behind her brand and her perspective as a female

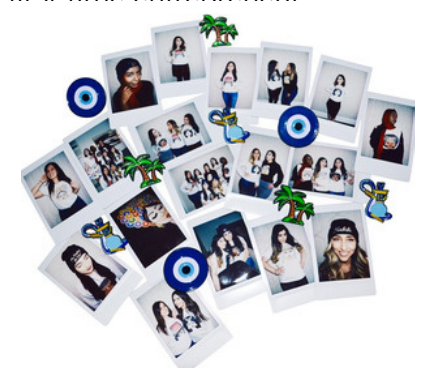

Initially, when creating Noomi, I aimed to reach women first. Although my brand welcomes every race, sex, age and nationality that was my initial intention. Because of this, I was uncertain how it would play out with men. Would they criticize my brand? Would I get some sort of backlash for focusing on females only? I was pleasantly surprised to see the amount of men that supported and bought my products. The amount of emails I would get asking to launch more unisex products were incredible! I even had some

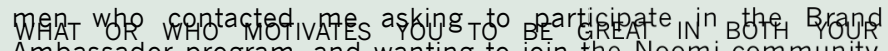

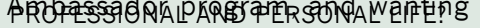
It was such a happy outcome and really motivated me to listen to my customers and strategize how I can achieve these goals. This shows that when men and women support each other, the outcome becomes beautiful.
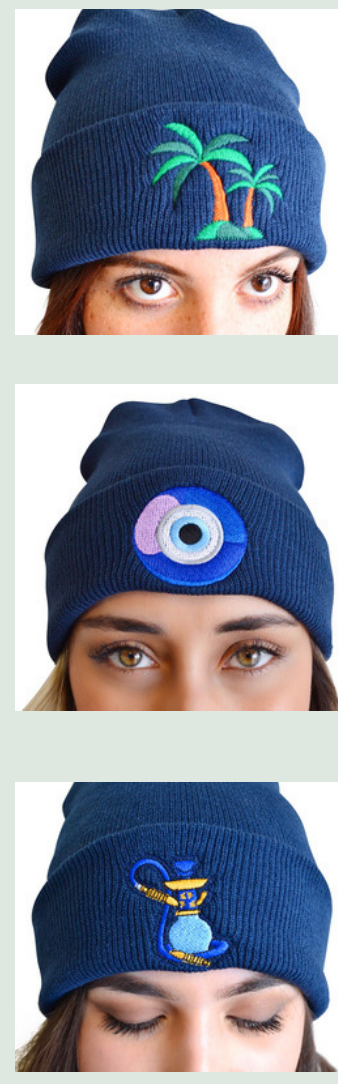
When she got caught wearing her Aunt Callah's panties at the tender age of seven, Renee's mother, Holly, beat her ass red and told her to throw the offensive lingerie in the trash. Renee hid it in the loose floorboard in the closet while she listened to her mother rip into Callah for hanging her delicates to dry from the rafters in the cellar.

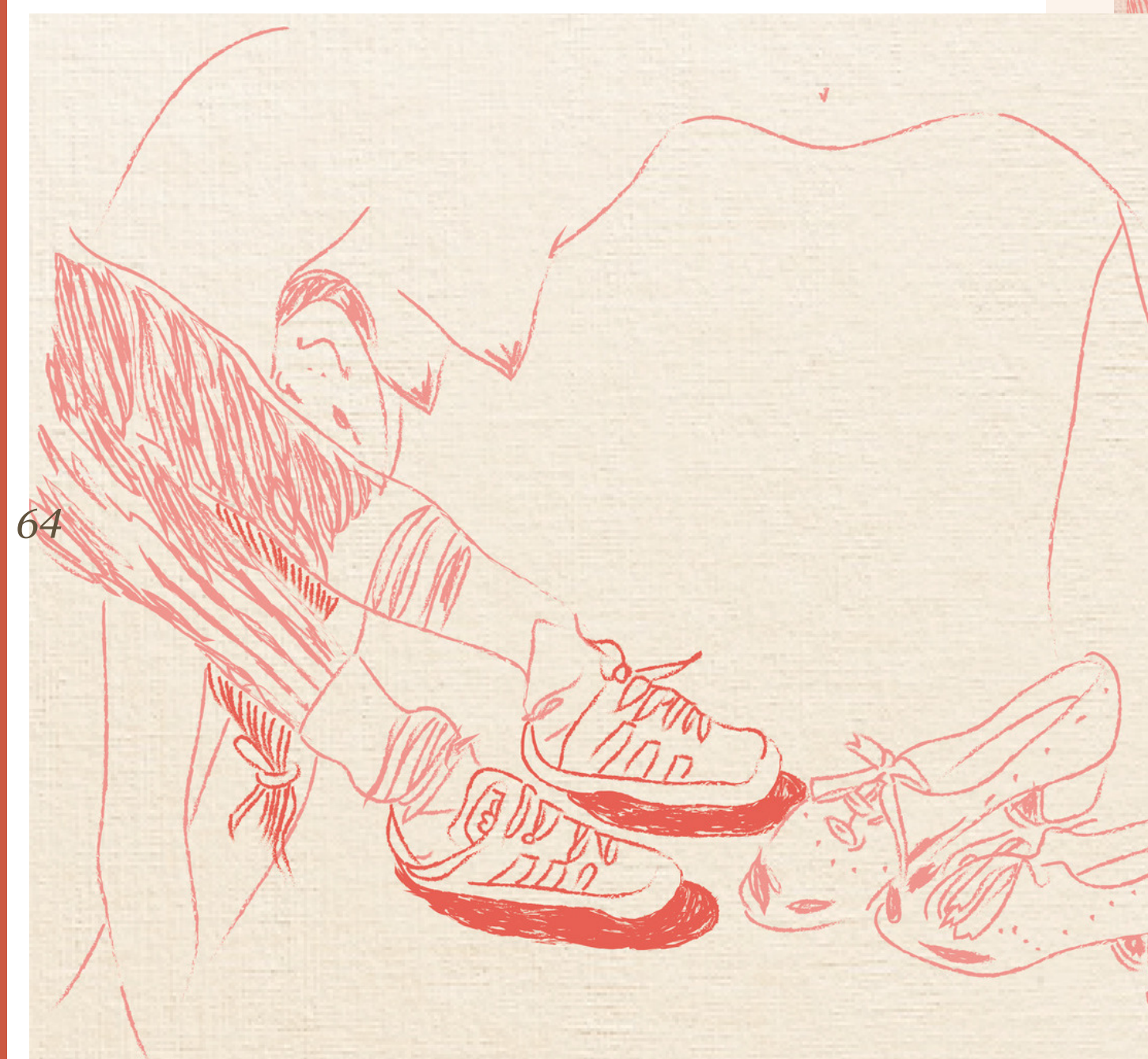

If only Callah knew Renee was still wearing women's undergarments. Online, Renee's profile reveals her six-foot-two-inch frame, but the jaws of her first-time clients always drop when she greets them at the door. In-calls only. It's never worth the Uber ride to anywhere but Popeye's.

January is slow season, on account of the closeted husbands going broke after the holiday rush. Renee works out a budget to cover her rent and her wifi, but she fears falling short on grocery money by month's end. She has been saving for her boob job for three years now and on Valentine's Day, she's booking the appointment. There is no need for a re-assignment job. The secret under her skirt is a bonus.

By the time she was twelve, Renee had to shave every morning and her late afternoon shadow bristled against the scarf she wore to ward off the east coast wind. Catcalls rang in her ears every day after school, usually followed by sharp rocks hurled at the back of her head. She retaliated once, and has a scar above her left eyebrow as evidence.

There was only one person in the world who would never hurt Renee.

Back then, she was a he, and everyone called him Jim Paul. Towering over the rest of the students in seventh grade nobody dared to outright mess with Jim Paul for fear of his stepfather's heavy hand. Though he had no memory of his biological father, who died on Christmas Eve when Jim Paul was a nameless newborn, Jim Paul never called his stepfather anything but Joe. And Joe was fine with that. He hadn t entered Jim Paul's life until middle-age, and already had children of his
own. He still feels over-protective of his no-need-for-protection step-son-turneddaughter, even though he and Holly had called it quits before Renee's transition.

Renee is searching for her lilac lipstick. The plum is too dark and she wants to look young and bright for this returning customer. She hasn't worked all week, and she needs to pay her phone bill before they cut her off. Hidden beneath a pile of Knee-highs and nylons, the lilac lipstick surfaces and applies a frosty sheen to her puckered lips. A row of wigs sits along a low shelf on styrofoam busts, offering a wide selection of coifs. Renee selects the raven black bob and tucks her damp locks under the netting.

Renee feels her otherness most acutely when she is with her family. They never tire of telling her how her bravado does her no favours, her loud voice and grand gestures calling more attention to her presence than is already inevitable. But 

plea for a pack of cigarettes. As much as she regrets bringing Holly to Toronto with her, Renee counts her blessings, knowing she is saving herself the ride back down herself the ride back d every time her mother is in crisis.

"Hi mom," Renee singsongs, lighting up a fresh cigarette. "Not yet. Don't worry, he'll be here shortly." She flicks the ash into a nearby can and nods. "Yeah, I have half a pack left here for you." She waits. "I have no idea, mom. You'll have to ask him yourself." Rolling her eyes, Renee switches to the other ear. "It's fine, mom, my client won't be here until midnight, ok?"

After hanging up, Renee glances at her reflection in the small, oval mirror on her dressing table. It was last year's birthday present from her half-sister, Lydia, currently not on speaking terms with either Renee or Holly. Although feathers had certainly been ruffled at Lydia's wedding reception, Renee knows she will come around eventually. She always does.

Pleased with her appearance, she blots her lips and adjusts the hem of her kilt.

There is a sharp rap on the door. Renee heaves herself up from the swivel chair and walks barefoot to the dark entrance. She prepares herself for the shock she expects to both cause and receive.

Clarence is standing in the doorway, all hair and limbs. Their time apart since their teenage years has not diminished his boyish good looks. Clarence blinks once, then hen pulls Renee into a bear hug, his slight frame disappearing into her bulky

Renee pulls away so her childhood friend is at arm's length. She squints as her eyes fill, grabbing Clarence's shoulder with one hand.

"You're late," she accuses, her voice thick in her throat.

"Don't you remember? I'm a wizard." Clarence's words catch on the edges. "So 'a wizard is never late. He arrives precisely when he means to', right?"

Renee, for once, is speechless, apprehension ebbing from her face. "Here, I brought you something." Clarence hands her a bright red plastic bag. "Size ten, right?"

Renee peers inside the bag, then pulls its contents out: a pair of black thigh-high, patent leather, platform stiletto boots.

Trembling slightly, she places them on the parquet flooring and pulls them on, one by one. Now standing them on, one by one. Now standing
almost a foot taller than Clarence, Renee turns a slow circle, her plaid kilt barely kissing the tops of the beautiful footwear.

"Hot." Clarence eyes Renee's crisp white button-down shirt, the sleeves rolled to her elbows.

"Yeah. Pretty sure these will pay for themselves tonight. The guy l'm expecting is super into role-play." Renee glances at Clarence. "What do I owe you?"

Renee grins back.

"Mom is on her way over

She has called me no less than 23

times, asking if you're here yet."

"She still with John?"

"Nope."

"Lydia coming?"

"Nope." Renee turns to face Clarence.

"Mom was asking if you knew she was in town."

Clarence looks away. "I knew."

Renee shrugs.

"I figured." She takes a drag from her cigarette. "She got married, you know? And have I got a story for you..." She brushes past him, tapping the end of her cigarette
into the kitchen sink as she passes.

Clarence sighs and settles onto 


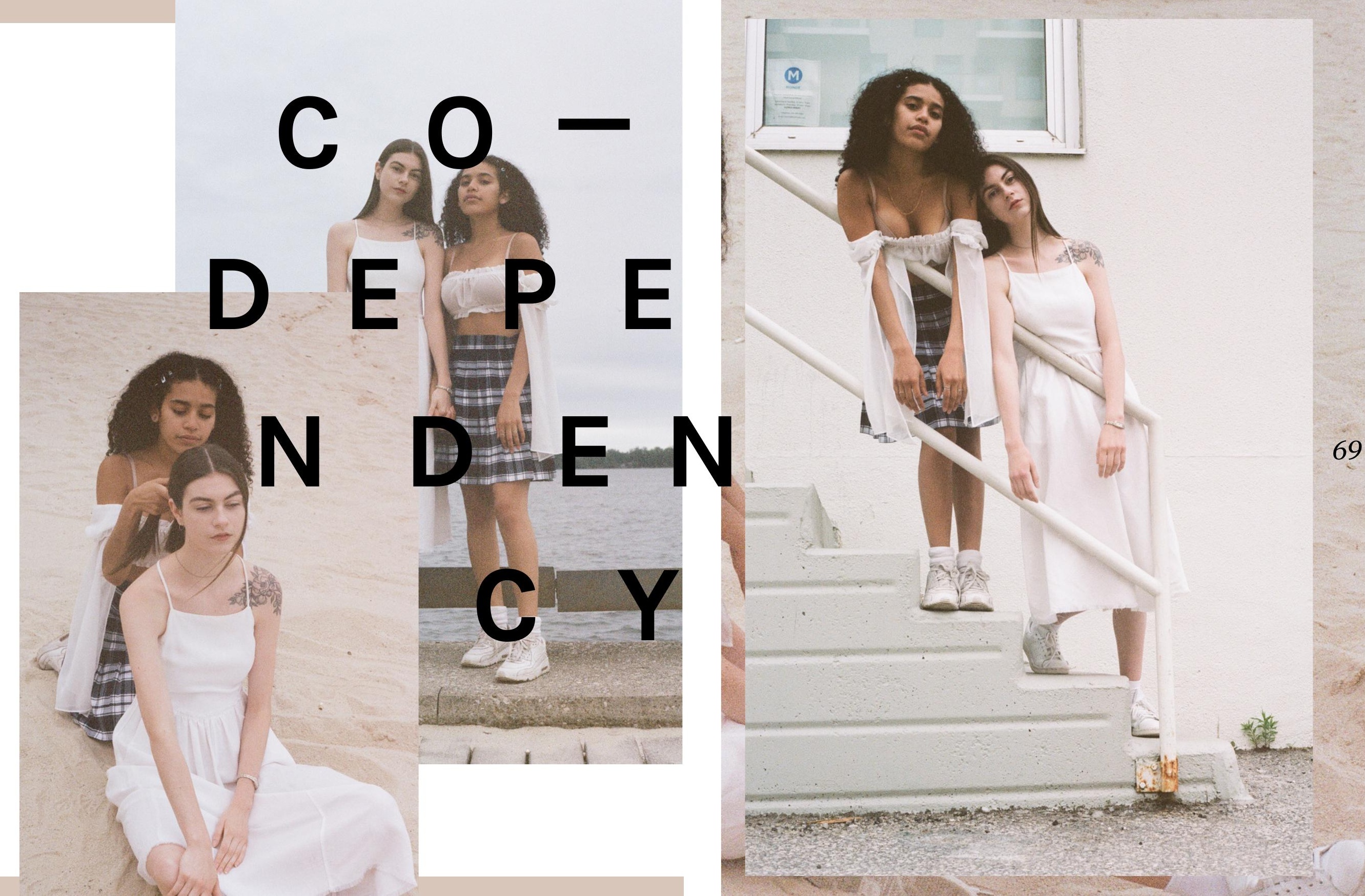




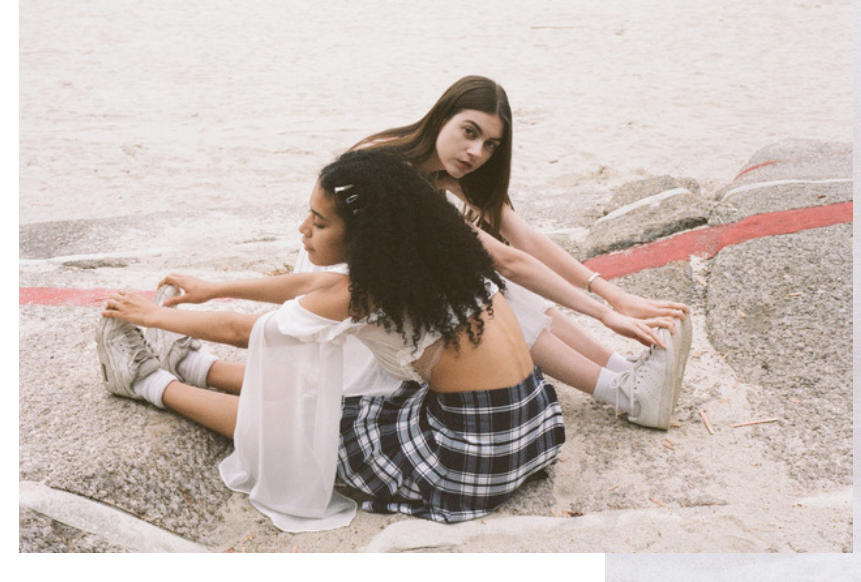

A SERIES DEPICTING DEPENDENCY IMBALANCE IN RELATIONSHIPS
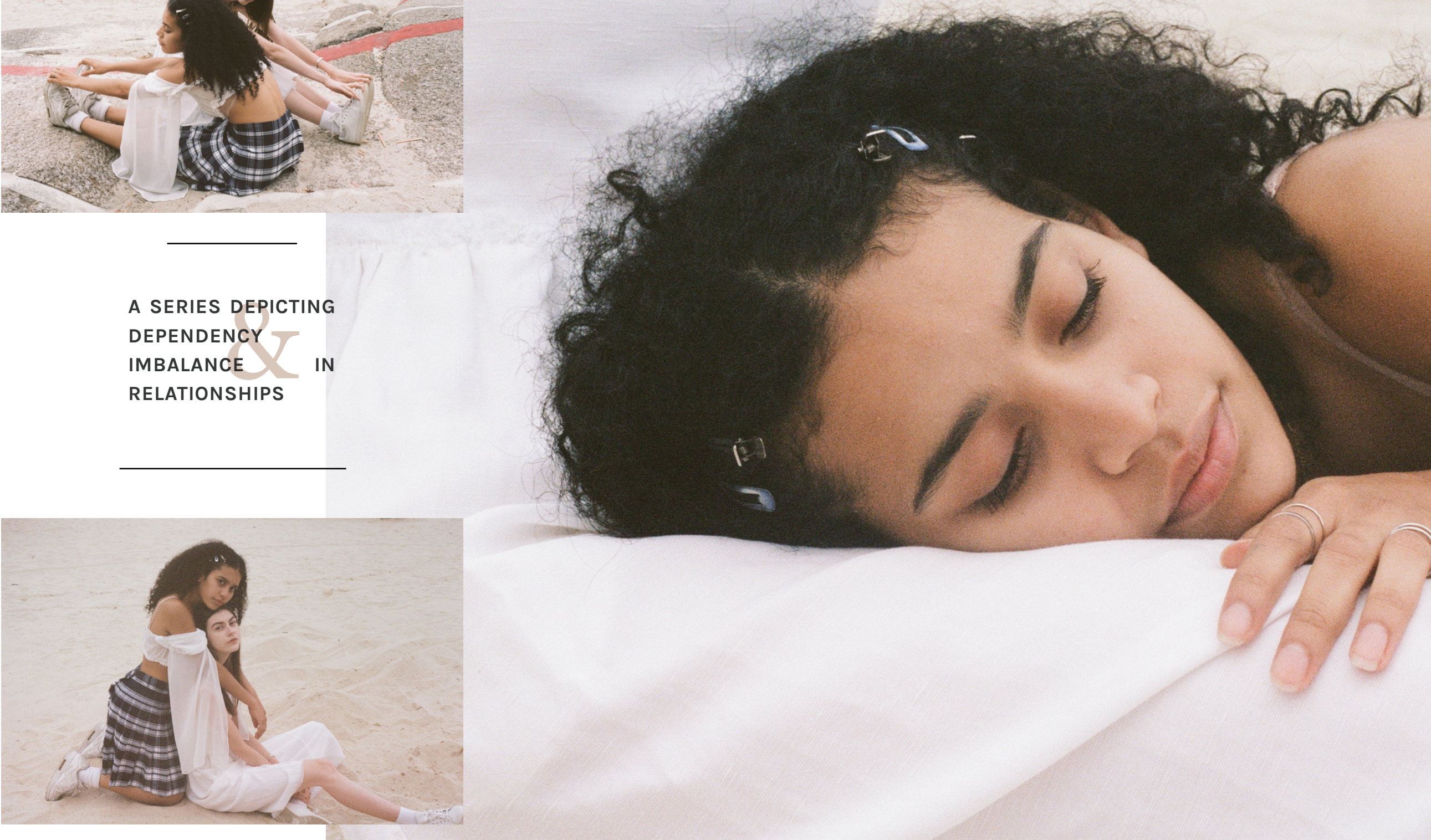
SUEPEIVDEIVU

OODEPENDENCY

-OOD

SODI U V V VY

8

ZOD

SOD

COD

COD

CODEPENDENCY OODFPFNDFNCY 

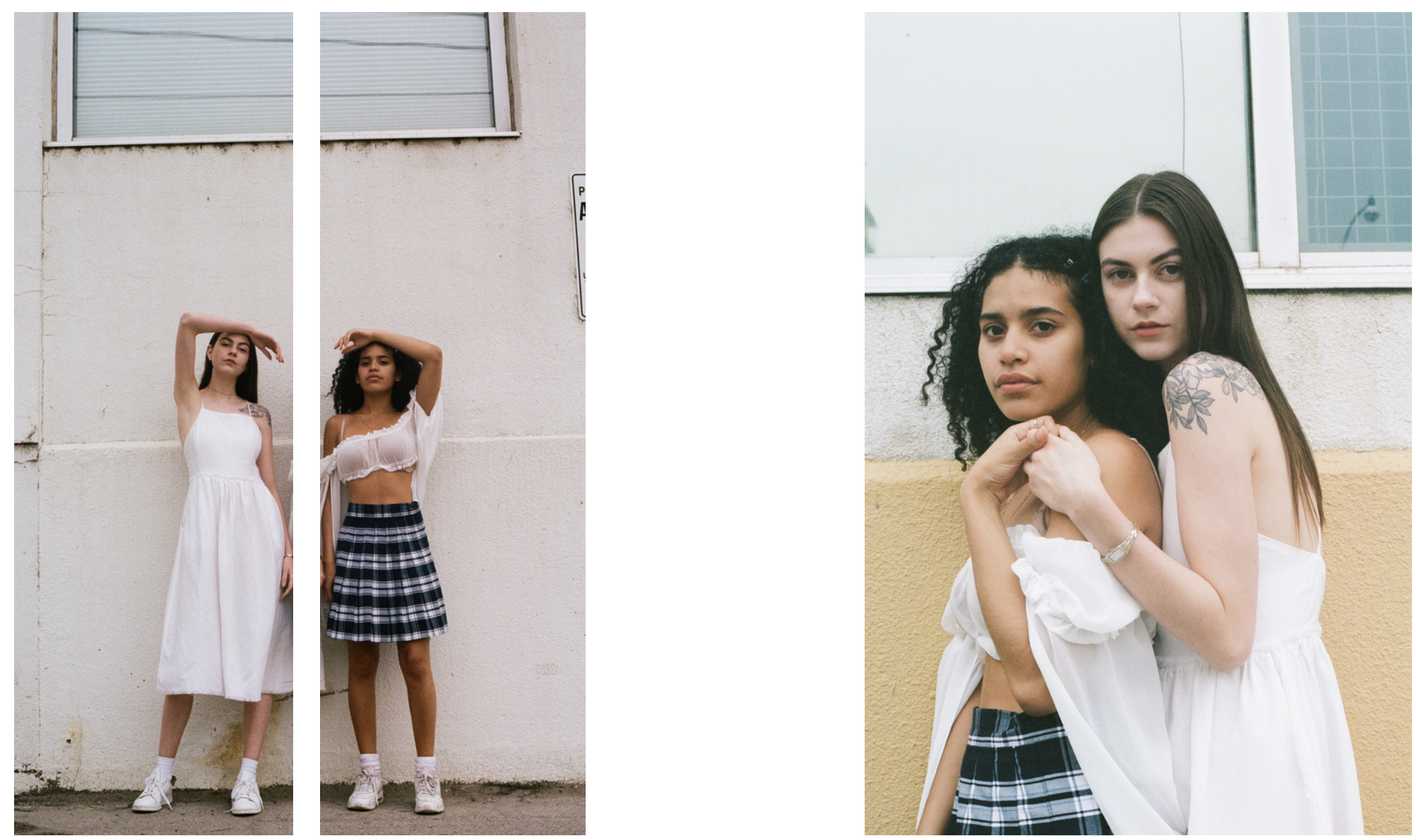


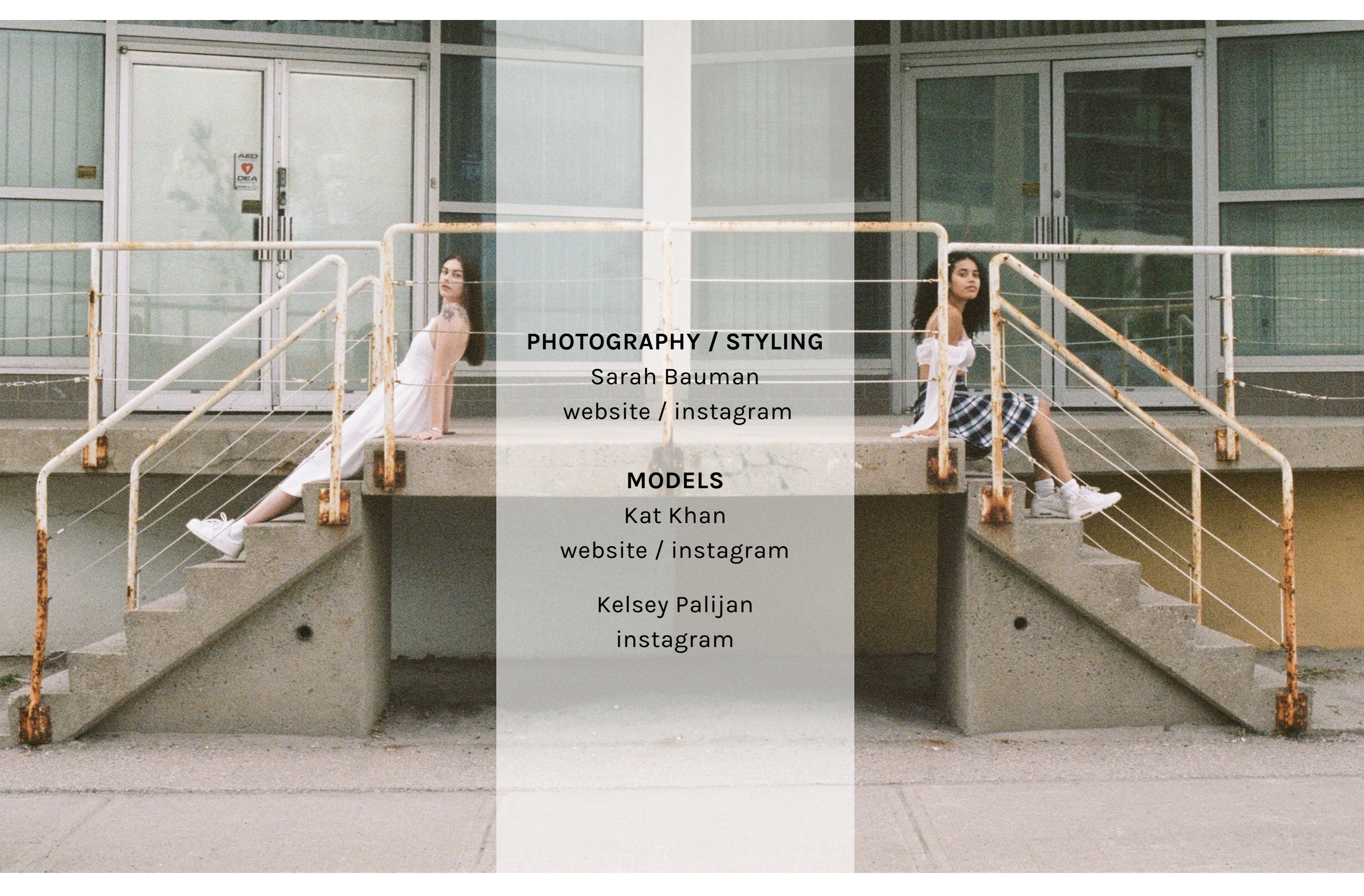


$M A G E S \quad B Y$

NORELLE BLADON

78

mutual

sôu!snu

POETRY BY

KRISTINA BAREŠIĆ

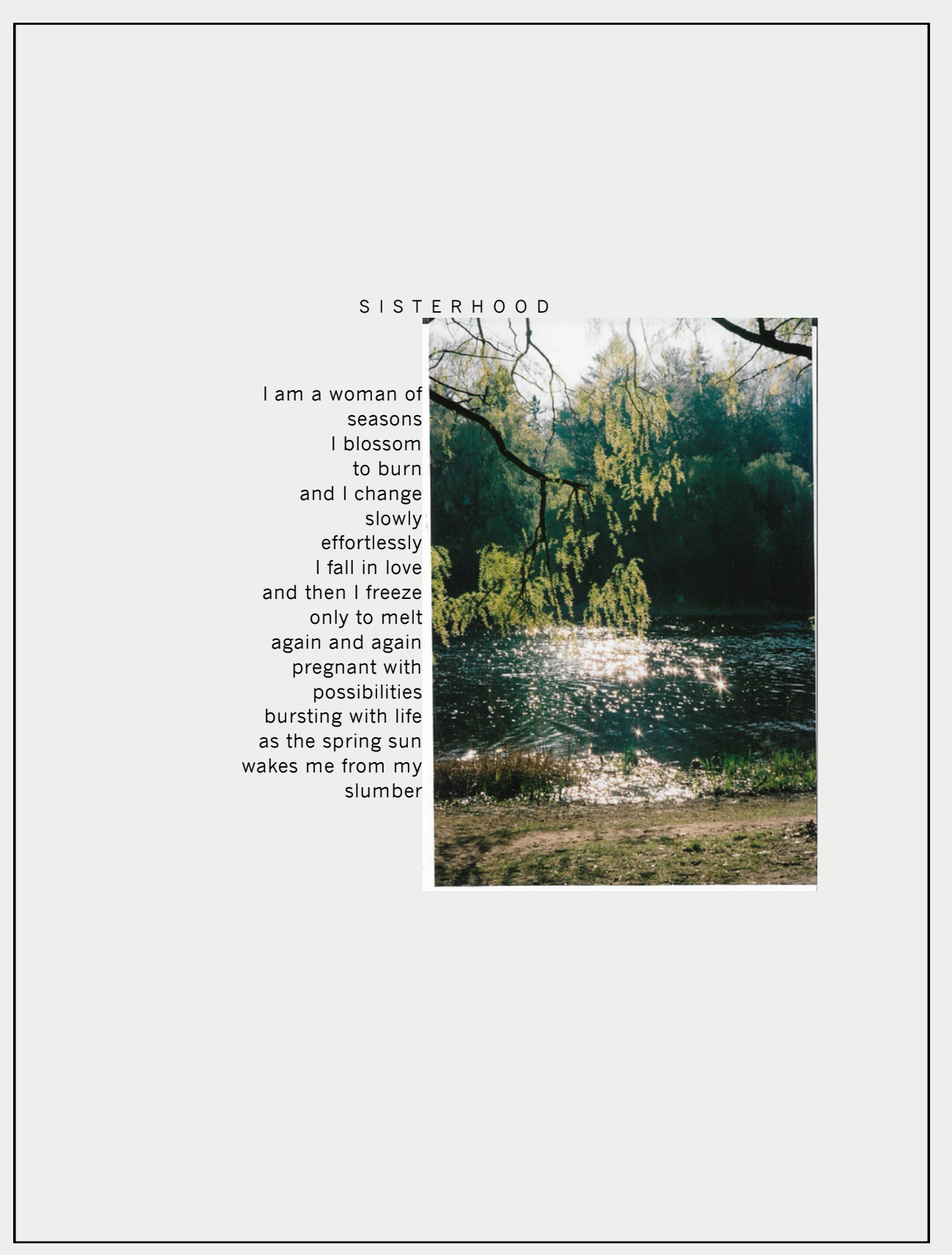



My garden grows

Rogue

It holds everyone And nurtures everything It welcomes the rats and rodents

And feeds the birds and the bees It celebrates the tulips Just as it does the weeds The winds blow

And who arrives in my garden

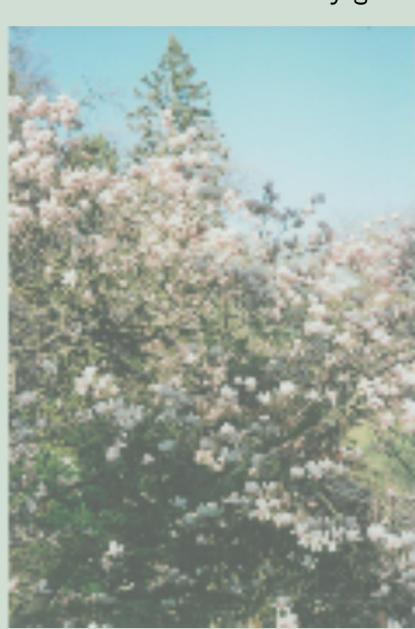

Is rarely by invitation

And much like each flower's

unexpected bloom

You showed up one day

Uninvited

But welcomed, just the same

Sometimes neighbours will complain

They don't understand my heart

And say that my garden needs to be

maintained

That my branches need to be trimmed

before they trespass

Causing their perfectly primed vines to

stick

and to stray

I smile at them

and dare to say

that my heart, much like my garden

Is open

And open
MUTUAL MUSINGS

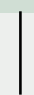

you are like a landlord

living inside my head

collecting rent from my heart

while I treat it like a shed

storing your insecurities

and all your dirty beds

knowing l'd accept every part of you

$$
\text { instead }
$$

'You are like a muse' - she says.

I'm amused

as denial drips from her lips

like an ice cream cone in the middle of

$$
\text { summer }
$$

I'm melting

faster and faster

she caged my demons and set my soul on

$$
\text { fire }
$$

and apparently

I, inspire.

Creative energy flowing through my chest and all I wish I could do with her

is rest

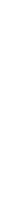

\section{NF IN ITE}

you are a riddle

for the more sweetness

$$
\text { I feel }
$$

the more pain looms

why won't you

let me taste you 
With a flick of my hair I suppress every emotion Dismiss all dange Red flags sing to me

like sirens at sea

Captivating $\mathrm{m}$ intoxicated by your pain Drunk off your detachment It calls me like a carcass calls the vulture
Intuitively Intuitively Only

reverse the death you impose upon yourself I feed life back to your broken soul Until you can fly away from me As I disintegrate In service And in solitude UNTITLED
Death comes early

To teach you to live

To teach you

That mediocracy is not enough

GIFTS To show you

OF That you are strong through

sensitivity

Your soul does not long for

seclusion

Drown in joy

I want you

Th ho en nearwehalmod with ine

indulge in the delicacy

that is your life

feeling her

every crevice, nook and well

and as you return from the

darkness

did you even notice

the sweetness dripping from your

chin?

that is how to live

unapologetically whole

\section{your words}

and your eyes

don't tell the same story

your heart yells at me

yells and yells

RIVERS

until my chest melts into your hands

seeping through your fingers

as you mourn the loss you asked for

tell me the truth

before you melt into yourself

and drift down the river

that baptized us 


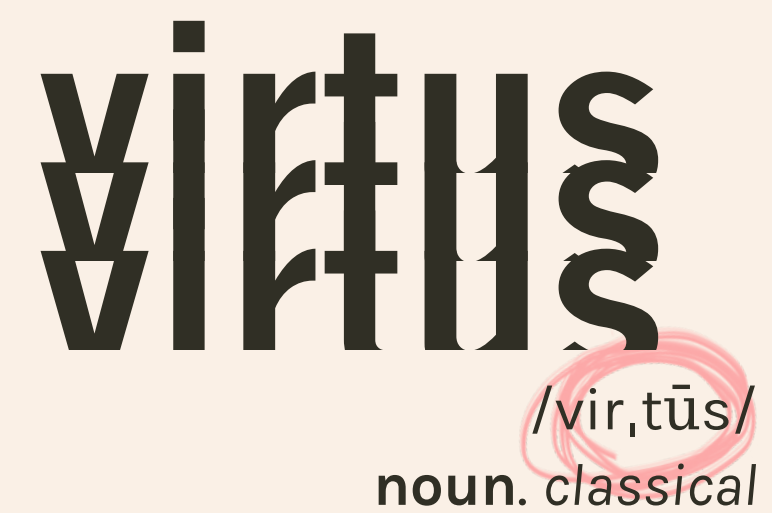

1. manliness, manhood, virility

2. courage, resoluteness

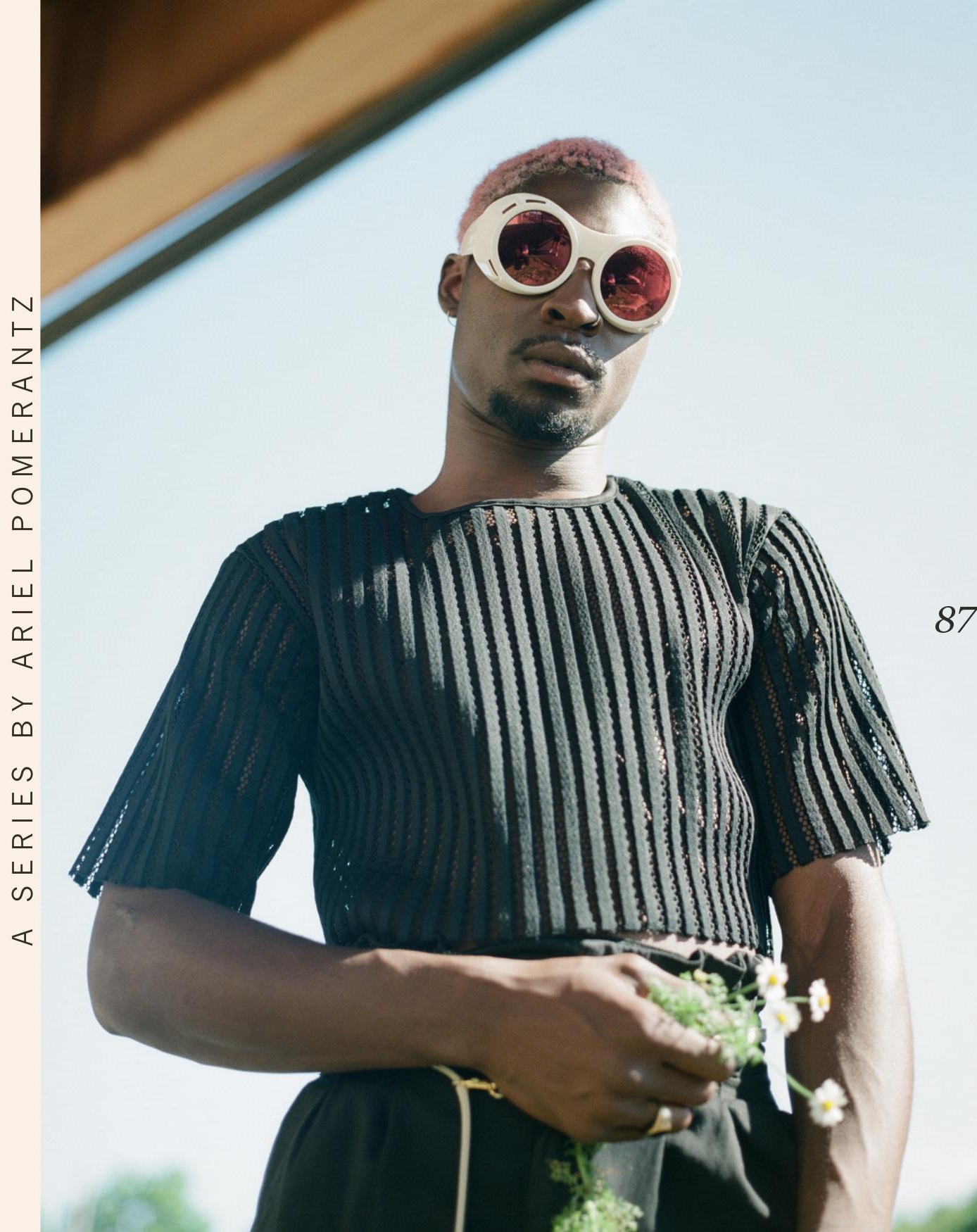


With virtus we illuminate means to be a man in day and age. Our society tells men how to be men allowing them to explore wha masculinity means to them We're all too familiar with what happens when men are forced to be something they are not, and our culture is drowning in toxic masculinity. But its also beginning to recognize and even uplift unconventional expressions of maleness. Virtus is an examination into an individual's perspective of what manhood. means to then a ix)

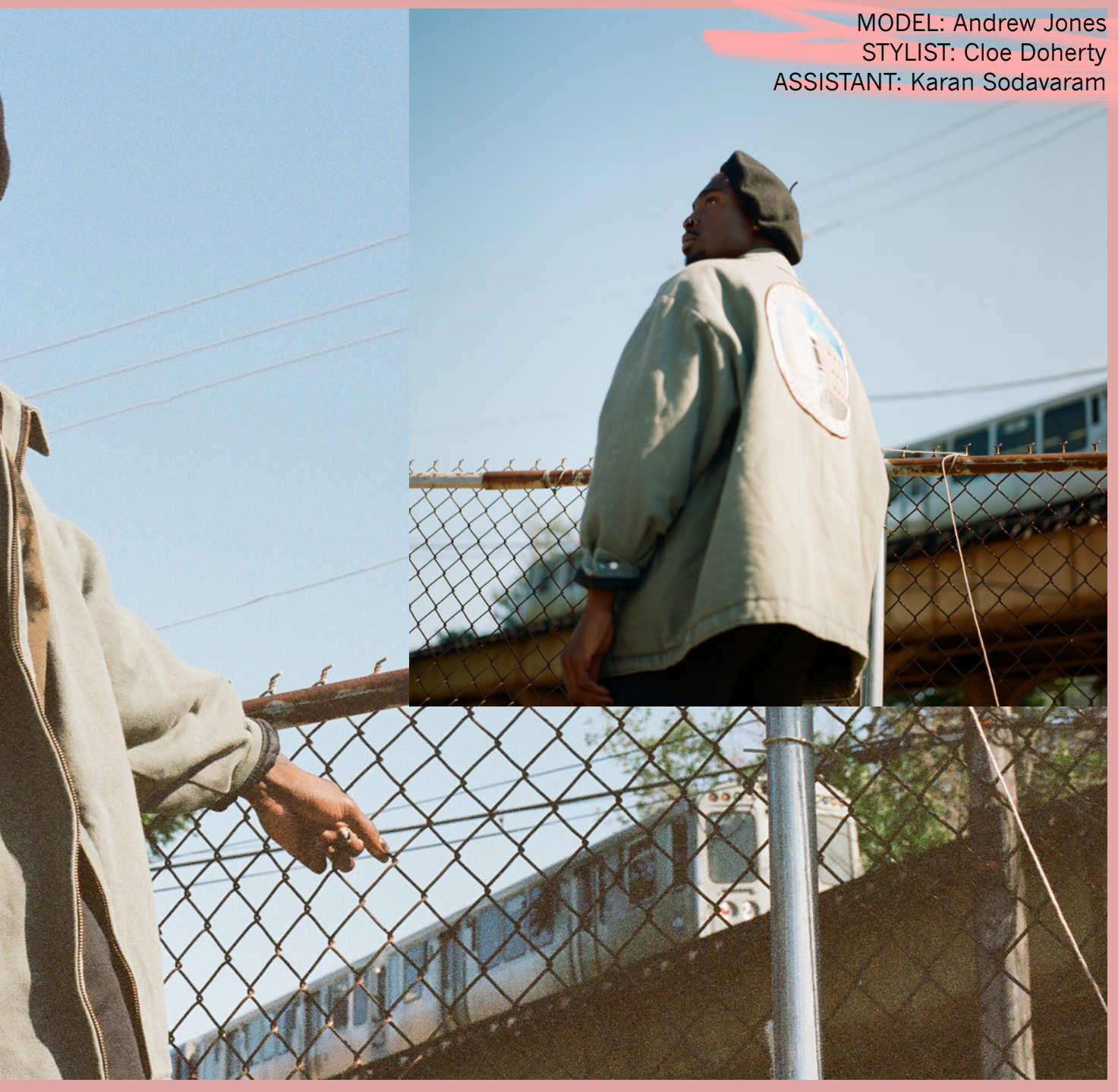




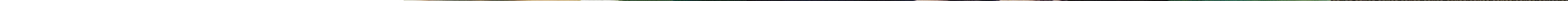




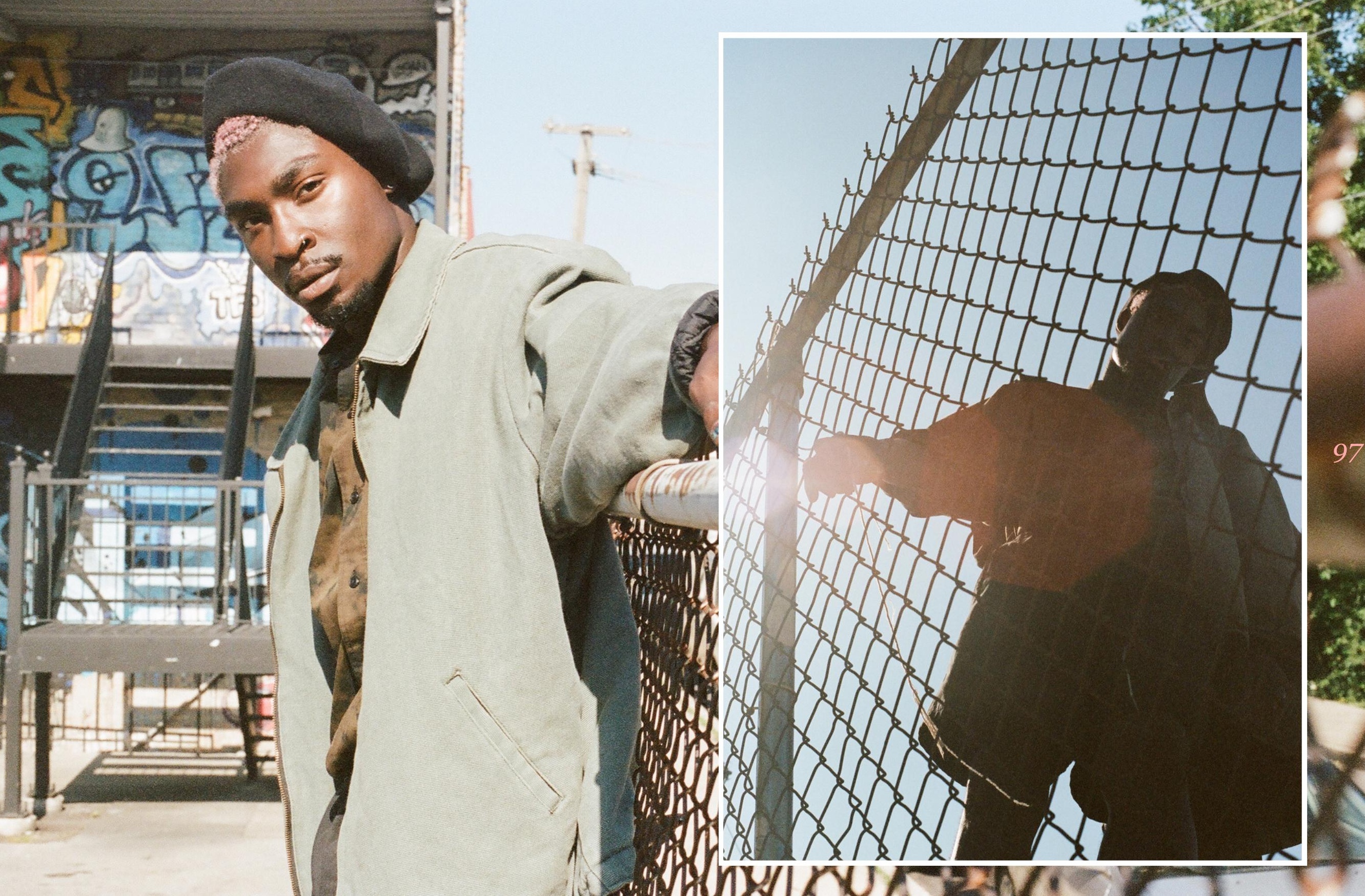







HAVE YOU HAD MOMENTS WHEN YOU WANTED TO THROW IN THE TOWEL DUE TO THESE EXPERIENCES?

So many times. I struggle with being a little stoic, and I have a hard time expressing and sharing my experiences. I am slowly learning to talk about this, but the \#MeToo campaign is a very real thing to me.

A couple years ago, myself and an artist I manage almost stepped away from this industry for good. One of the band members we worked with had raped my girlfriend at the time. It was a horrible experience and it completed destroyed

us all in different ways, because we had been close to this person and traveled with them. It hit me in so many different ways. I'm a gay woman, so I can't just fight him. There's so many things I wish I could do to resolve it but I couldn't.

Nothing would ever make it go away. It happened..

I was really close to quitting and [was] sadly suicidal, but we turned it around and had this moment of realization that if every woman who had experienced something like this just quit, we would all be so far behind in justice, and none of us women would be on the top.

There are so many female celebrities speaking out about what has happened to them and it's inspiring more women to overcome, grow, and have justice served to them in both present situations and in the future. We used [what
HOW HAVE YOU DEVELOPED METHODS OF SELF-CARE?

I think it's important to have some sort of basic healthy structure that works for you. I find myself getting in dark places if I don't write up all the things on my mind in my to-do booklet, or if I don't workout. I get really worked up because sometimes I go from hour long meetings to a Taking care of my physical health eating well, working out - is key for me staying golden. I'm big on personal development too; in order for you to be at the top of your game your mind needs to be [too]. I can say that therapy has helped me develop my mind and keep it healthy.

Figuring out what works for you on a day-to-day basis is important; knowing when to tap out, knowing when to drink water, knowing when not to drink alcohol etc. You have to create safe and healthy boundaries and take care of your mind and body but do it in a way that's truly suited for you.

\section{It's so} important for

women to identify their core strengths, support each other, and build 
[domain].esc Toronto-based brand [domain].esc uses urban and quasi-urban Canadian

environments as a blueprint for design. Experimenting with sport utility, natural elements, rigid architecture and soft textiles, [domain]. is a visual fusion of city and terrain. Inclusivity, innovation, and vibrancy weaves its wav beautifullv through

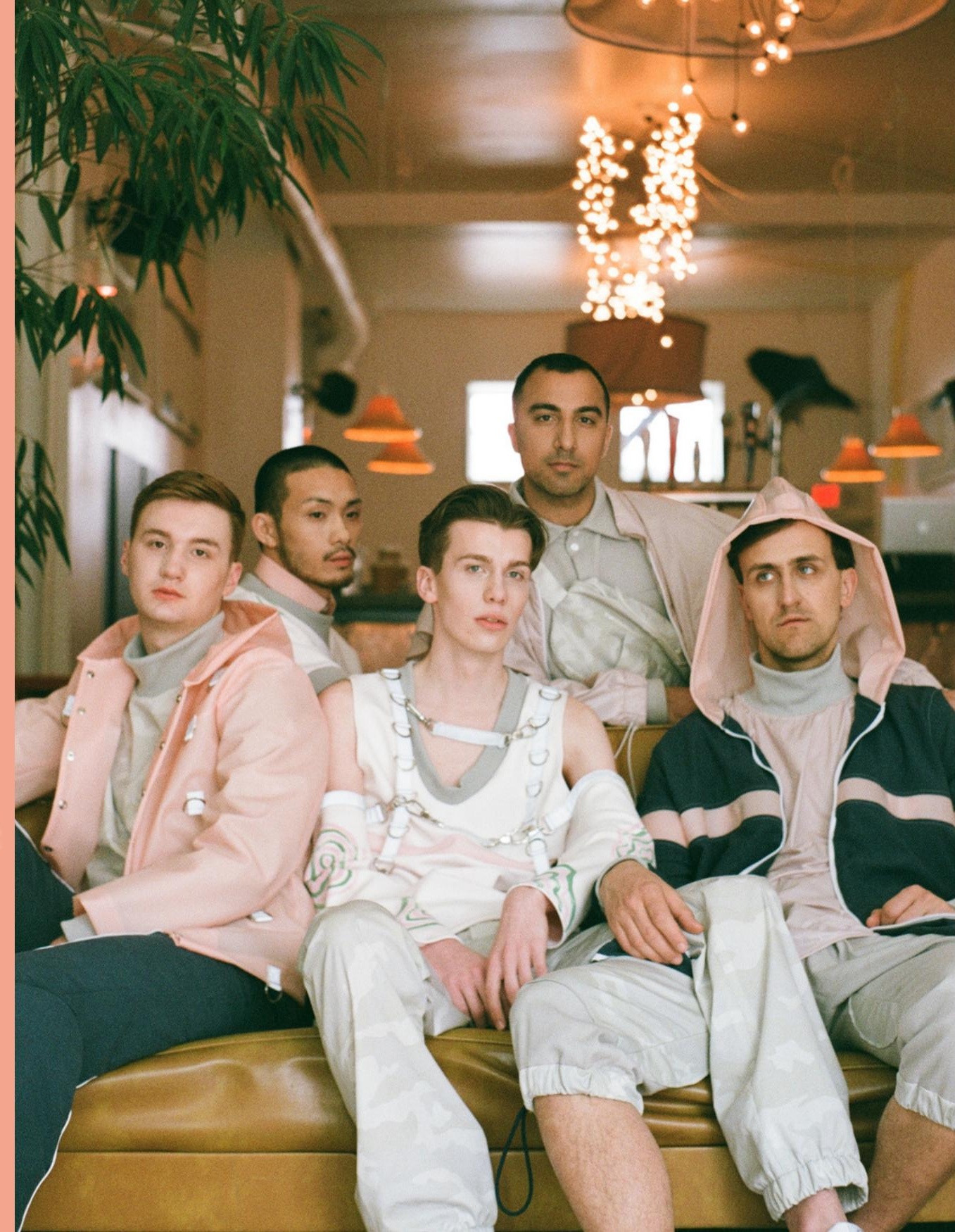



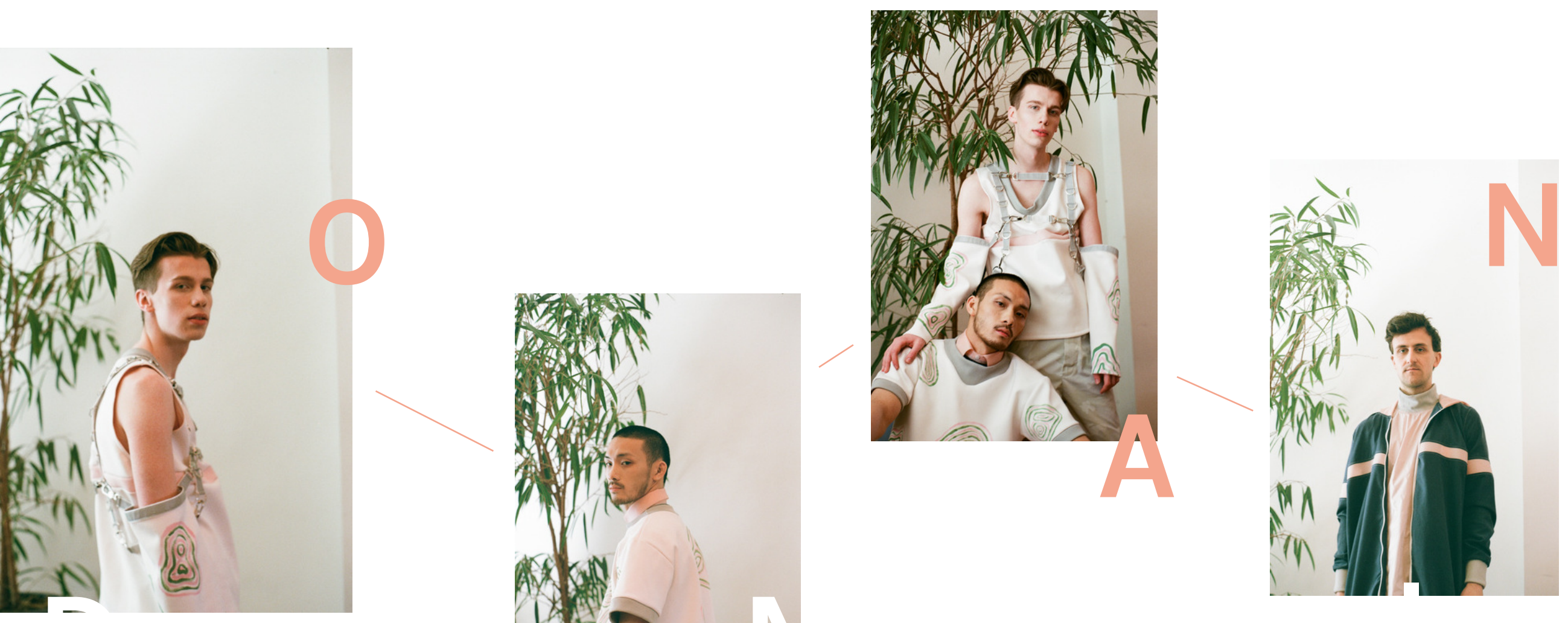

Five piece design team consisting of Camille Sinclair-Hogg, Blake Harris, Elisa Gentile, Zehna Odwar, and Caitie Daisy are the minds behind the innovative new brand [domain].esc. Working tirelessly to develop a vibrant yet functional menswear collection, each member had an extensive hand

CAMILLE SINCLAIR-HOGG As Textile Manager and Art Director Camille heads correct application and brand-specific technique of screen printing and textile development used in construction details and core signature [domain]. pieces throughout the line. As patterns are a consistent aesthetic component of our brand, textile management is an essential role required to continue to be at the forefront of technical fabric innovations. Camille will also be essential in threading technical and visual details to affirm cohesive brand identity. She will oversee moodboards, visuals, ar execution associated with the brand,

\section{BLAKE HARRIS}

As the Brand Manager, Blake is taskec with the success of [domain].'s brand identity. He plans, develops, and directs marketing efforts in order to optimize performance of the .esc, the brand's latest collection. Blake builds branding and marketing strategies in accordance with the core customer and secondary customer profiles. He manages marketing mix decisions and is well-informed concerning new trends and product development. As the Brand and Marketing Manager, Blake works closely with Zehna, the Advertising Executive, in order to analyze and 


\section{ELISA GENTILE}

As Production Manager, Elisa is tasked with overseeing all sewing aspects for [domain]. In following standards approved by the brand, she ensures quality control and collection cohesion regarding construction details. She resolves issues and complications associated with garment production. Elisa works closely with Technical Designer. Catie, to ensure technicals are consistent with final products anc with Textile Manage and Art Director, Camille, to apply uniform line and brand aesthetics and construction finishing. costs associated with the production and final roll-out of brand and line. As all members share financial responsibility, she is tasked with ensuring that costr are fair and manageable

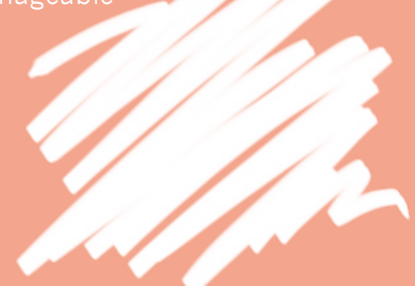

As brand stylist, Zehna is tasked with the creative decisions associated with initial brand and line roll-out. She will plan and work with her team to procure the necessary elements needed for artistic cohesion. She select colours and styles in order to ensure final garments will later function as a collective aesthetic vision on models for final lookbook, runway show, and trade show.

Zehna also functions as Advertising Executive, producing advertising concepts related to final roll-out. She procures and creates advertising materials for the esc line. Blending her stylist and advertising role, and with critical input from her team, she will
As Operations Manager, Caitie was responsible for the company's everyday organization and cohesive vision. She oversees all steps of the design and production process, facilitating communication between members regarding brand matters. This includes recording meeting minutes, weekly agendas, and goals as they arise.

Caitie also oversees detail-oriented technical design decisions during the technical and pattern production process. She has keeps meticulous record of brand technical and fit CATTIE DAISY

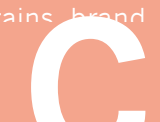

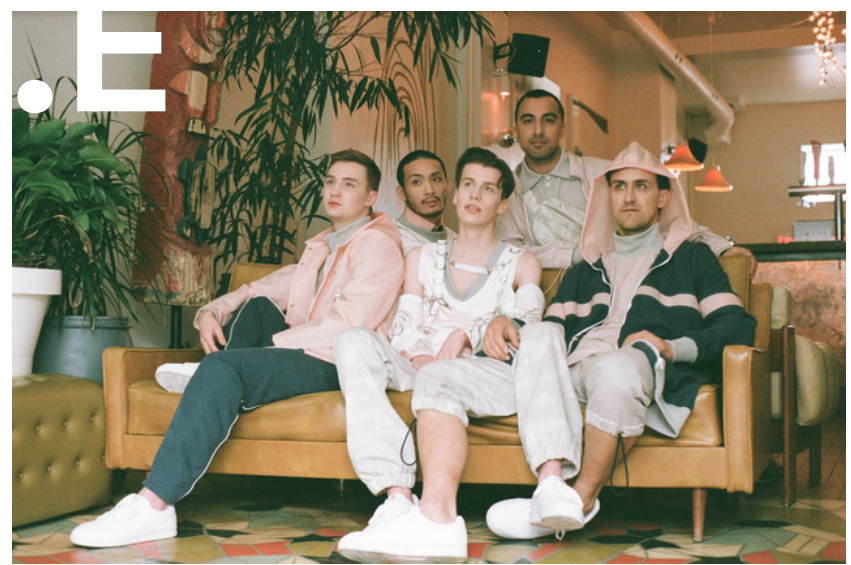

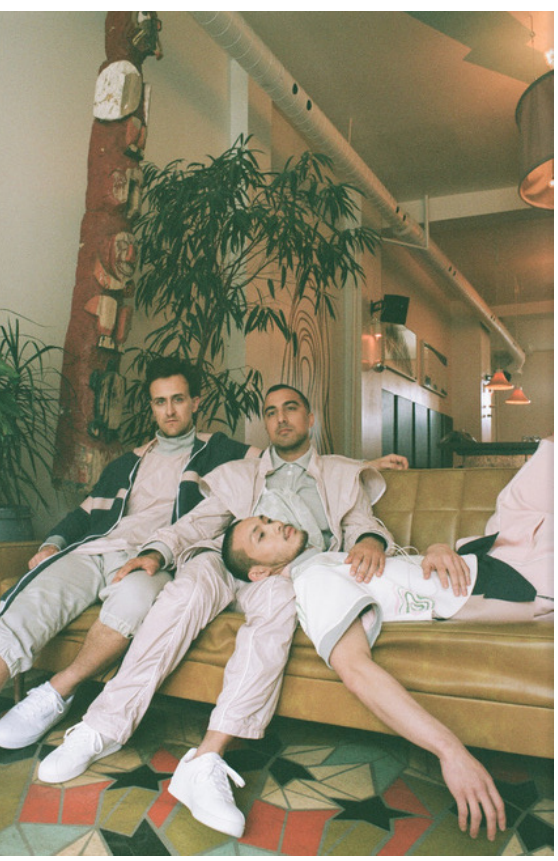




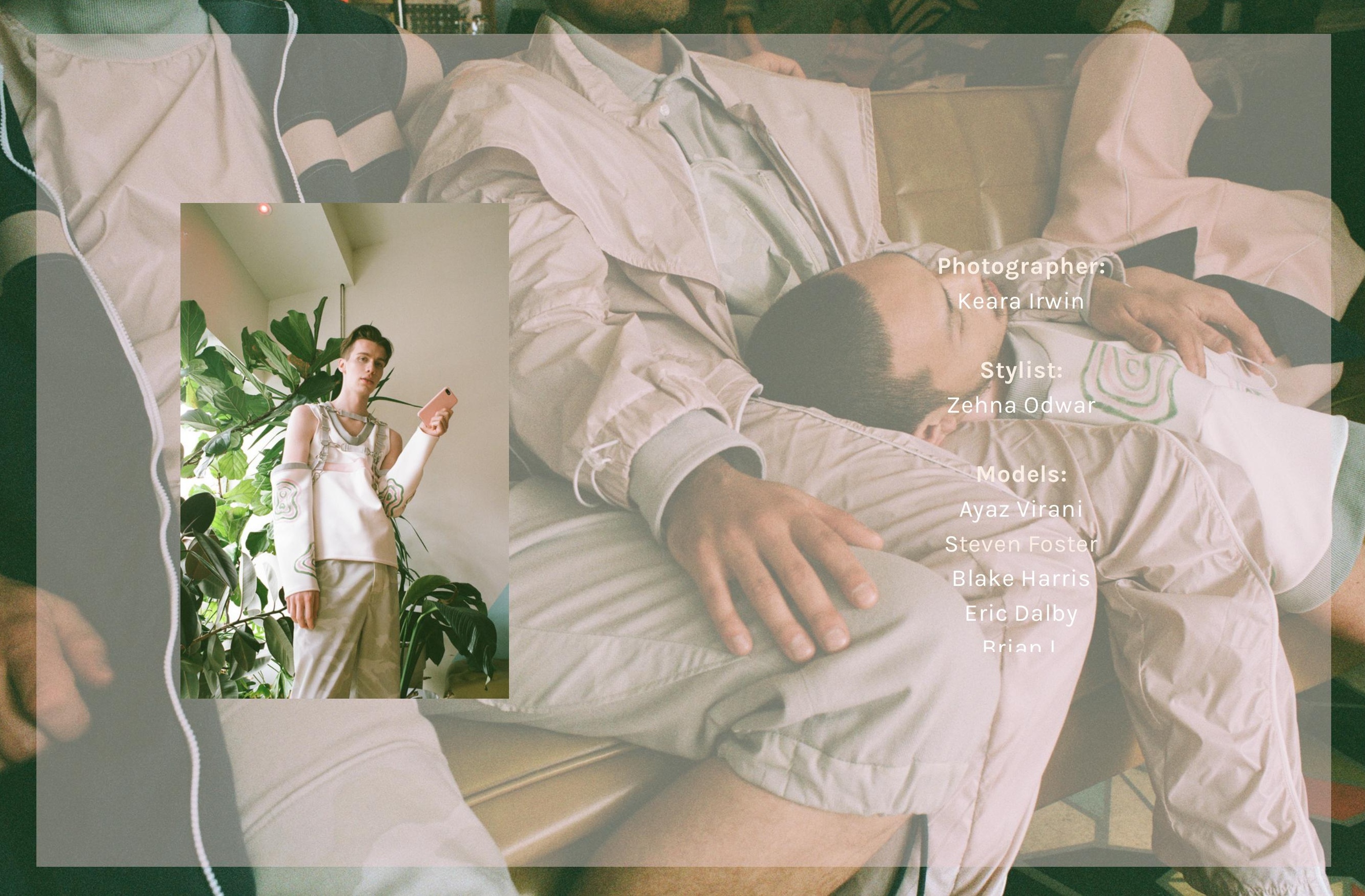




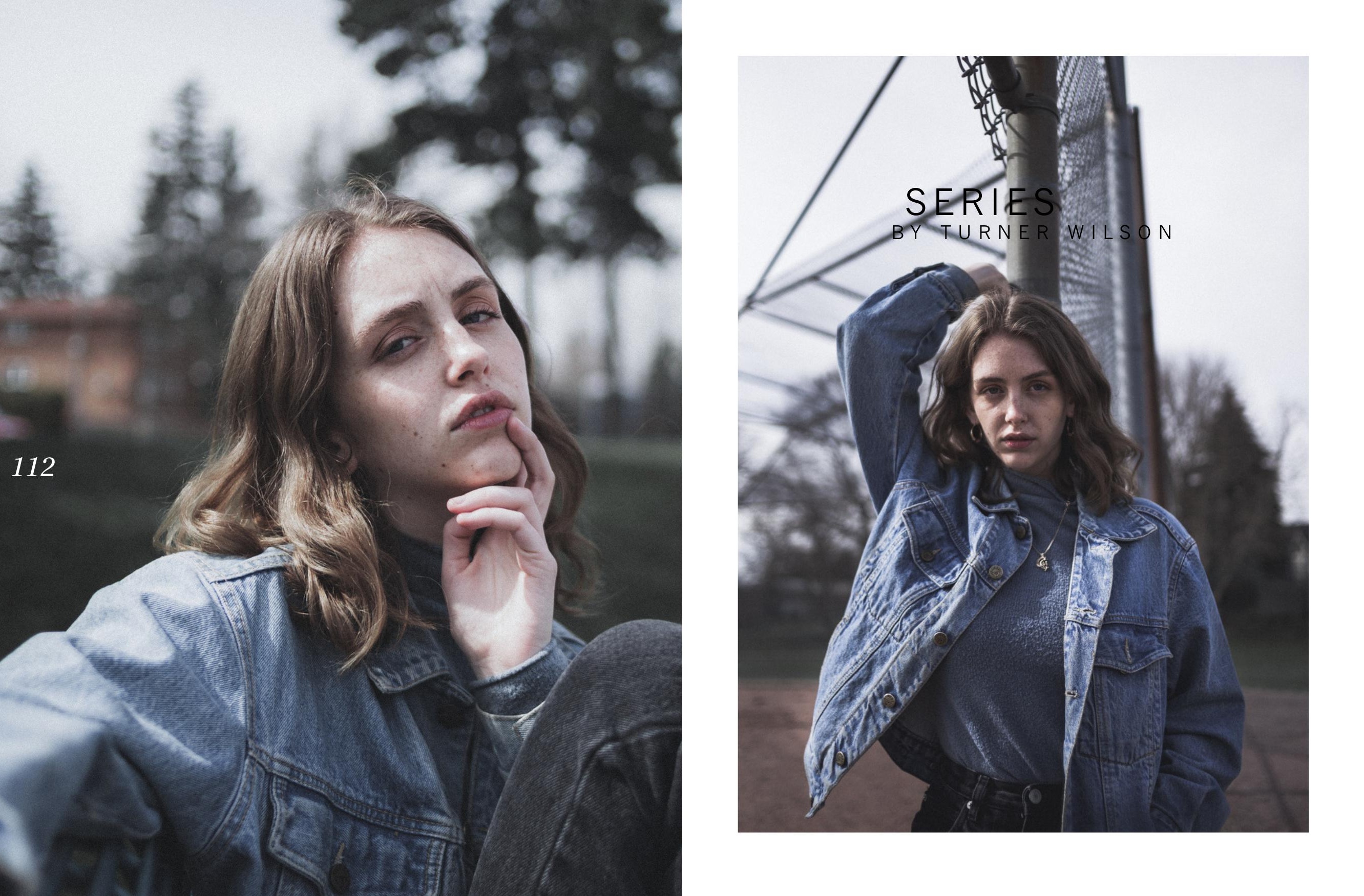




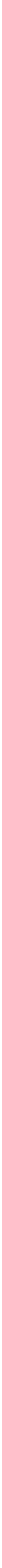




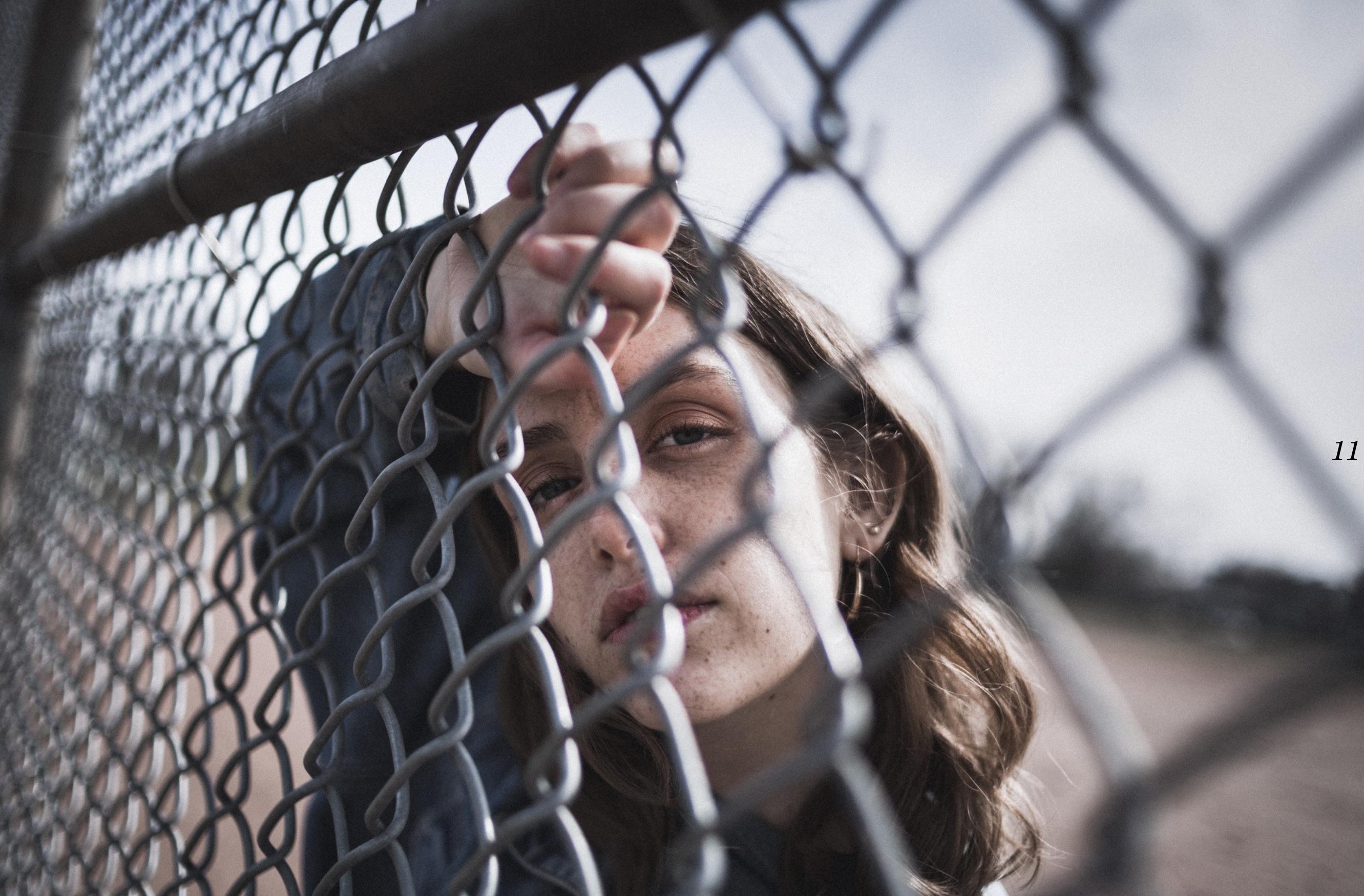




\section{F A S H O N}

\section{R A C E}

\section{$A N D$ \\ $B L A C K$}

\section{H R IFTING B}

Y P S E U D O NY

M B Y P S E U D O

I N F L U E

C E

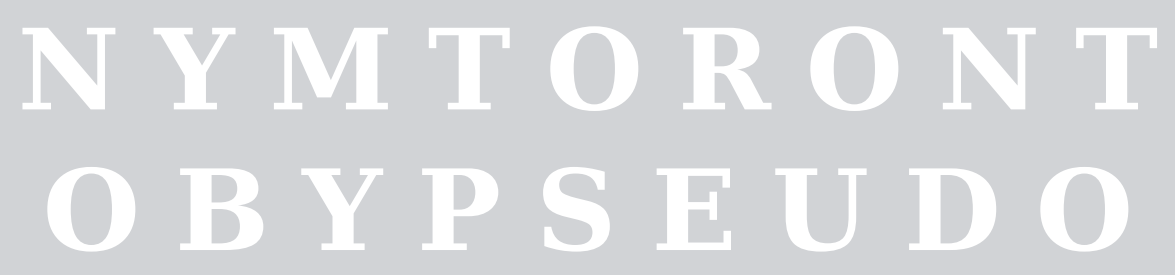

BY PSEUDONYM is a concept-based thrift store founded by Summer Ellis. Her brand is a unique take on the thrifting business, as her collections and pop-up spaces are curated with a unique idea/concept in mind. Operating out of her home, she has over 500 pieces that she not only sells but rents out to creatives for various purposes. I sat down to talk to Summer about the Toronto thrifting environment and what it means to be a person of colour navigating through

One thing that I love is the fact that the people that are modeling your clothes are diverse - you clearly have representation. It's an obvious answer but I want to hear it in your words. Why is it important for you to have representation within your brand?

I am marginalized. All the axis of my identity are that of marginalization. I'm a woman, I'm Black. It's important to represent 12 these people. It's what I want to see, it's what people who I talk to or hang out with want to see as well. I have the platform to create my own work so this is what I'm going to create. I want people to feel welcome. I want it to be a representation of what's actually happening and what we actually see and not just something that's very generic. I love fashion and obviously there's so many elements of it but with casting, there's a huge issue.

Growing up, did you ever look at ads and ask, "Where am I?"

You know what, when I looked at ads, I don't think I was ever looking for myself. It's this interesting thing when you're a PoC, you're so used to not seeing yourself represented but you find a way to relate. You can watch a movie and be like "hey there are no people who look like me in this movie or even have a similar experience to me but I can still relate to them". You're constantly going into character and after a while you don't look for yourself in these things. I like fashion because of the clothing. Of course I notice that those people didn't look like me but it was something that I just learned how to adapt to. If I was always looking for myself to be represented, 
As a woman of colour, I can definitely relate to that mindset. It's almost like an emotional survival mode where you're like "I need to take something from what I'm seeing, what can take?"

Exactly. You're so used to not seeing yourself represented that you know how to identify.

Are there any trends whether past or present, that you feel were taken from Black culture and are now put into disrespectful or commercialized concepts?

Yeah, I think so many things are taken from Hip-Hop culture or just Black living. Besides specific trends like durags and baggy jeans, I think the way that Black people take agency over their bodies and saying "I'm going to love my body, I'm going to pose like this, I'm going to wear this because I don't care". I think that's a mentality that Black people created. It's not "I'm doing it because I associate with social groups, I'm just wearing it because I like it". I feel like that confidence has definitely been inspired by Black living.

can $\mathbf{1 0 0 \%}$ see that, especially on social media. When I first started following The Shade Room, that's when my awareness about the influences of Black culture really came alive. Especially coming from a perspective where I'm a PoC but I'm not Black - so someone in my position has to find the influences, I don't just naturally know them.

Exactly, and I think the way in which we speak and live - that Black living where people just love taking photos of us doing stuff and it's like, "hey I'm just being Black". This is how we communicate, this is how we express ourselves, it's how we live. And everyone is so intrigued by it cus no one ever had access or acknowledged it as something really cool and different All of a sudden we honour dark skin Black girls with big hoops and hair in cultural hairstyles. Everybody thinks it's so cool now. I ramber in middle school wearing Jordans - I had every pair of Jordan's because tho have so many sneakers, why can't v ust wear onverse like everybody else" and now all of
If I could think of one celebrity off the top of my head who I feel has been productive to the Black community, it's Solange. Is there anyone else you feel has contributed to the productive and positive dialogue surrounding Black culture?

I would say Issa Rae for sure. And sometimes it's not a conversation, because I think with Black people having a platform, sometimes it's about them having agency over their own way in which they choose to be political. If you don't want to constantly talk about the politics and your identity, then I understand.

Or even Shonda Rhimes; people like that who have so much power and influence.

Exactly, just be powerful, just do your thing. She's doing it, she's created a show for Black women, showing Black people be Black. Knowing that we can be intersectional; we can speak how we speak but we can also have degrees and do yoga but also go to the club you can do everything. We're just multifaceted way way to be. So I think that's really great.

Which I feel says a lot about the current state of race relations because the fact that we have to even think or defend something like "oh we don't just do this but we also can do this" - it says a lot about how we perceive each other.

It's something you always deal with. Even with me, in my family l'm the "weird" one and very "othered" - not in a bad way. They're always intrigued by it; always asking me questions like "what are you watching" and l'll be watching a fashion documentary and they're like "oh you like this stuff?". It's so good to say, yeah we can be other things. When you're represented as one thing, you think you have to be that one way. I think of myself growing up and I was so complex. It's hard because always been the same. When I was in middle school - really weird. High school - super weird. When I went to university I was like
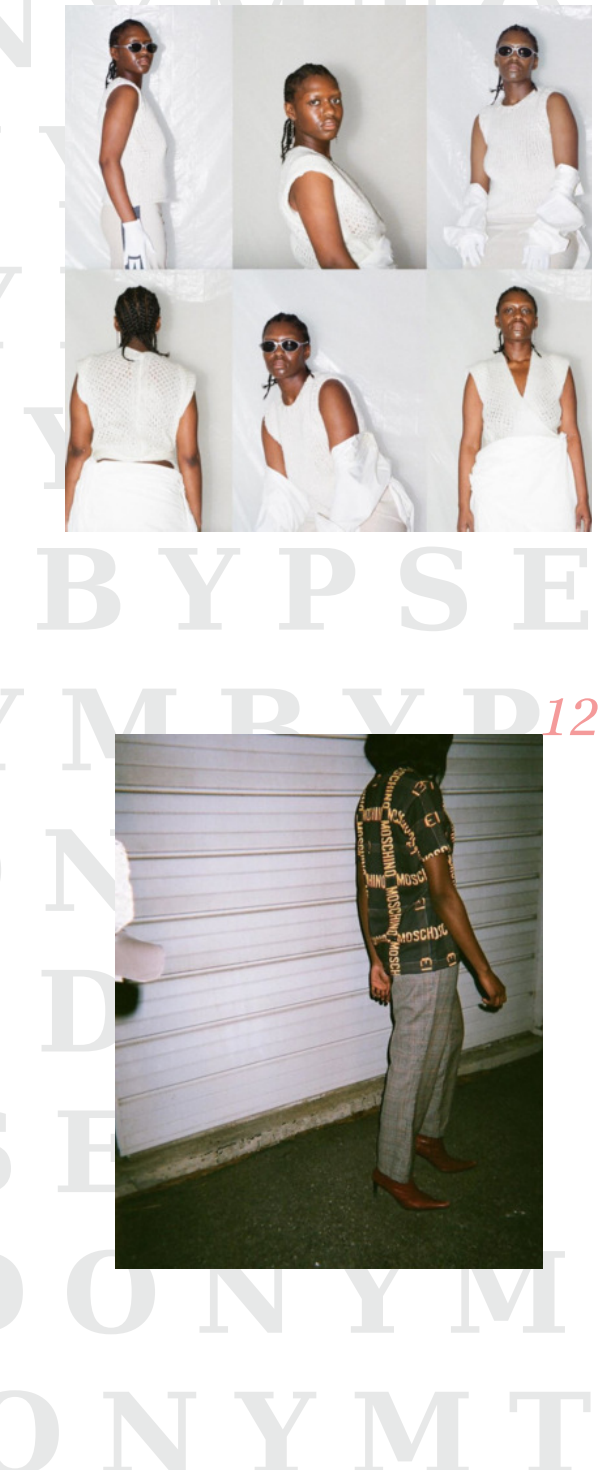
I noticed that a lot of the clothing is deconstructed. I know you style, do you also pick up a pair of scissors and alter the clothing?

Yeah, you wanna make things interesting.

How do you know what to cut?

Honestly, you just go for it. If it doesn't work, it cost a couple dollars anyway - not a huge loss. But normally, I'll see a silhouette that I like that l've seen in fashion but it's not represented in the thrift store because you don't always find what you want in a thrift store, it's a scavenger hunt. I'm like "this is close to it, if I can do this, I can make it look like this". Pseudonym has a brand called "Refined" and there's another one called "Repurposed". Refined is for people who like to thrift but are looking for high quality pieces. So you want your wool, silk, you want your clothing that has longevity. Some people look for really quality clothing. For Repurposed, I work in tandem with my friend Sydney, she goes to George Brown and does fashion design so she's really great at alterations and executing, and I have the ideas. So I'll take some pieces to her and be like "I like these pieces but I think it will sell/people will like it if we change this about it, so can you do this technique or cut here" I'll show it to her and show her my references she'll go ahead and execute it.

I love that. So I notice you also shot some of the photos on the IG page, what do you shoot with? Digital? Film?

I do primarily film. I do it myself sometimes, other times I'll get an actual photographer, l've usually worked with friends. One of my friends from middle school, Jason, he shot photos for me for quite a while. I've worked with Michelle, she shot an editorial for me, so l've worked with different photographers all time time.

Shifting the gears for the last question; If you could tell your 15 year-old self a piece of advice what would that be?

I would say...don't feel bad about what you haven't done. Don't feel bad about the little things that you haven't accomplished. Tomorrow is a new day just do it. It's never too late to start. There's times where I'll have a day where I have multiple plans and I don't do anything and then I feel really bad but then I'm like no, I'll try again tomorrow. That's one of them. I'd also say to just utilize your resources, know you have them. Those are things I would tell myself then and I tell myself now too. Don't be afraid to execute and try, and keep it simple. That's my motto - keep it simple. An overall way I live my life is working smart not hard. Think about what you're going to do and the most efficient way to do it. I want to do a lot of things, how can I do them all with $X$ amount of time and $X$ amount of resources?

It's a battle of quality over quantity

Yeah, like work really smart and be smart about what you're doing

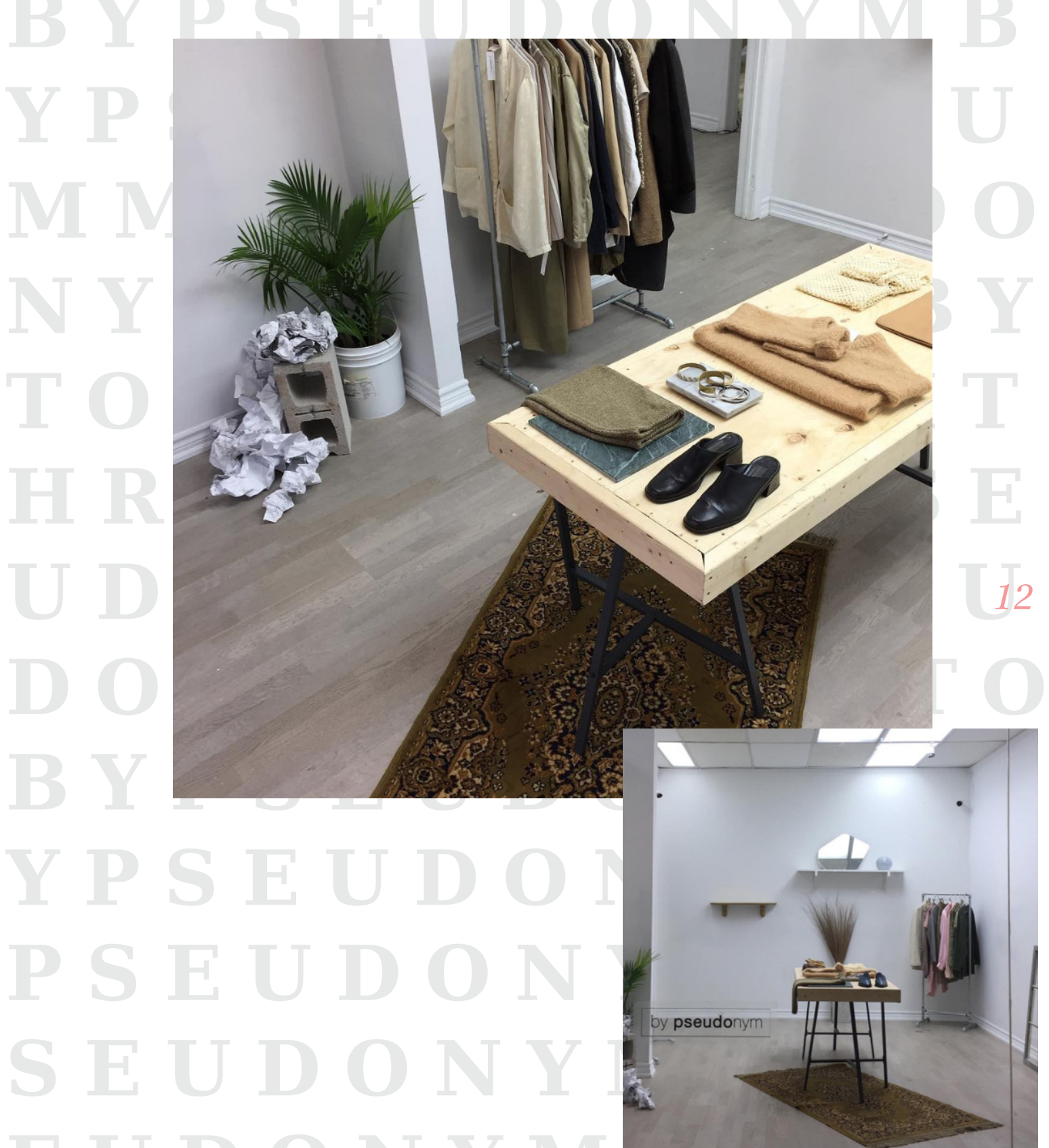

() 2018 INFLUENCE MAGAZINE 


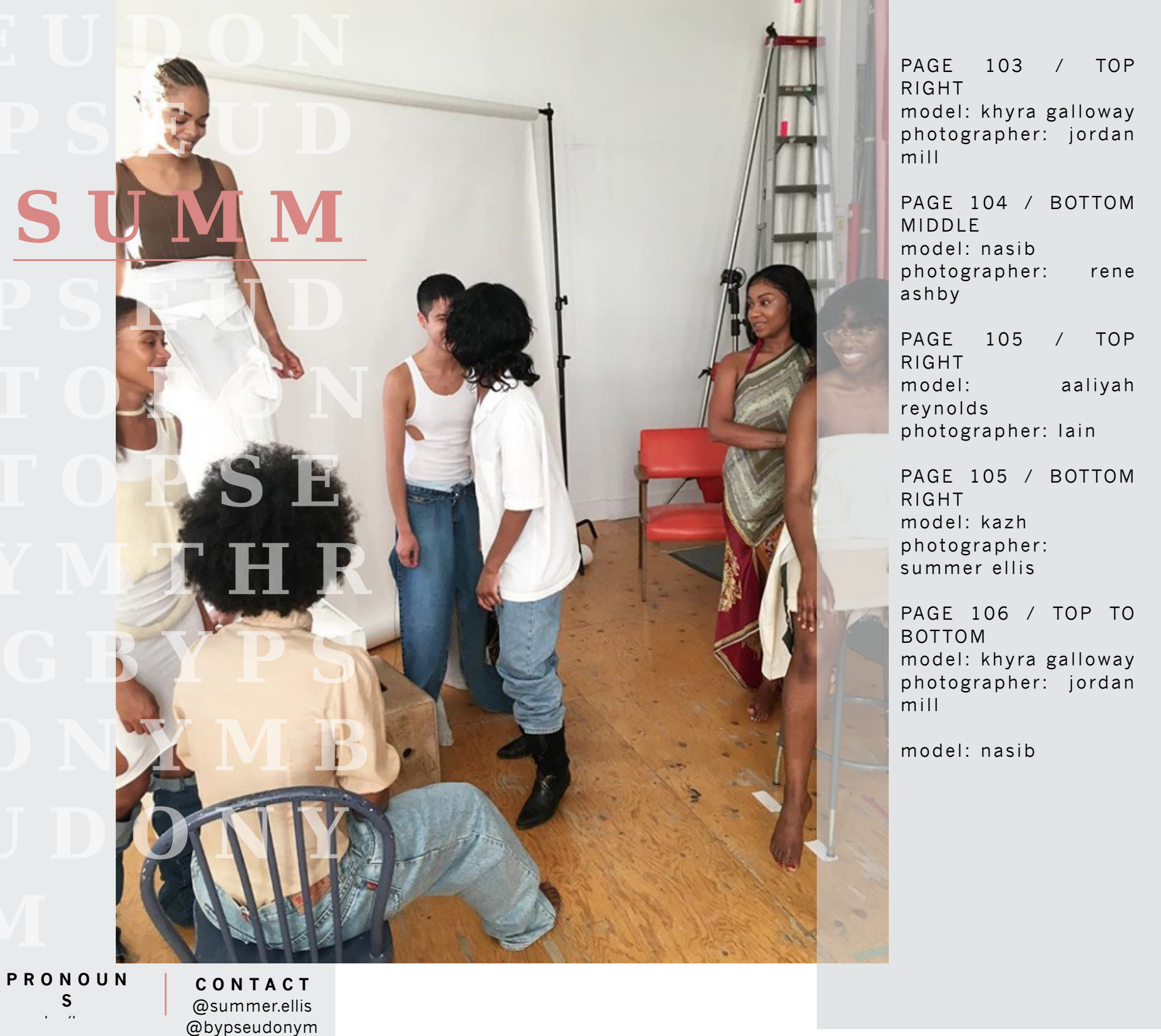




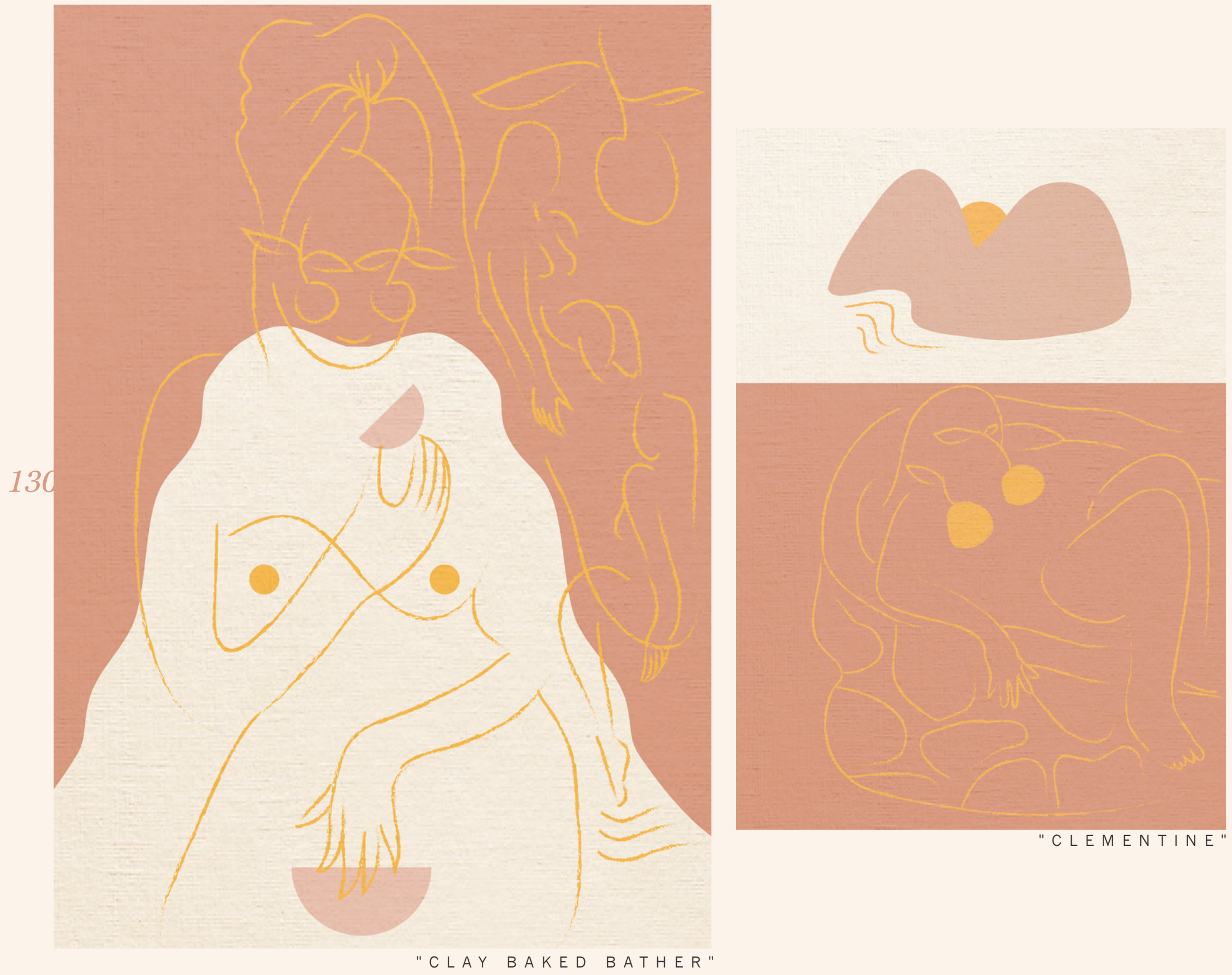

mirañ da crabtree

Miranda Crabtree is a

Toronto-based artist who

studied Interdisciplinary

Fine Art at NSCAD U. Her

figurative work makes use

of installation, painting, and

printed matter to describe

rich, fantastical narratives.

Taking cues from

landscape, Crabtree

recently returned from a

residency at Listastofan Art

Space in Reykjavik, Iceland.

Her most recent Risograph

prints are inspired by this

WEBSITE

N.STAGRAM 


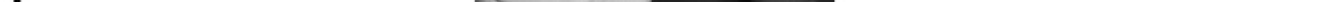

